\title{
FORMAÇÃO DE PREÇOS NA CADEIA AGROINDUSTRIAL DA SOJA NA DÉCADA DE 90
}

\author{
ROBSON LEANDRO MAFIOLETTI
}

Engenheiro Agrônomo

Orientador: Prof. Dr. GERALDO SANT'ANA DE CAMARGO BARROS

Dissertação apresentada à Escola Superior de Agricultura "Luiz de Queiroz", Universidade de São Paulo, para obtenção do título de Mestre emi Ciências, Área de Concentração: Economia Aplicada.

\author{
PIRACICABA \\ Estado de São Paulo - Brasil \\ Outubro -2000
}




\title{
Dados Internacionais de Catalogação na Publicação (CIP) \\ DIVISÃo DE BIBLIOTECA E DOCUMENTAÇÃo - Campus "Luiz de Queiroz"/USP
}

\author{
Mafioletti, Robson Leandro \\ Formação de preços na cadeia agroindustrial da soja na década de 90 / \\ Robson Leandro Mafioletti. - - Piracicaba, 2000. \\ $95 \mathrm{p}$. \\ Dissertação (mestrado) - - Escola Superior de Agricultura Luiz de \\ Queiroz, 2000. \\ Bibliografia. \\ 1. Agribusiness 2. Indústria agrícola 3. Mercado externo 4. Mercado \\ interno 5. Preço 6. Soja I. Título
}

CDD 338.17334

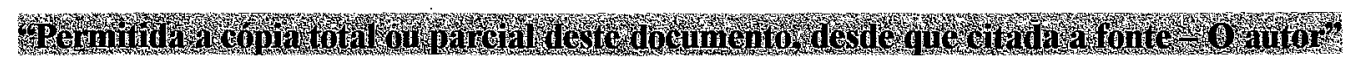

Data de depósito junto à CPG/ESALO

$30 / 10 / 2000$ 
Aos meus pais,

Olandino (in memorian) e Maria

OFEREÇO

À minha noiva,

Amanda

DEDICO 


\section{AGRADECIMENTOS}

Ao professor Geraldo Sant'Ana de Camargo Barros, pela confiança, orientação e amizade.

À professora Miriam R. P. Bacchi pela ajuda e sugestões oferecidas durante a realização dos testes econométricos.

Aos professores e funcionários do Departamento de Economia Administração e Sociologia (DEAS) da ESALQ/USP pelos ensinamentos e amizade.

Aos colegas do curso de mestrado, pelo companheirismo e apoio, em especial aos colegas e amigos Ary e Paulo.

A FAPESP, pela Bolsa de Estudos, pois sem ela não seria possível realizar meu curso de mestrado.

A meus familiares pelo apoio, base para minhas conquistas.

Aos meus colegas de República André, Ary, Canziani e Daltro pelo excelente convívio.

A SEAB/DERAL, CONAB, Safras \& Mercado, ABIOVE, CEPEA e OCEPAR pelos dados fornecidos e pela atenção dispensada pelos técnicos dessas instituições.

Aos Professores Judas Tadeu e Vânia Guimarães pelos ensinamentos no curso de agronomia e por acreditarem que tinha condições para continuar meus estudos. 


\section{SUMÁRIO}

Página

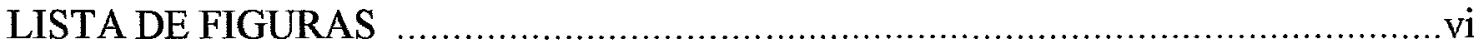

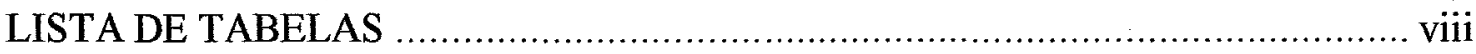

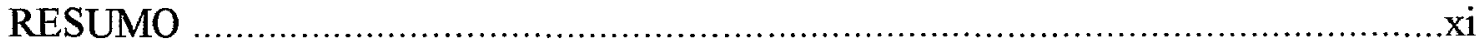

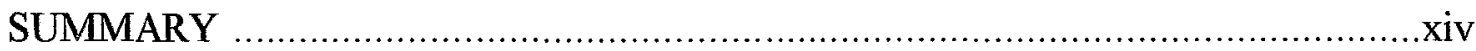

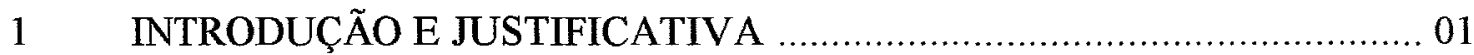

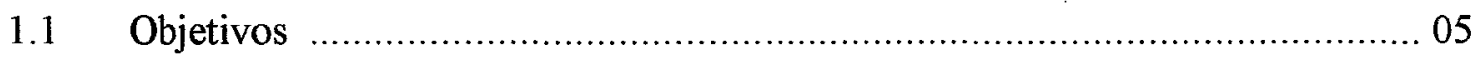

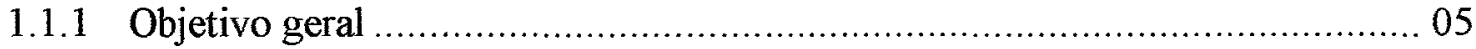

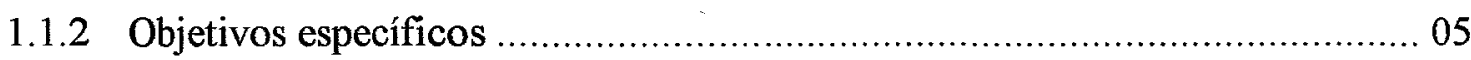

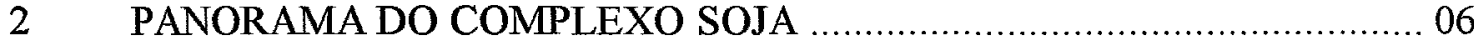

2.1 Fatores determinantes do sucesso da cultura da soja no Brasil ..................... 07

2.2 Importância do complexo soja no Brasil e no mundo..................................... 08

2.3 Estrutura de produção, processamento, exportação e importação do complexo soja no Brasil ................................................................... 15

2.4 Fatores determinantes da formação de preços do complexo soja .................... 20

2.4.1 Fluxogramas da comercialização do complexo soja .................................... 22

2.4.2 Como são formados os preços do complexo soja no mercado interno ............ 27

$2.5 \quad \mathrm{O}$ setor de transportes, portos e armazenamento ........................................ 32

3 REVISÃO DOS MODELOS TEÓRICOS DE FORMAÇÃO

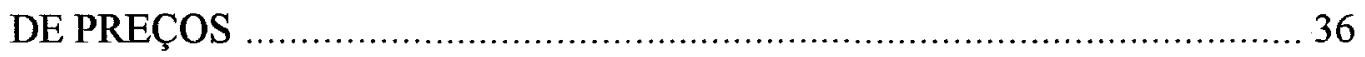

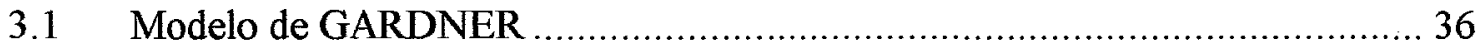

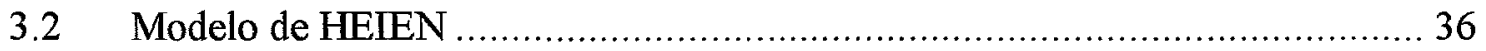

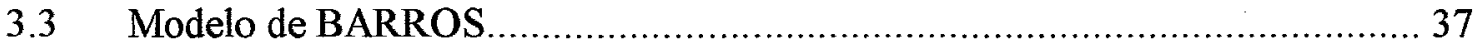


3.4 Modelo de equilíbrio para o mercado de soja brasileiro ............................. 37

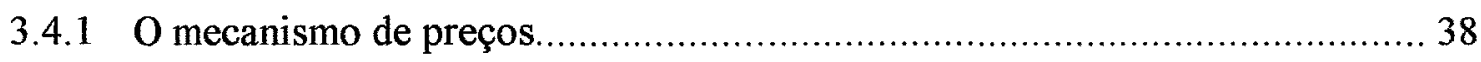

3.4.2 A demanda em blocos - modelos e estimativas ......................................... 41

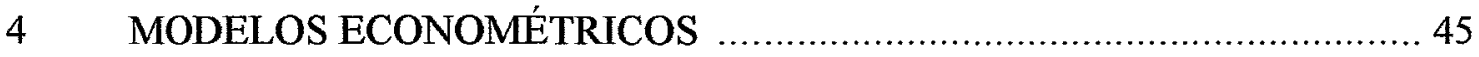

4.1 Intensidade e período de transmissão de preços .......................................... 45

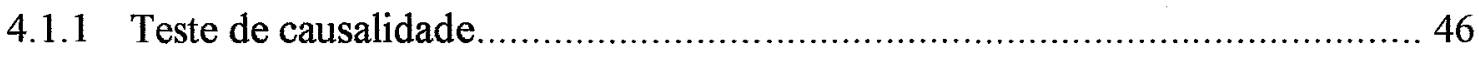

4.1.2 Teste do padrão sazonal de formação dos preços ........................................ 48

4.1.3 Elasticidades de transmissão de preços em modelos de

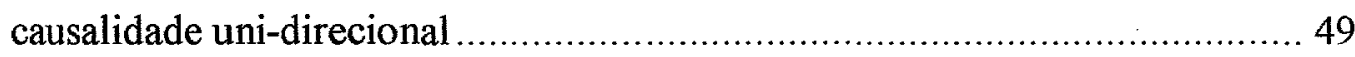

4.1.4 Elasticidades de transmissão de preços em modelos de

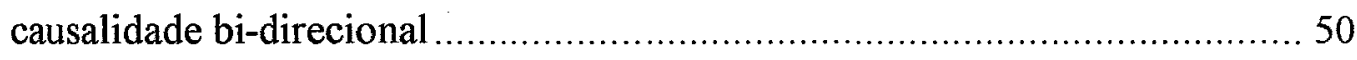

4.2 Assimetria na transmissão de preços ...................................................... 51

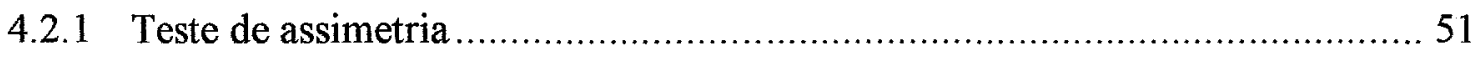

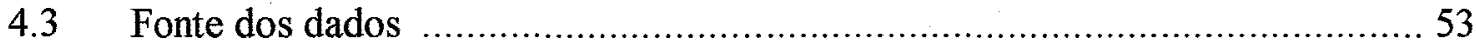

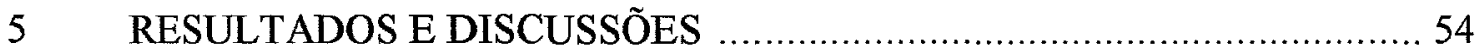

$5.1 \quad$ Análise dos testes de causalidade (Granger) …...........................................5 54

5.2 Teste do padrão sazonal de formação dos preços ......................................... 68

5.3 Elasticidades de transmissão de preços ....................................................... 70

5.4 Assimetria na transmissão de preços ......................................................... 78

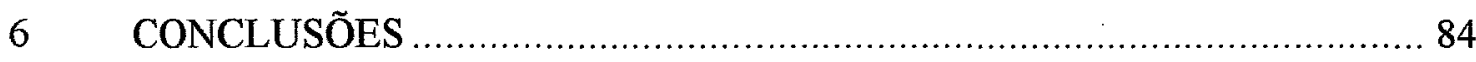

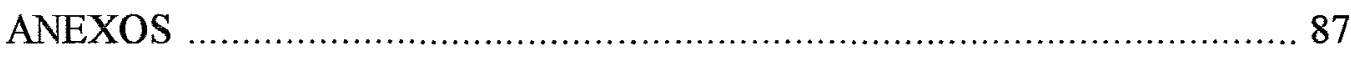

REFERÊNCIAS BIBLIOGRÁFICAS _................................................ 91 


\section{LISTA DE FIGURAS}

Página

1 Evolução da área colhida total no Brasil e nas regiões tradicionais e em expansão de soja, período $1980-2000$

2 Evolução da produtividade média no Brasil e nas regiões tradicionais e em expansão de soja, período $1980-2000$

3 Evolução da produção total no Brasil e nas regiões tradicionais e em expansão de soja, período 1980 - 2000

4 Evolução da área colhida nos principais países produtores de soja e no mundo, período $1980-2000$

5 Evolução da produção de soja nos principais países produtores e no mundo, $1980-2000$

6 Evolução da produtividade de soja nos principais países produtores e no mundo, período $1980-2000$

7 Evolução dos estoques finais nos principais países estocadores e no mundo, período $1980-2000$

8 Evolução do processamento nos principais países processadores e no mundo, período $1980-2000$.

9 Balanço da capacidade de processamento e produção por estado - 1998 (em milhões de ton.)

10 Mapa dos canais de comercialização do complexo soja

11 Saldo do balanço de oferta e demanda dos estados, valores de 1996

12 Fluxograma do complexo soja

13 Fluxograma do complexo soja para 1999, (valores entre parênteses em milhões de toneladas)

14 Fluxograma dos canais de comercialização do complexo soja 
15 Meios de transporte do complexo soja no Brasil ..................................... 33

16 Meios de transporte do complexo soja nos Estados Unidos....................... 33

17 Custo de transporte da soja no Brasil - 1998......................................... 34

18 Custo de transporte da soja nos (EUA) - 1998 ........................................ 34

19 Fluxograma do mercado de soja brasileiro ........................................... 40

20 Fluxograma do modelo simplificado da demanda de soja em grão e derivados (farelo e óleo) para o Brasil..................................................... 44

21 Esquema dos resultados dos testes para o mercado de soja, farelo e óleo, no período todo .................................................................. 59

22 Esquema dos resultados dos testes para o mercado de soja, farelo e óleo, na década de 80

22 Esquema dos resultados dos testes para o mercado de soja, farelo e óleo, na década de 90 


\section{LISTA DE TABELAS}

Página

1 Evolução das exportações brasileiras do complexo soja, 1995 - 2000 (em milhões de ton.)

2 Evolução das entradas de receitas cambiais provenientes das exportações do complexo soja, Brasil, 1995 - 2000 (em bilhões de dólares)

3 Capacidade instalada de processamento e produção de soja, segundo os principais estados brasileiros, Brasil 1998

4 Estratificação da capacidade de processamento por tamanho de planta, 1999

5 Procedimento de cálculo para internalização do preço da soja em grão para Rondonópolis, novembro de 1997

6 Teste de causalidade entre preços da soja e derivados em diferentes regiões de comercialização no mercado interno e externo, $1982-1999$

7 Teste de causalidade entre preços da soja e derivados em diferentes regiões de comercialização no mercado interno e externo, na década de 80 60

8 Teste de causalidade entre preços da soja e derivados em diferentes regiões de comercialização no mercado interno e externo, na década de 90

9 Equações de transmissão de preços da soja na década de 80 considerando o padrão sazonal de formação dos preços

10 Equações de transmissão de preços da soja na década de 90 considerando o padrão sazonal de formação dos preços 
11 Equações de transmissão de preços da soja no período todo considerando o padrão sazonal de formação dos preços.

12 Duração das defasagens significativas (em meses) para as equações de transmissão de preços, conforme resultados das análises de causalidade, período todo

13 Duração das defasagens significativas (em meses) para as equações de transmissão de preços, conforme resultados das análises de causalidade, década de 80

14 Duração das defasagens significativas (em meses) para as equações de transmissão de preços, conforme resultados das análises de causalidade, década de 90

15 Equações de transmissão de preços da soja e derivados no período todo

16 Equações de transmissão de preços da soja e derivados na década de 80

17 Equações de transmissão de preços da soja e derivados na década de 90

18 Teste de assimetria na transmissão de preços da soja, no período todo

19 Teste de assimetria na transmissão de preços da soja, na década de 80

20 Teste de assimetria na transmissão de preços da soja, na década de 90

21 Equações de transmissão de preços segmentadas para a década de 80

22 Equações de transmissão de preços segmentadas para a década de 90 
23 Elasticidade de transmissão totais convencionais e segmentadas para acréscimo e decréscimo de preço da soja, para o período todo .

82

24 Elasticidade de transmissão totais convencionais e segmentadas para acréscimo e decréscimo de preço da soja, para a década de 80 83

25 Elasticidade de transmissão totais convencionais e segmentadas para acréscimo e decréscimo de preço da soja, para a década de 90 83 


\title{
FORMAÇÃO DE PREÇOS NA CADEIA AGROINDUSTRIAL DA SOJA NA DÉCADA DE 90
}

\author{
Autor: ROBSON LEANDRO MAFIOLETTI \\ Orientador: Prof. Dr. GERALDO SANT'ANA DE CAMARGO BARROS
}

\section{RESUMO}

Esta pesquisa analisou o processo de formação dos preços do complexo soja tanto entre níveis de mercado, ou seja, produtor, atacado e varejo e mercado externo, quanto entre as principais regiões produtoras e consumidoras de soja e derivados no mercado interno. A análise foi realizada no período de janeiro de 1982 a dezembro de 1999, após subdividiu as séries de preços mensais em dois períodos, década de 80 e década 90 , tendo como objetivo captar o efeito das mudanças ocorridas na década de 90 , com o advento da abertura comercial e maior liberalização dos mercados.

As regiões definidas para o estudo foram os principais estados produtores de soja e derivados, Rio Grande do Sul, Paraná, São Paulo, Goiás, Mato Grosso do Sul e Mato Grosso e no mercado externo considerou-se as cotações da CBOT como proxy dos preços internacionais. No estudo do panorama do complexo soja ficou evidente a grande importância que este exerce em todo o agribusiness brasileiro. Tanto na produção de farelo para alimentação animal, como de óleo comestível para o consumo da população internamente, quanto na geração de divisas. Setenta por cento da produção são exportados nas formas de soja em grãos, farelo e óleo, gerando nesta última década em torno de $9 \%$ do total das receitas cambiais provenientes das exportações brasileiras. 
A metodologia utilizada para determinar a relação causal entre os preços foi o teste de Granger. Depois de determinado o sentido de causalidade estimou-se as elasticidades de transmissão de preços e finalmente testou-se a assimetria na transmissão de preços.

Os resultados demonstram a rapidez de transmissão de preços no setor, com períodos de defasagem de no máximo de um mês. Somente em poucos casos ocorreu período de transmissão de dois ou três meses. Isso indica a eficiência na transmissão dos preços entre os níveis de mercado e entre as regiões estudadas. Observou-se ainda que as variações dos preços ao nível de produtor tendem a ser antecedidas pelas variações que ocorrem no mercado internacional e ao atacado (tanto de óleo como de farelo). Isso pode ser explicado pelo menor poder de mercado que o produtor rural tem em relação aos demais níveis, e a maior dificuldade que o produtor tem de acesso às informações. Os acréscimos de preços tendem a ser transmitidos mais do que proporcionalmente do que no caso de decréscimos de preços em todos os casos estudados.

Para a década de 1980 não se verificou relação de causalidade entre os preços da soja em grão do mercado externo para o mercado interno. No caso do farelo, houve relação dos preços externos para os internos; no entanto, estas relações foram unicausais e transmissão menos do que proporcional. No caso do óleo, não houve relação de causalidade dos preços externos para os preços internos e ocorreu relação bi-causal dos preços do óleo ao atacado e ao varejo internamente.

Os resultados encontrados por Aguiar no estudo do complexo soja na década de 1980 apresentaram variações dos preços externos transmitidas mais que proporcionalmente aos preços internos. Ocorreram, dessa forma, algumas mudanças em relação aos resultados encontrados neste estudo, como relação bi-causal no mercado do farelo e causalidade dos preços externos para os preços internos no mercado do óleo. Uma possivel explicação para as diferenças encontradas é a área de abrangência do estudo e o tipo de teste de causalidade utilizado. Aguiar estudou o estado de São Paulo e empregou o teste de causalidade de Sims. Neste estudo considerou-se o país todo e o teste de causalidade foi o de Granger. 
Na década de 1990 houve relação causal dos preços internacionais para os preços domésticos, aqui representados pelos estados do Rio Grande do Sul e Paraná, para soja em grãos. No caso do farelo os preços continuaram sendo determinados no mercado internacional. No Brasil considerando-se o Estado de São Paulo e Paraná, observa-se causalidade dos preços do farelo no primeiro para os preços do farelo no segundo. Essa relação não ocorreu na década de 1980 . No caso do óleo, as relações aconteceram dos preços externos para os internos e, internamente, não houve relação entre os preços ao atacado e ao varejo. 


\title{
PRICE FORMATION IN THE SOYBEAN AGROINDUSTRIAL CHAIN IN THE DECADE OF 90
}

\author{
Author: ROBSON LEANDRO MAFIOLETTI \\ Adviser: Prof. Dr. GERALDO SANT'ANA OF CAMARGO BARROS
}

\section{SUMMARY}

This research analyzed the price formation process of the complex soybean so much among market levels producer, wholesale, retail and external market as well as the main soybeans producers and consumers areas of soybean and derivatives of the internal market. The analysis was accomplished in the period of January 1982 to December of 1999, after it subdivided the monthly prices series in two periods, decade of 80 and decade 90 , having as objective to get the changes effect that happened in the decade of 90 , with the coming of the commercial opening and larger liberalization of the markets.

The defined areas for the study were the main soybean and derivatives producers of the states, Rio Grande do Sul, Paraná, São Paulo, Goiás, South of Mato Grosso, Mato Grosso and in the external market was considered the quotations of CBOT as proxy of the international prices. In the study of the complex soybean was evident the great importance that it has on the whole Brazilian agribusiness. So much in the meal production for animal feeding, such as edible oil for the consumption of the internal population, as in the generation of exchange value. Seventy percent of the production is exported in soybean grains, meal and oil, generating on this last decade around $9 \%$ of the total coming exchange revenues of the Brazilian exports. 
The methodology used to determine the causal relation among the prices was the test of Granger. After being established the causality sense, the elasticities of transmission of prices was estimated and finally the asymmetry was tested in the transmission of prices.

The results shows the speed of transmission of prices in the section, with overlap periods of at the most one month. Only in few cases it happened two or three months period of transmission. That indicates the efficiency in prices transmission among the market levels and between the studied areas. The variation of the prices at the producer level tend to be preceded by the variation that happen at the international market and to the wholesale (as much of oil as of meal). That can be explained by the smallest market power that the rural producer has in relation to the other levels, and the largest difficulty that the producer has to access the information. The prices raise tend to be transmitted more proportionally than in the case of prices decrease in all the studied cases.

For the decade of 1980 causality relation was not verified among the prices of the soybean in grain of the external market for the internal. In the meal case, there was relation of the external prices for the internal; however, these relation were unit-causal and transmission less than proportional. In the oil case, there was no causality relation for the external prices towards the internal prices and it happened bi-causal relation of the prices from the oil to the wholesale and the retail internally.

The results found by Aguiar in the study of the complex soybean in the decade of 1980 presented variations of the external prices transmitted more than proportionally to the internal prices. In that way, some changes happened in relation to the results found in this study, as bi-causal relation in the meal market and causality of the external prices towards the internal prices in the oil market. A possible explanation for the differences found is the area of inclusion of the study and the type of causality test used. Aguiar studied the state of São Paulo and used the causality test of Sims. In this study was considered the whole country and the causality test used was Granger.

In the decade of 90 there was causal relation of the international prices for the domestic prices, here represented by the states of Rio Grande do Sul and Paraná, for soybean in grains. In the meal case, the prices remained being determined in the international market. In Brazil, considering the State of São Paulo and Paraná, meal 
prices causality is noted in the first meal prices for the second one. That relation didn't happen in the decade of 80 . In the oil case, the relation happened in the external prices for the internal and, internally, there was not relation among the prices to the wholesale and the retail. 


\section{INTRODUÇÃO E JUSTIFICATIVA}

A passagem da década de 80 para a de 90 trouxe importantes mudanças para o complexo agroindustrial da soja no Brasil. No front externo, a abertura econômica integrou ainda mais o setor às forças dinâmicas da economia globalizada. Internamente esses efeitos externos somaram-se às tendências de desregulamentação econômica e reestruturação do agronegócio brasileiro e do complexo agroindustrial da soja em particular.

O Brasil é o segundo maior produtor mundial de soja, produzindo cerca de 31 milhões de toneladas ( $20 \%$ da produção mundial), ficando à frente da Argentina que produz 21 milhões de toneladas (13,5\% da produção mundial) e atrás apenas dos Estados Unidos que produz 77 milhões de toneladas (50\% da produção mundial) que se encontra em 155 milhões de toneladas (USDA 2000).

Dentre os produtos agrícolas a soja tem grande importância, não apenas para $o$ mercado interno, mas como fonte geradora de divisas para o país. A grande quantidade produzida permite abastecer o mercado interno com farelo para alimentação animal e óleo para o consumo humano, além de gerar divisas através da exportação de soja em grão, farelo e óleo, que em média, nesta última década, representaram $9 \%$ do valor das exportações totais e $30 \%$ das exportações agrícolas. Na safra 98/99 participou com 3,76 bilhões de dólares e a previsão para a safra de 99/00 é de 4,01 bilhões de dólares de divisas para a economia brasileira, ABIOVE (2000).

Willians \& Thompson (1988) ressaltam que o objetivo principal das medidas de políticas do governo brasileiro foi, na década de 80 , de assegurar uma adequada oferta de farelo e óleo de soja para o mercado interno, estimular a utilização e expansão da capacidade de processamento e exportar o excesso de oferta de farelo e óleo, de 
preferência a exportação da soja grão. Afirmam, porém, que a década de 1980 foi marcada pela redução do controle sobre as exportações e aceleração das desvalorizações cambiais. Apenas as importações permaneceram fortemente controladas.

Segundo Roessing (1989), na década de 80, houve uma forte tendência de redução da interferência governamental na comercialização dos produtos do complexo soja brasileiro. Após 1982 as cotas de exportações foram abolidas, sendo apenas mantido o tabelamento do óleo de soja, com o objetivo de conter a elevação dos índices de preços.

Para o período de 1982 a 1989, analisando o mercado da soja em São Paulo, Aguiar (1990) constatou que o mercado internacional era a origem predominante das oscilações de preços e, no mercado interno, o atacado tende a iniciar as variações de preços, pelo maior acesso às informações e maior poder de barganha. $\mathrm{O}$ varejo (óleo refinado) mostrou-se passivo no processo, devido provavelmente a uma política de markup na formação dos preços ao consumidor, encontrou também, que o mercado interno de farelo tende também a influenciar o mercado externo, devido à importância do Brasil na produção mundial de farelo. Outro resultado interessante é o valor próximo a uma unidade obtido para a elasticidade de transmissão de preços entre os níveis do mercado interno. Nesse mesmo estudo, Aguiar (1990), encontrou elasticidades acima da unidade para o repasse das variações externas de preço para o mercado interno. $\mathrm{O}$ autor aponta a rigidez do custo de exportação como justificativa deste resultado. Com relação aos níveis de mercado, a variação dos preços internos pode iniciar no nível de produtor ou no nível de atacado. Variações no nível de varejo são pouco prováveis, pois o óleo (principal produto do complexo vendido no varejo), por sua característica de essencialidade, deve apresentar baixas elasticidades preço e renda da demanda.

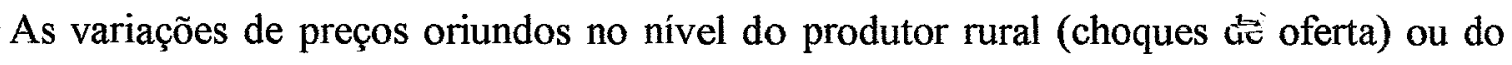
atacado (maior acesso às informações e maior poder de mercado), tenderiam a ser repassadas ao varejo do óleo através da aplicação de um markup sobre os custos de produção.

Outro fator relevante é a isenção total do ICMS (13\%) na exportação de produtos primários, estabelecido a partir de 1996, que também está afetando o processo de 
formação de preços. Na década de 1990, as barreiras comerciais foram reduzidas mais fortemente, como parte das medidas de política de abertura comercial, econômica, financeira e desregulamentação dos mercados, e neste novo ambiente toma maior importância às barreiras não tarifárias.

Internamente, de modo geral, observa-se substancial incremento nas relações comerciais e financeiras entre as diversas regiões do país, as quais podem alterar o processo de formação de preços da soja em todos os níveis de mercado (produtor, atacado e varejo). A constante agroindustrialização das regiões de fronteira, a nova alternativa de transporte através dos rios Madeira e Amazonas (Hidrovia do Madeira), permitindo acesso ao oceano Atlântico para parte da produção da região Centro-Oeste e Norte, que atualmente respondem por grande parcela da produção nacional, podem estabelecer novos padrões de formação de preços.

A proposta desta pesquisa é analisar as mudanças que ocorreram no mercado da soja e seus derivados ao longo da década de 90. Especificamente, pretende-se analisar as relações de preços entre os níveis de mercado (produtor, atacado, varejo) no mercado interno e externo do complexo soja (grão, farelo e óleo) e comparar os resultados com estudo semelhante para a década anterior e também com os obtidos por Aguiar (1990).

O Estado do Paraná por ser considerado o mais importante na formação de preços tende a ser o primeiro a internalizar as variações de preço do mercado externo, transmitindo-os posteriormente para as demais regiões produtoras. Pode-se justificar esta importância relativa na formação de preços, em termos de mercado interno por três razões básicas: (i) pela capacidade industrial instalada no estado; (ii) pela quantidade produzida; (iii) e pela localização geográfica, destacando-se o porto de Paranaguá por onde é escoada grande parte das exportações de soja e derivados. Margarido \& Souza (1998) não rejeitam essa hipótese de que o preço médio recebido pelos produtores paranaenses é uma boa estimativa ou proxy do preço médio nacional, podendo servir de preço de referência para os produtores de outros estados.

Tanto produtores quanto industriais e exportadores afirmam que o mercado externo de soja tem grande influência na formação dos preços no mercado brasileiro durante o período de março a setembro, quando a safra é colhida e a maior parte das 
exportações é concretizada. Segundo dados da ABIOVE (2000), nos últimos cinco anos, em média, $85 \%$ da soja produzida foi comercializada no período entre os meses de março a agosto. Já o volume de produtos exportados entre os meses de março a setembro foi de $93 \%$ para a soja em grão, $70 \%$ para o farelo e $73 \%$ para o óleo. No segundo semestre, no entanto, o mercado interno se comporta de forma independente da Bolsa de Chicago, centro de formação de preços do complexo soja em termos mundiais.

Outra preocupação com relação à transmissão de preços entre níveis de mercado é a possível assimetria com respeito a elevações e reduções de preços. A assimetria na transmissão dos preços pode ocorrer entre atacado e varejo e entre produtor e atacado. Devido ao poder de mercado das empresas atacadistas, pode surgir maior transmissão de acréscimos de preços. A assimetria na transmissão pode-se dar também entre os preços externos e domésticos. As barreiras comerciais do Brasil podem dificultar a importação quando preço externo for mais baixo que o interno, fazendo com que a queda do preço de exportação seja transmitida internamente de forma um tanto quanto atenuada. Por outro lado, as políticas de exportação e de estabilização de preços criaram diversas vezes uma série de barreiras à exportação de óleo e farelo, sendo no primeiro caso devido ao custo de vida e no segundo para atender reivindicações de avicultores, quando os preços externos subiam demasiadamente. No entanto, este controle de mercado não foi tão relevante nesta última década, mas na anterior foi um artifício bastante utilizado.

O presente estudo pretende analisar, além das relações de preços entre níveis de mercado, o processo de formação de preços entre as principais regiões produtoras de soja do país, ou seja, entre os estados do Sul, Sudeste e do Centro-Oeste e entre ambos e o mercado externo. A análise destas relações pode dar indicação do grau de eficiência dos canais de comercialização do produto, permitindo ainda compreender os mecanismos de formação de preço ao apontar as principais causas de suas variações e os segmentos que tendem a liderar essas variações. 


\subsection{Objetivos}

\subsubsection{Objetivo Geral}

O objetivo geral dessa pesquisa é identificar possíveis mudanças no processo de formação dos preços da soja no Brasil que possam ter ocorrido a partir de 1990, de forma a compreender melhor como se transmitem os preços do mercado externo para o interno, e internamente entre os vários segmentos da cadeia agroindustrial da soja.

\subsubsection{Objetivos Específicos}

i) Determinar a relação causal entre os preços, nos vários mercados.

ii) Mensurar a transmissão das variações de preços entre os níveis de mercado externo e interno e no mercado interno entre os preços das várias regiões relevantes para a formação dos preços.

iii) Determinar a defasagem em meses para ocorrer o completo ajustamento dos preços.

iv) Verificar a existência ou não de assimetria na transmissão com relação a acréscimos e decréscimos de preços.

v) Verificar o padrão sazonal na formação de preços da soja. 


\section{PANORAMA DO COMPLEXO SOJA}

A soja foi introduzida no Brasil em 1936 no município de Santa Rosa, Rio Grande do Sul, onde mostrou boa adaptação, mas somente em 1941 apareceu nas estatísticas oficiais daquele estado. No entanto somente na década de 1950 com os incentivos governamentais para expansão da cultura do trigo (Plano de Fomento à expansão da cultura do trigo) é que a soja tomou grande importância, para fazer parte do sistema de rotação de culturas com o trigo. A evolução da cultura da soja segundo Aguiar (1990), citando Zockum (1978), deu-se principalmente em áreas onde anteriormente havia alguma cultura agrícola ou pastagem (88,4\%), e não matas virgens $(11,6 \%)$. Esse mesmo autor cita também que nos estados do Paraná e Rio Grande do Sul, a cultura substituída foi o milho, enquanto que em São Paulo foram o algodão e o arroz. No Centro-Oeste, a conversão se deu principalmente em áreas de pastagens.

No Paraná, a cultura evoluiu em função dos efeitos das geadas em 1953, 1955 e mais recentemente em 1975, que destruíram parte dos cafezais e levaram os produtores a optar pela soja devido a sua maior liquidez e facilidade de comercialização tanto no mercado interno quanto externo.

Nos Cerrados, a cultura evoluiu graças ao desenvolvimento de técnicas de adubação e calagem adotadas para solucionar a alta acidez e baixa fertilidade natural daqueles solos. Quanto à pesquisa e desenvolvimento de novas variedades de soja que se adaptem as condições edafoclimáticas dos Cerrados não se pode deixar de destacar o papel desenvolvido pela EMBRAPA. 


\subsection{Fatores determinantes do sucesso da cultura da soja no Brasil}

O desenvolvimento da cultura da soja no Brasil se dá não somente pelos aspectos agronômicos positivos, mas tạmbém pela conjunção de vários fatores macroeconômicos e de mercado. Dentre estes fatores, destacam-se: (i) a existência de um mercado de futuros com liquidez em Chicago; (ii) a participação da iniciativa privada nas operações de crédito; (iii) a demanda firme no mercado mundial; e (iv) a grande capacidade de processamento ociosa.

Mercado futuro com liquidez: as operações envolvendo bolsa de commodities agrícolas têm sido utilizadas no Brasil há bastante tempo. A Bolsa de Mercadorias e Futuros - (BM\&F) tem atuado fortemente nos mercados de café e boi gordo, lançando contratos cambiais. Além destas duas commodities também são comercializados contratos de algodão em pluma, açúcar, álcool, milho e soja em grãos. Em 1999 foram negociados 13.424 contratos de soja, ou seja, $1 \%$ da produção nacional de soja grão na BM\&F (sintese de dados da BM\&F).

São inúmeras as dificuldades encontradas para se obter sucesso nas operações usando o mercado de futuros no Brasil. Cultura conservadora dos empresários agrícolas brasileiros, e também pouco conhecimento que estes detêm sobre o funcionamento do mercado de futuros, entre outras dificuldades.

$\mathrm{Na}$ cultura da soja (soja em grãos, farelo e óleo), tem-se em termos mundiais como principal referência a Bolsa de Chicago, que representa forças de oferta e demanda de todos os países produtores e consumidores desses produtos no mundo. Pode-se verificar que o volume anual de soja grão negociado na Chicago Board of Trade (CBOT) chega a atingir quase dois bilhões de toneladas, ou cerca de 15 vezes a produção mundial. A grande liquidez é conferida pela presença marcante dos fundos de pensão e pelo grande volume operado pelos hedgers que tentam se proteger das variações de preços.

Iniciativa privada nas operações de crédito: a participação das processadoras no crédito tem sido decisiva na manutenção da área plantada de soja no país. Estas atuam repassando os "ACC's" (adiantamento de contrato de câmbio) captados nos bancos 
privados para produtores e cooperativas na forma de compra antecipada de soja. Essas compras podem ser realizadas a "preço fixo" ou na modalidade a "fixar", sendo essa segunda opção a mais utilizada quando as relações de troca por insumos estão muito baixas. Sabendo-se que a participação do crédito oficial do governo na cultura da soja é bastante reduzida (devido as áreas de cultivo serem relativamente grandes), restando aos produtores a opção de alocação de recursos a juros de mercado.

Demanda firme no mercado nacional e internacional: a produção de óleo comestível de boa qualidade a preço competitivo para abastecer o mercado interno, bem como o aumento da demanda de farelo para a composição da ração animal, conferiram a este derivado uma importância crescente no complexo soja. Trata-se da fonte de proteína mais barata disponível do mercado, que conta com a grande demanda da Comunidade Econômica Européia (CEE) pela matéria-prima farelo para a produção de rações para a alimentação animal, como parte da Política Agrícola Comum (PAC).

\subsection{Importância do complexo sojạ no Brasil e no mundo}

As figuras a seguir evidenciam algumas relações do complexo soja que ajudam a compreender melhor as relações existentes entre as regiões produtoras de soja no Brasil e também entre os principais países produtores e consumidores de soja no mundo.

Entre essas regiões estão a tradicional que compreende os estados do Rio Grande do Sul, Santa Catarina, Paraná e São Paulo, e a região em expansão que compreende o estado de Minas Gerais, e os estados do Centro-Oeste, além de alguns estados do Norte e Nordeste do Brasil. Entre os principais países produtores e consumidores estão os Estados Unidos, Brasil, Argentina e China.

A seguir são apresentadas informações sobre o mercado nacional e internacional da soja e derivados. As fontes dos dados são o Instituto Brasileiro de Geografia e Estatística (IBGE) e a Companhia Brasileira de Abastecimento (CONAB) para as regiões brasileiras, e para os países a fonte de dados é o United States Departament of Agriculture (USDA). 
A figura 01 mostra a evolução da área colhida de soja no Brasil que passou de 8,8 para 13,3 milhões de hectares. Nas regiões tradicionais e em expansão passaram, respectivamente de 7,5 para 6,6 milhões de hectares e 1,3 para 6,7 milhões de hectares no período de 1980-2000.

A figura 02 mostra a evolução da produtividade de soja no Brasil que passou de 1,7 para 2,4 toneladas por hectare. Nas regiões tradicionais e em expansão passaram, respectivamente de 1,7 para 2,1 toneladas por hectare e 1,7 para 2,6 toneladas por hectare no período de 1980-2000.

A figura 03 mostra a evolução da produção de soja no Brasil que passou de 15,0 para 31,4 milhões de toneladas. Nas regiões tradicionais e em expansão passaram, respectivamente de 12,8 para 13,9 milhões de toneladas e 2,2 para 17,5 milhões de toneladas no período de 1980-2000.

A figura 04 mostra a evolução da área colhida de soja no mundo, que passou de 50 para 72 milhões de hectares no período de 1980-2000, sendo que os quatro países mencionados acima representam $85 \%$ de toda a área colhida de soja no mundo. A Argentina e o Brasil foram os países que mais aumentaram as áreas colhidas, passando, respectivamente, de 1,8 para 8,8 milhões de hectares e de 8,5 para 13,4 milhões de hectares, enquanto na China e nos Estados Unidos à área cultivada ficou estagnada.

A figura 05 mostra a evolução da produção no mundo, que passou de 81 para 169 milhões de toneladas no período de 1980-2000, sendo que os quatro principais países produtores representam $87 \%$ da produção mundial. A maior expansão da produção ocorreu na Argentina, passando de 3,5 para 21,5 milhões de toneladas, no Brasil a produção mais que dobrou passando de 15,2 para 31,4 milhões de toneladas. Estes dois países tiveram aumento de produção devido ao aumento de área e da produtividade. Os Estados Unidos tiveram um grande aumento da produção passando de 48,9 para 78 milhões de toneladas devidas principalmente ao aumento de produtividade. A China teve um aumento considerável de produção devido ao aumento de produtividade, que era muito baixa.

A figura 06 mostra a evolução da produtividade média no mundo que passou de 1,63 para 2,24 toneladas por hectare. O Brasil foi o país que mais aumentou a 
produtividade média no período, passando de 1,79 para 2,45 toneladas por hectare. A China passou de 1,1 para 1,6 toneladas por hectare, e Estados Unidos e Argentina, que já possuíam produtividade acima das 2,0 toneladas por hectare, passaram a 2,65 e 2,44, respectivamente.

A figura 07 mostra a evolução dos estoques finais de soja no mundo que passou de 11,5 para 23.1 milhões de toneladas, sendo que Estados Unidos Argentina e Brasil detêm $70 \%$ dos estoques mundiais e somente os Estados Unidos possuem $60 \%$ do total desses estoques.

A figura 08 mostra a evolução do processamento de soja no mundo que passou de 70 para 136 milhões de toneladas no período de 1980-2000, sendo que os quatro países representam $70 \%$ do processamento de soja no mundo. A Argentina foi o país que mais aumentou a capacidade de processamento passando de 1,5 para 16,7 milhões de toneladas. O Brasil também apresentou uma boa performance passando de 13,8 para 21.6 milhões de toneladas, a China passou de 1,52 para 12 milhões de toneladas e Estados Unidos passou de 27,8 para 44,4 milhões de toneladas. 


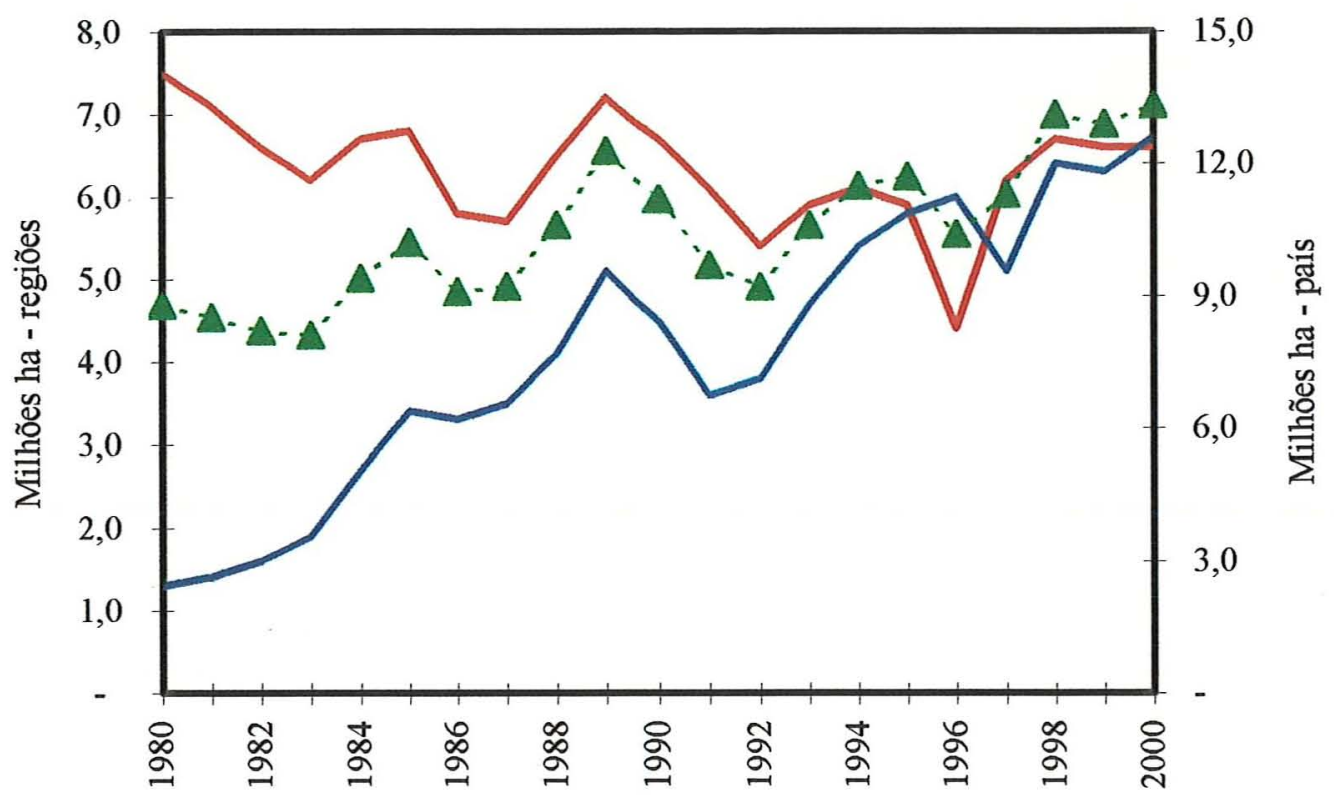

Área - Região tradicional

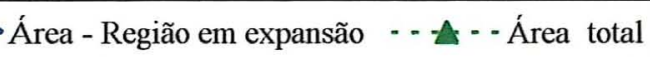

Figura 01 - Evolução da área colhida total no Brasil e nas regiões tradicionais e em expansão de soja, período 1980/2000. Fonte: IBGE e CONAB - 2000.

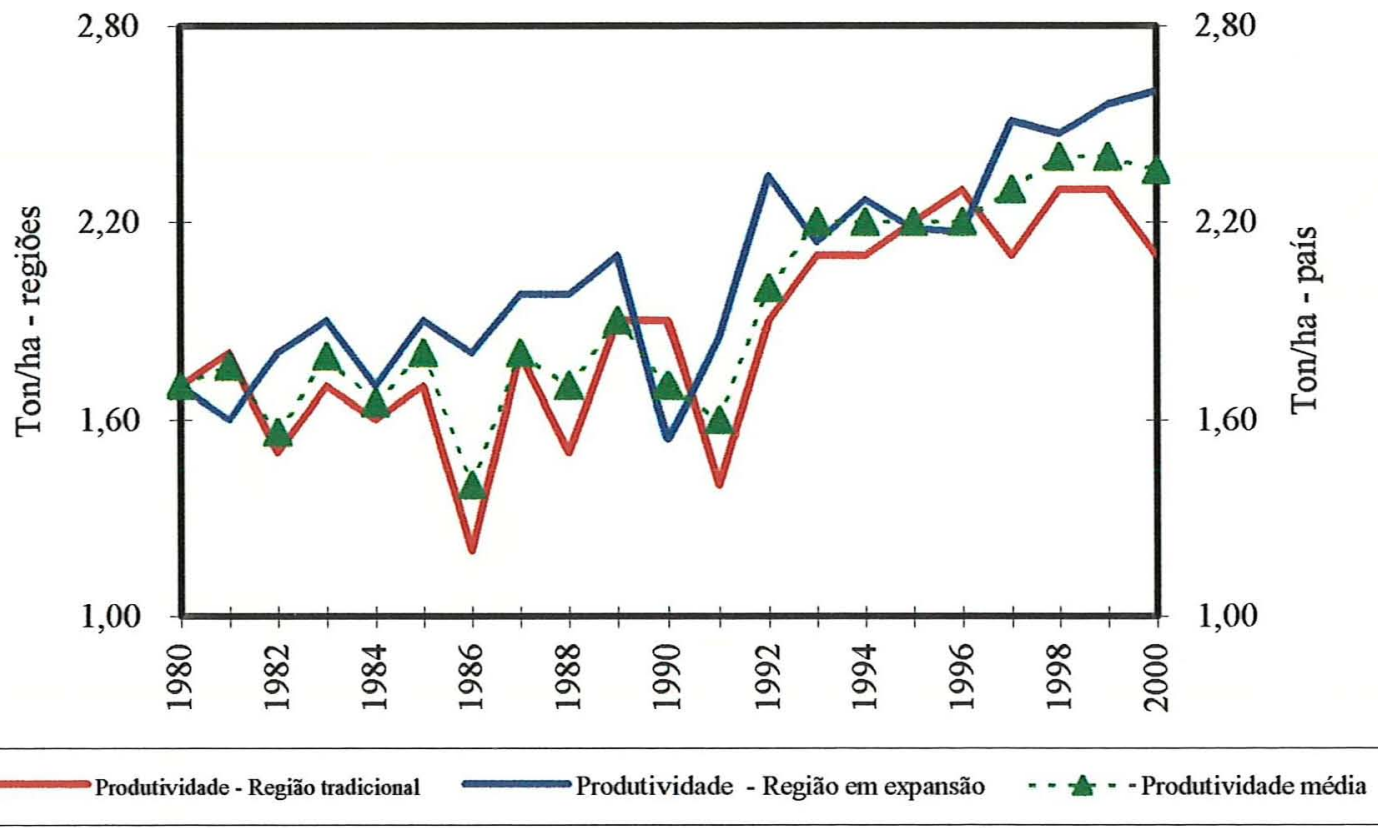

Figura 02 - Evolução da produtividade média no Brasil e nas regiões tradicionais e em expansão de soja, período 1980 - 2000. Fonte: IBGE e CONAB - 2000. 


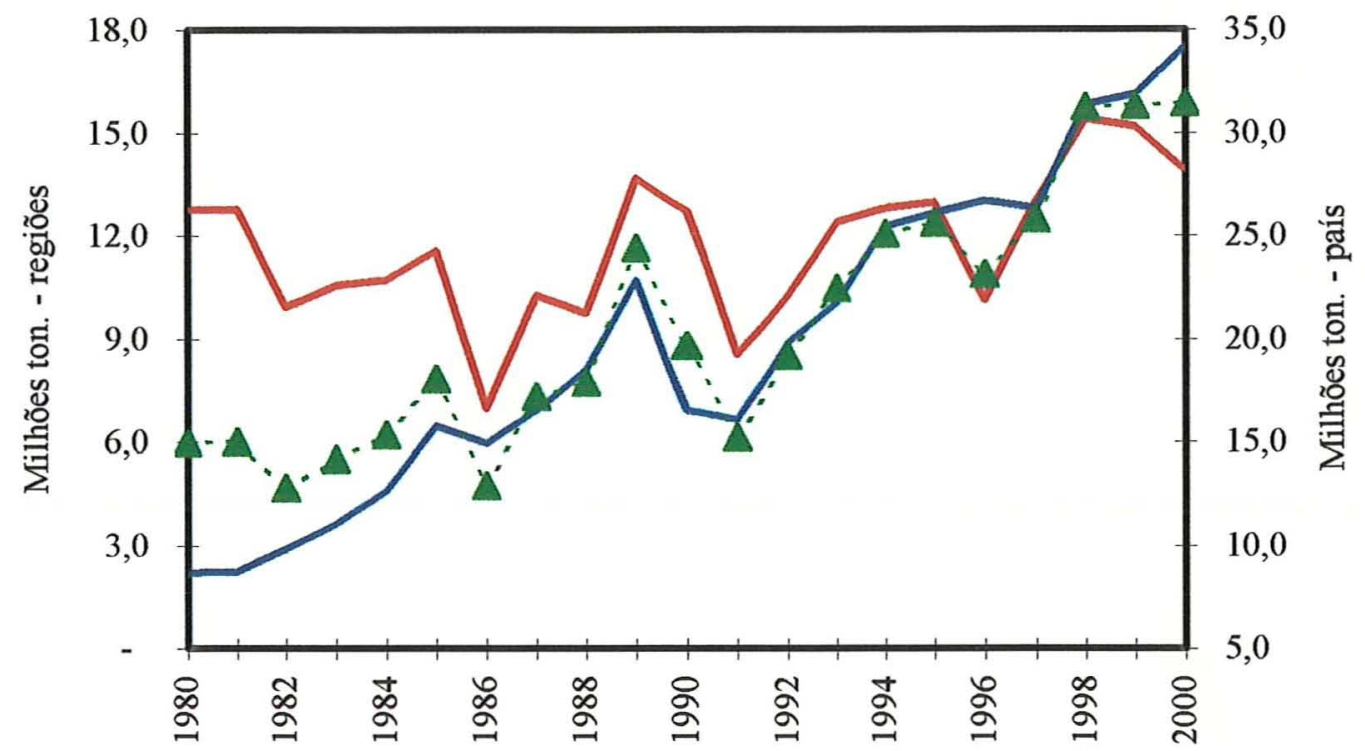

$\longrightarrow$ Produção - Região tradicional $\longrightarrow$ Produção - Região em expansão - - * - Produção total

Figura 03 - Evolução da produção total no Brasil e nas regiões tradicionais e em expansão de soja, período 1980 - 2000. Fonte: IBGE e CONAB - 2000.

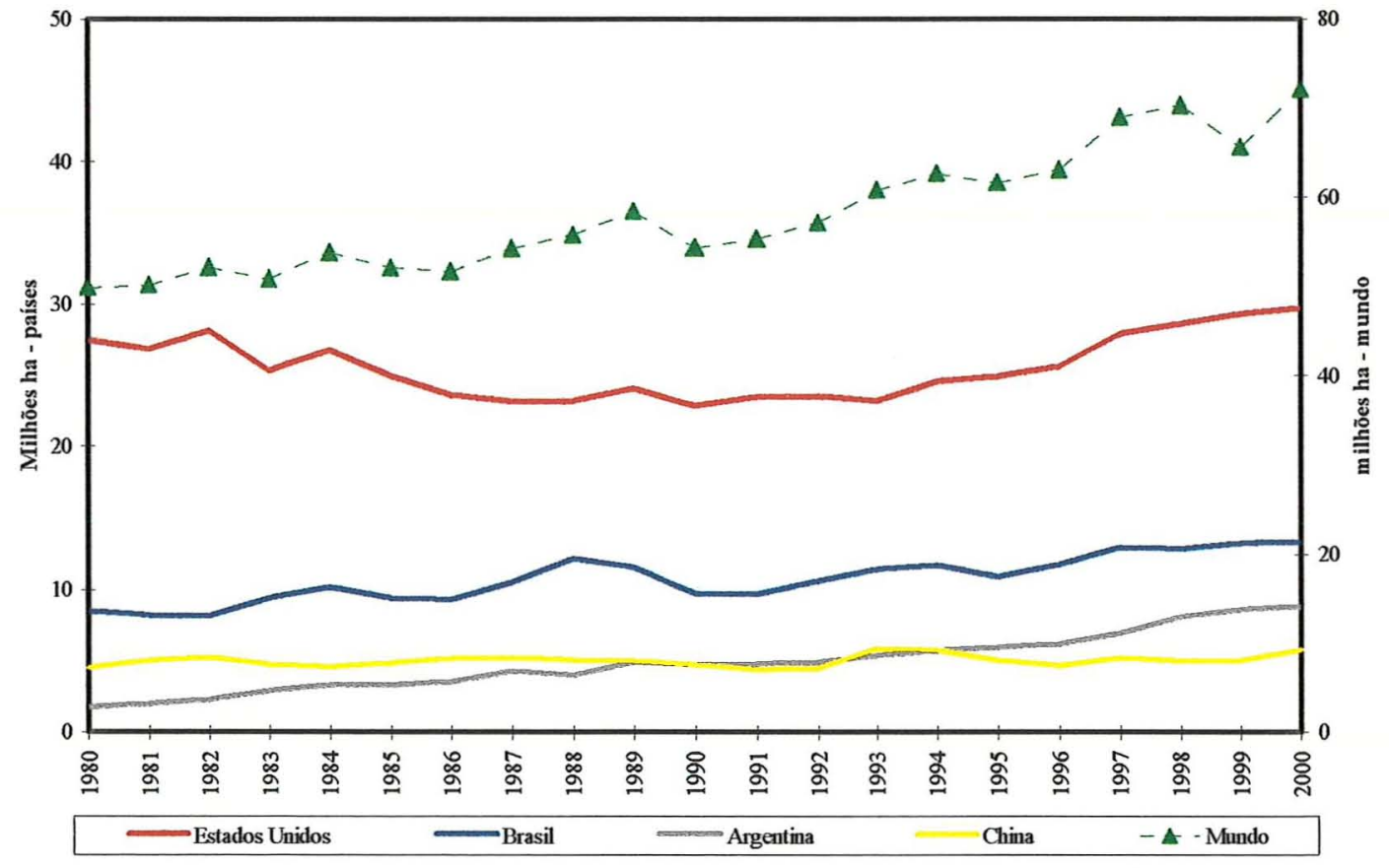

Figura 04 - Evolução da área colhida nos principais países produtores de soja e no mundo, período 1980 - 2000. Fonte: USDA - 2000. 


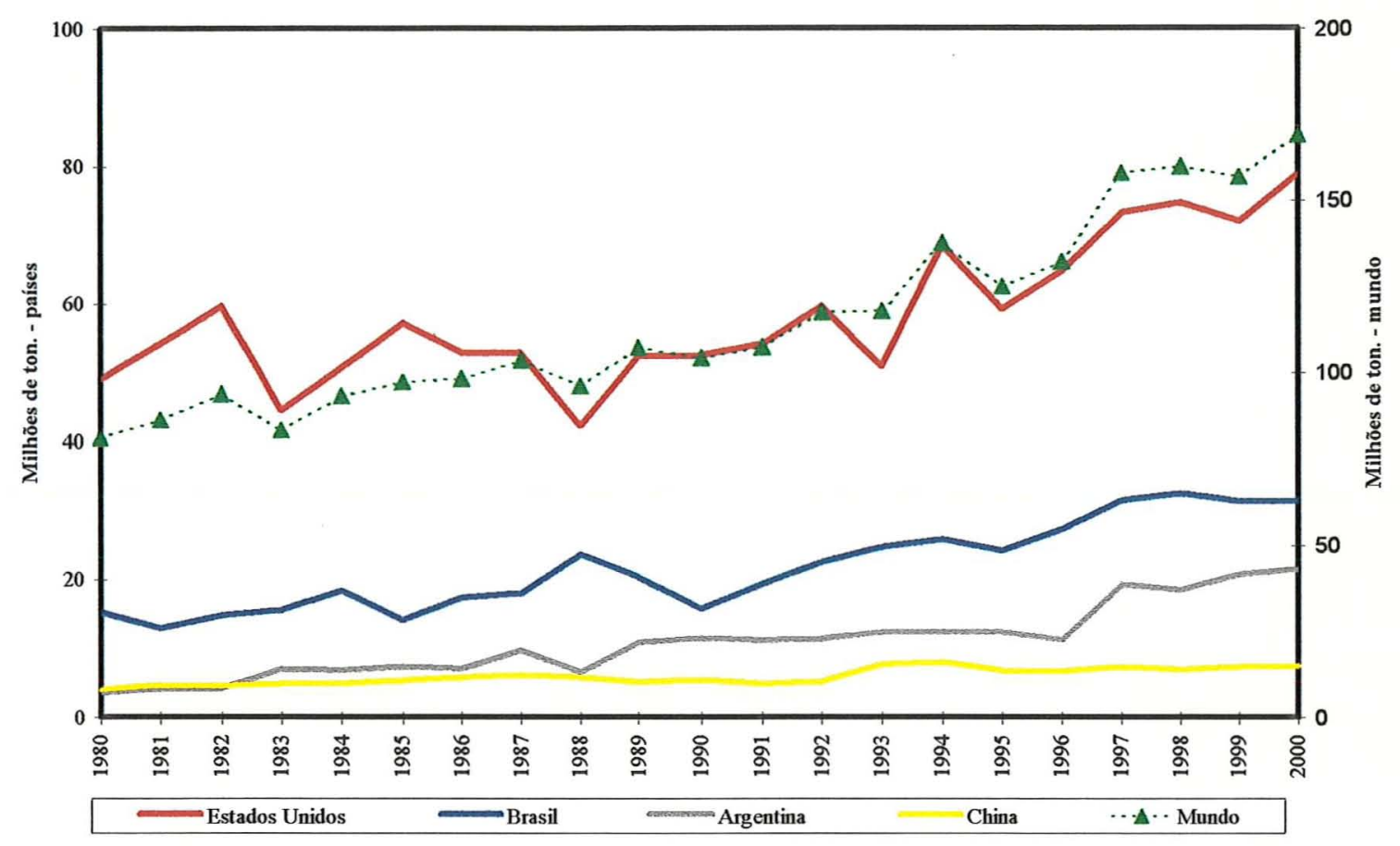

Figura 05 - Evolução da produção de soja nos principais países produtores e no mundo, período 1980 - 2000. Fonte: USDA - 2000.

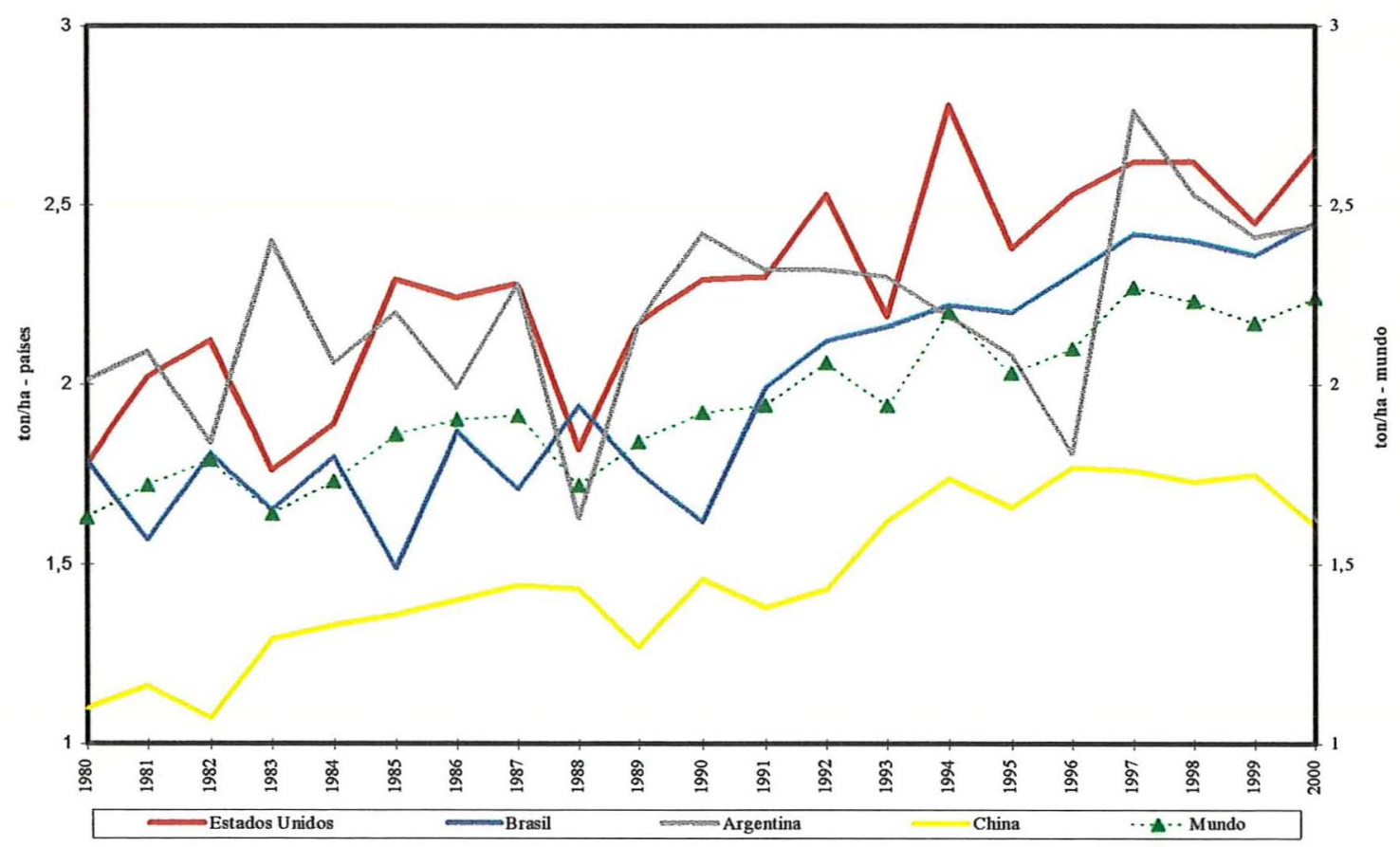

Figura 06 - Evolução da produtividade de soja nos principais países produtores e no mundo, período 1980 - 2000. Fonte: USDA - 2000. 


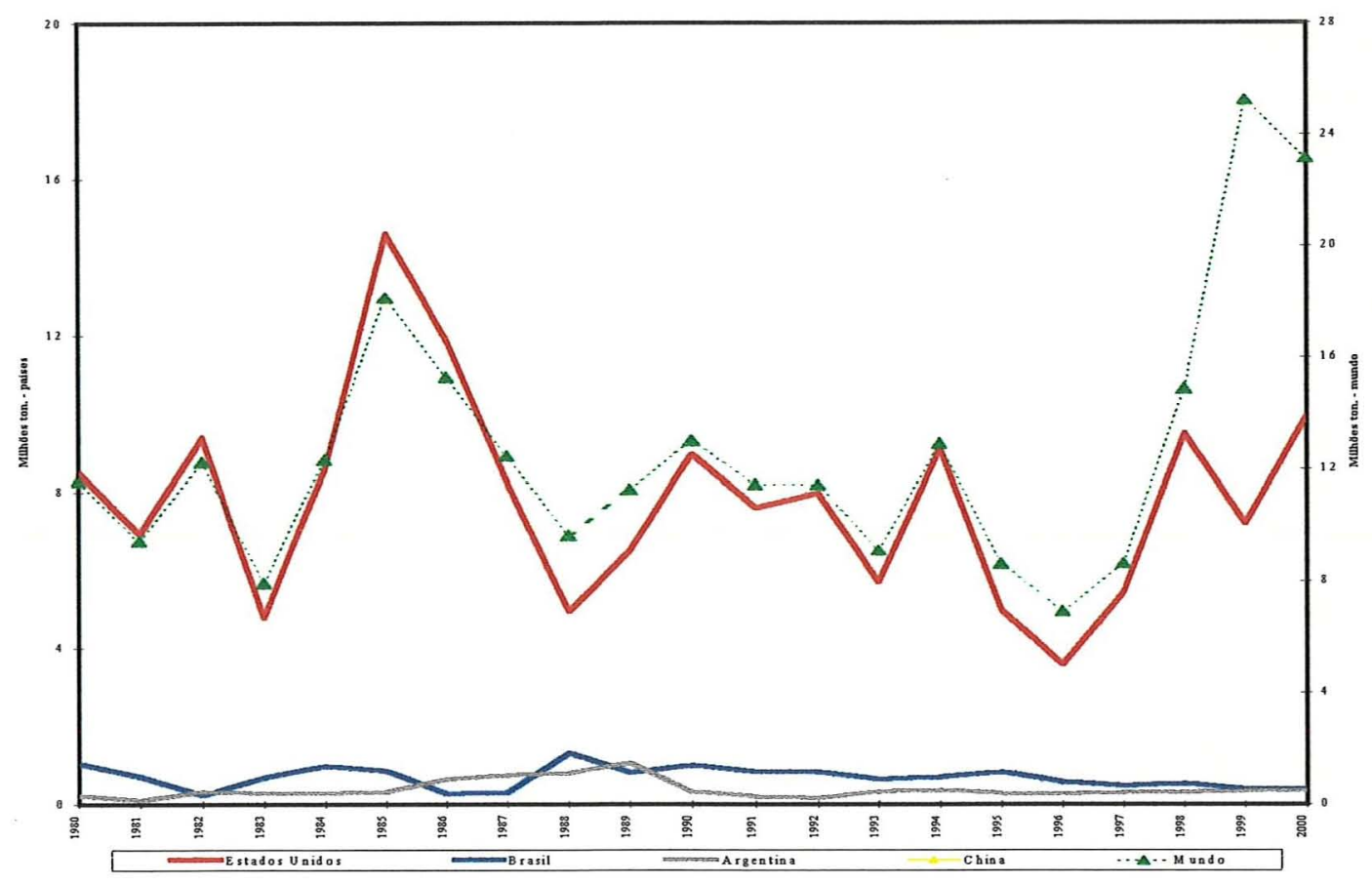

Figura 07 - Evolução dos estoques finais nos principais países estocadores e no mundo, período 1980 - 2000. Fonte: USDA - 2000.

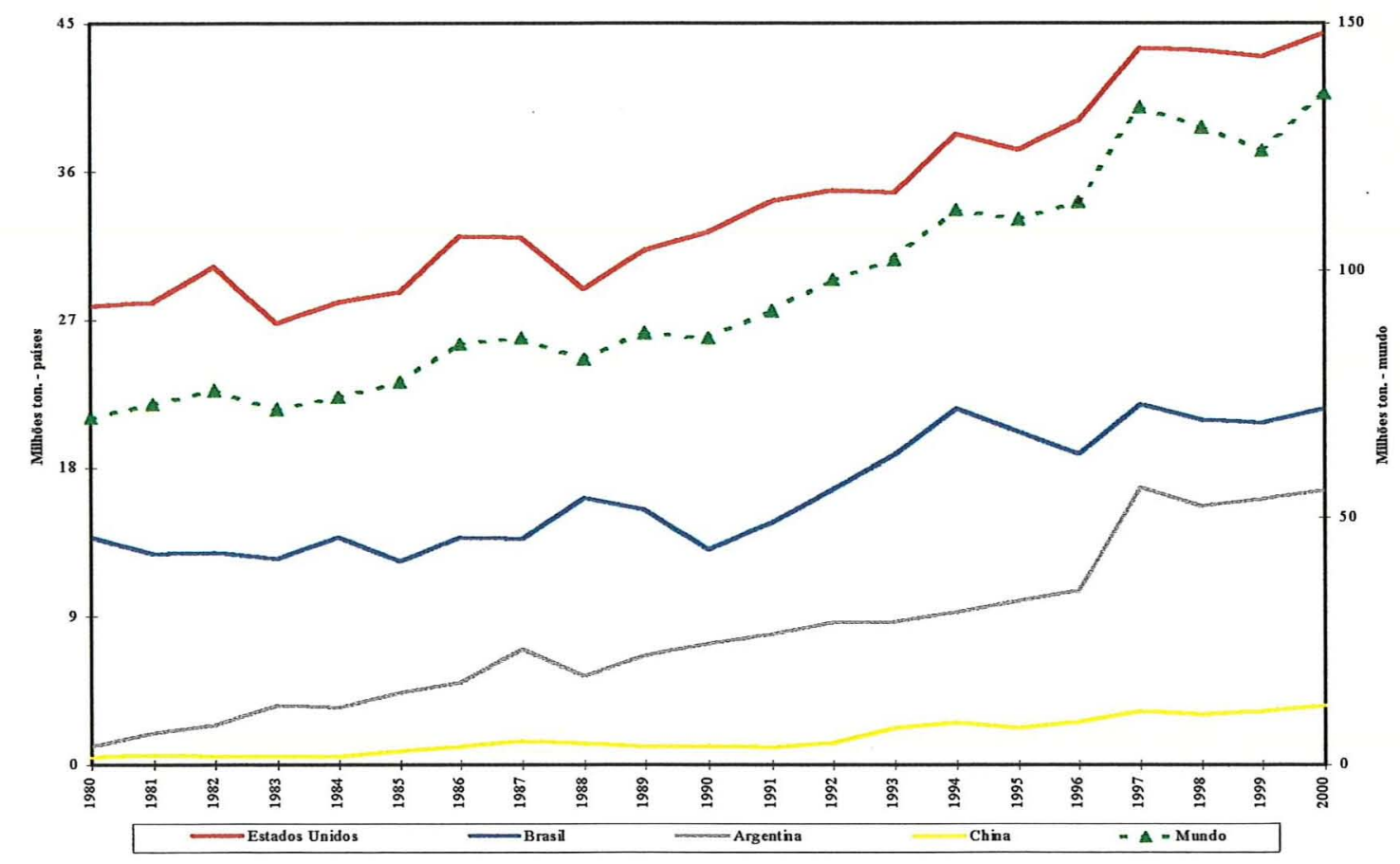

Figura 08 - Evolução do processamento nos principais países processadores e no mundo, período 1980 - 2000. Fonte: USDA - 2000. 


\subsection{Estrutura de produção, processamento, exportação e importação do complexo soja no Brasil}

Tradicionalmente, a soja produzida no Centro-Oeste era destinada às outras regiões, sendo transportada até os estados do Sul e Sudeste para o processamento ou exportação através dos portos de Santos e Paranaguá. No entanto, com a evolução da cultura na região Centro-Oeste, iniciou-se um processo de industrialização, com a implantação de processadoras principalmente no sul de Goiás e do Mato Grosso e no Mato Grosso do Sul. Assim parte da produção começou a ser processada na própria região. A condição de ociosidade da agroindústria brasileira foi agravada nos últimos anos com a isenção do ICMS sobre as exportações de produtos primários, que ampliou significativamente as exportações de soja em grão, reduzindo e/ou estabilizando as vendas ao exterior de farelo e óleo de soja.

A tabela 01 apresenta essa inversão das quantidades exportadas, com destaque para o volume de soja em grão exportado que passou de 3,6 milhões de toneladas na média do biênio 1995-1996, para mais de 8,8 milhões de toneladas no período de 1997-2000.

Tabela 01 - Evolução das exportações brasileiras do complexo soja, 1995 - 2000, (em milhões de ton.)

\begin{tabular}{c|c|c|c|c|c|c|c}
\hline Produto & 1995 & 1996 & 1997 & 1998 & 1999 & $2000^{*}$ & Média \\
\hline Soja em grãos & 3,49 & 3,65 & 8,34 & 9,29 & 8,92 & 8,80 & $\mathbf{7 , 0 8}$ \\
\hline Farelo de soja & 11,60 & 11,26 & 10,01 & 10,45 & 10,43 & 9,80 & $\mathbf{1 0 , 6 0}$ \\
\hline Óleo de soja & 1,76 & 1,33 & 1,12 & 1,36 & 1,52 & 1,45 & $\mathbf{1 , 4 2}$ \\
\hline Total & $\mathbf{1 6 , 8 5}$ & $\mathbf{1 6 , 2 4}$ & $\mathbf{1 9 , 4 7}$ & $\mathbf{2 1 , 1 0}$ & $\mathbf{2 0 , 8 7}$ & $\mathbf{2 0 , 0 5}$ & $\mathbf{1 9 , 1 0}$ \\
\hline
\end{tabular}

A tabela 02 apresenta as receitas cambiais provenientes das exportações do complexo soja que, em média, resultaram em 4,42 bilhões de dólares. Foi o farelo de soja que mais contribuiu, com 2,07 bilhões de dólares em média no período de 19952000 . 
Tabela 02 - Evolução das entradas de receitas cambiais provenientes das exportações do complexo soja, Brasil, 1995 - 2000, (em bilhões de dólares)

\begin{tabular}{c|c|c|c|c|c|c|c}
\hline Produto & 1995 & 1996 & 1997 & 1998 & 1999 & $2000^{*}$ & Média \\
\hline Soja em grãos & 0,77 & 1,02 & 2,45 & 2,17 & 1,59 & 1,67 & $\mathbf{1 , 6 1}$ \\
\hline Farelo de soja & 2,00 & 2,73 & 2,68 & 1,75 & 1,50 & 1,76 & $\mathbf{2 , 0 7}$ \\
\hline Óleo de soja & 1,05 & 0,71 & 0,60 & 0,83 & 0,67 & 0,58 & $\mathbf{0 , 7 4}$ \\
\hline Total & $\mathbf{3 , 8 2}$ & $\mathbf{4 , 4 6}$ & $\mathbf{5 , 7 3}$ & $\mathbf{4 , 7 5}$ & $\mathbf{3 , 7 6}$ & $\mathbf{4 , 0 1}$ & $\mathbf{4 , 4 2}$ \\
\hline Fonte: SECEX/DECEX, ABIOVE, 2000, adaptação do autor
\end{tabular}

Tabela 03 - Capacidade instalada de processamento e produção de soja, segundo os principais estados brasileiros, Brasil, 1998

\begin{tabular}{c|c|c|c|c|c}
\hline \multirow{2}{*}{ Estados } & \multicolumn{2}{|c|}{$\begin{array}{c}\text { Capacidade } \\
\text { instalada (*) }\end{array}$} & \multicolumn{2}{c|}{ Produção } & $\begin{array}{c}\text { Capacidade instalada } \\
\text { menos a produção }\end{array}$ \\
\cline { 2 - 6 } & volume & $\%$ & volume & $\%$ & \\
\hline Paraná & 10,72 & 30 & 7,60 & 24 & $+3,12$ \\
\hline Rio Grande do Sul & 8,68 & 25 & 5,56 & 18 & $+3,12$ \\
\hline São Paulo & 4,03 & 11 & 1,38 & 4 & $+2,65$ \\
\hline Goiás & 2,70 & 8 & 3,30 & 11 & $-0,60$ \\
\hline Mato Grosso & 2,56 & 7 & 7,08 & 23 & $-4,52$ \\
\hline Mato Grosso do Sul & 2,02 & 6 & 2,74 & 9 & $-0,72$ \\
\hline Minas Gerais & 1,62 & 5 & 1,31 & 4 & $+0,31$ \\
\hline Santa Catarina & 1,58 & 4 & 0,45 & 1 & $+1,13$ \\
\hline Outros & 0,82 & 4 & 1,82 & 6 & $-1,00$ \\
\hline Total & 34,73 & 100 & 31,24 & 100 & $+3,49$ \\
\hline
\end{tabular}

Fonte: ABIOVE, 1998 e CONAB, 1999, elaboração AGROMARKET

$\mathrm{Na}$ tabela 03 pode-se comparar a capacidade instalada de processamento de oleaginosas e o volume de produção da matéria-prima, segundo os principais estados produtores. A conclusão a que se pode chegar é que há falta de capacidade de processamento na região Centro-Oeste, principalmente em Mato Grosso, o qual produz 
7,08 milhões de toneladas e tem capacidade de processamento de apenas 2,56 milhões de toneladas, e um grande excedente de capacidade instalada nos estados do Paraná, Rio Grande do Sul e São Paulo, que em conjunto possuem uma produção de 14,54 milhões de toneladas e possuem uma capacidade de processamento de 23,42 milhões de toneladas. Evidenciando desta forma o "passeio" que a matéria-prima tem de fazer até chegar às regiões de industrialização e aos portos exportadores (Santos e Paranaguá).

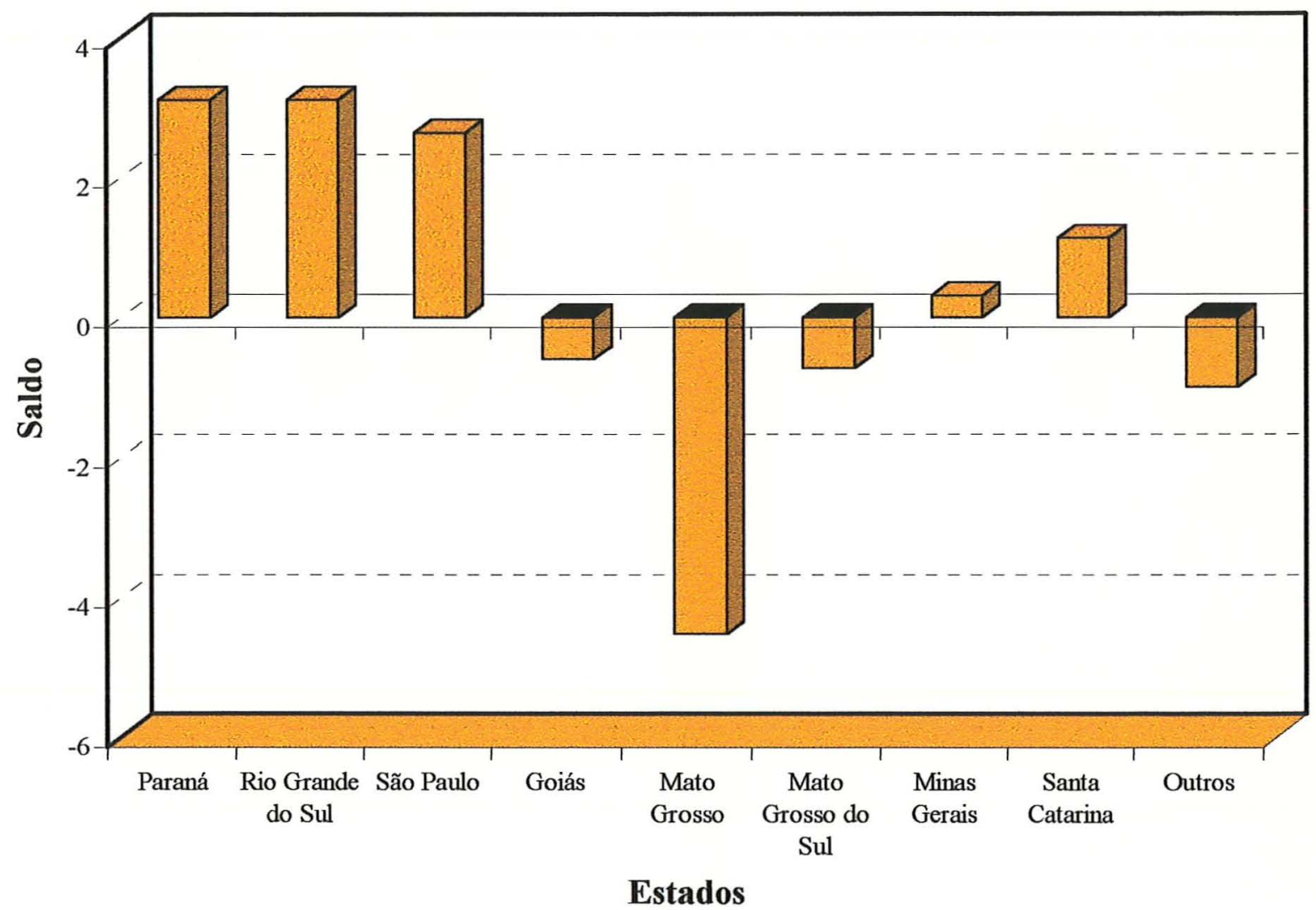

(*) Valores determinados tendo como base o funcionamento da indústria durante 300 dias por ano

Figura 09 - Balanço da capacidade de processamento e produção por Estado - 1998 (em milhões de toneladas, última coluna da tabela 03)

Canziani \& Mafioletti (1999) relatam que a capacidade ociosa está por volta dos $30 \%$ desde 1996. A tabela 03 mostra essa conta, levando em consideração uma capacidade instalada de processamento no Brasil de 34,73 milhões de toneladas/ano e 
uma quantidade processada de 24,2 milhões de toneladas, considerando uma produção interna de 31,24 milhões de toneladas, exportações de soja em grão de aproximadamente 8 milhões e importações (em regime $d r a w-b a c k{ }^{l}$ ) de cerca de 1 milhão de toneladas. Segundo Aguiar (1994), esta ociosidade é proposital, pois as indústrias adotam a estratégia de processar toda a soja antes de se iniciar a safra norte-americana, aproveitando as cotações mais elevadas que ocorrem no primeiro semestre no mercado.

A indústria processadora nacional está se direcionando para os estados do Centro-Oeste e Nordeste. A comprovação disto se dá pela comparação entre trabalhos anteriores a 1995 e os dados de capacidade de esmagamento nos anos seguintes. Para o ano de 1993, Aguiar (1994) argumenta que, apesar dos estados do Rio Grande do Sul, Paraná e São Paulo ainda concentrarem mais de $73 \%$ da capacidade de esmagamento total brasileira (enquanto que Goiás, Mato Grosso e Mato Grosso do Sul correspondem a $14,5 \%$ ), quando se analisa a desativação e os projetos de novas plantas industriais, notase uma tendência de deslocamento das áreas tradicionais para a região Centro-Oeste. Seus dados indicam que nos estados do Rio Grande do Sul (11.730 t/dia desativadas) e São Paulo (5.880 t/dia desativadas) se concentram $92,7 \%$ da capacidade desativada brasileira naquele ano. Por outro lado, da capacidade total de novas plantas planejadas, $72,4 \%$ se concentravam em Goiás (4.200 t/dia) e 17\% no Maranhão (1.000 t/dia). Além disso, no Mato Grosso e Mato Grosso do Sul foram concluídas naquele ano as obras de plantas que correspondem às capacidades de $5.150 \mathrm{t} /$ dia e $3.700 \mathrm{t} /$ dia, respectivamente.

Bulhões (1998) também demonstra que entre 1988 e 1995 a participação dos estados tradicionais (Paraná, Rio Grande do Sul, Santa Catarina e São Paulo) na capacidade de esmagamento de soja brasileira estava se reduzindo e passando para os outros estados (principalmente no Mato Grosso, Goiás, Mato Grosso do Sul e Bahia).

Trigueirinho (1999) em informação pessoal afirma que as novas plantas de processamento não estão se direcionando para as regiões Noroeste do Mato Grosso e Norte do Brasil, mas sim para a região Nordeste. Um dos motivos é a infra-estrutura

\footnotetext{
${ }^{1}$ Vem a ser o retorno, no todo ou em parte, dos direitos cobrados sobre a entrada de produtos estrangeiros no país, os quais serão objetos de reexportação no seu estado original, ou sobre a importação de matéria-prima ou produtos semimanufaturados que serão utilizados na produção de artigos manufaturados nacionais a serem exportados.
} 
precária e também a inexistência de um mercado consumidor para o óleo e farelo no Norte do Brasil, dado que as indústrias de rações, ainda não se deslocaram para essas novas regiões produtoras de matéria-prima. Já no Nordeste há um bom mercado consumidor para o óleo, dessa forma as novas plantas de processamento estão se instalando neste mercado para abastecimento local. Salienta, também, que a isenção total do ICMS (13\%) sobre as exportações dos produtos primários, em 1996, fez com que as possíveis iniciativas de investimento em processamento perdessem força, pois se tornou mais vantajoso e lucrativo exportar soja em grãos do que farelo e óleo.

A tendência das empresas processadoras é a instalação de suas novas plantas processadoras com capacidade acima de 1.500 tonelada/dia para possibilitar ganhos de escala no processamento, em detrimento de plantas com capacidades menores, o que pode ser observado na tabela 04 , para dois períodos distintos.

Tabela 04 - Estratificação da capacidade de processamento por tamanho de planta, 1999

\begin{tabular}{c|c|c}
\hline Processamento em ton/dia & 1989 & 1998 \\
\hline Até 599 & 20.386 & 10.560 \\
\hline $600-1.499$ & 38.020 & 40.980 \\
\hline Acima de 1.499 & 42.020 & 69.370 \\
\hline Total diário & 100.426 & 120.910 \\
\hline Total anual ${ }^{*}$ em mil toneladas & 30.128 & 36.273 \\
\hline
\end{tabular}

Fonte: ABIOVE - 1999

* Considerando o funcionamento da indústria 300 dias por ano.

Quanto à exportação de óleo, esta é feita apenas pelos principais estados produtores, onde estão instaladas as maiores capacidades instaladas de esmagamento (Paraná, Rio Grande do Sul, Santa Catarina, Mato Grosso, Mato Grosso do Sul e Goiás). Os outros estados com capacidades menores de processamento da soja colocam o óleo produzido no mercado interno, que é um grande demandante, sendo o terceiro maior consumidor de óleo de soja do mundo, ficando atrás apenas dos Estados Unidos e da China (Roessing - 1997). 
Segundo dados da ABIOVE e Oilseeds (2000), no período de 1990/2000, o Brasil ocupou nas exportações e importações mundiais as seguintes parcelas de mercado (market share).

(i) $1^{\circ}$ lugar nas exportações de farelo com média de $30 \%$ do mercado mundial, ficando à frente da Argentina com $26 \%$ e Estados Unidos com 20\% do mercado mundial;

(ii) $3^{\circ}$ lugar nas exportações de óleo com média de $15 \%$ do mercado mundial, ficando atrás da Argentina com $30 \%$ e União Européia com $25 \%$ e à frente dos Estados Unidos com $13 \%$ do mercado mundial;

(iii) $2^{\circ}$ lugar nas exportações de soja em grãos com média de $25 \%$ do mercado mundial, ficando atrás dos Estados Unidos com $66 \%$ e à frente da Argentina com 10\% do mercado mundial.

Quanto às importações mundiais o Brasil participa com menos de $0,5 \%$ das importações de óleo e farelo e com $2 \%$ das importações de soja em grãos.

\subsection{Fatores determinantes da formação de preços do complexo soja}

Aguiar (1990) relata que é importante analisar a formação de preços tanto a respeito de seus determinantes teóricos quanto em relação a sua mensuração empírica. Enquanto a preocupação teórica consiste em encontrar relações que se repetem sistematicamente, dadas às mesmas condições, a preocupação empírica consiste em mensurar essas relações e testar as hipóteses formuladas através da teoria.

A formação de preços da maioria das commodities agrícolas ocorre nas bolsas de mercadorias e futuros internacionais e através da dedução dos custos de transporte, armazenamento e impostos chega-se aos preços nas várias regiões de comercialização do mercado físico (Spot). No caso da soja a expectativa é de que os preços sejam formados na Chicago Board of Trade (CBOT).

Barros (1987) afirma que o mecanismo de formação e determinação dos preços e produção agrícola opera sob a dependência de uma superestrutura institucional, dada prioritariamente pelo grau de competitividade do mercado e pelo grau de intervenção 
governamental do mesmo. Esta superestrutura condiciona um mecanismo de transmissão de preços do consumidor ao produtor e vice-versa, através do setor de intermediação.

Assim sendo, um modelo que pretende explicar o comportamento dos preços agrícolas deve considerar que os seguintes fatores podem levar a variações no preço de um determinado produto agrícola; da seguinte forma:

(i) ao nível do produtor - mudanças tecnológicas, preços dos fatores e produtos alternativos, financiamento, clima, etc.;

(ii) ao nível do intermediário - variações nos custos dos insumos de comercialização (transporte, armazenamento, condições de financiamento, etc.);

(iii) ao nível do consumidor - variações na renda, população, preços de outros bens, etc.

Ainda que esse conjunto de fatores permanecesse inalterado, isto é, incluído nas condições ceteris paribus, outras circunstâncias associadas principalmente à defasagem de tempo poderiam ocasionar variações nos preços e quantidades. As principais variações desse tipo seriam as seguintes:

Variações cíclicas de origem na defasagem entre a decisão de produção e a disponibilidade do produto para comercialização. Nesse intervalo de tempo ocorre a formação de expectativas de diferentes graus de confiabilidade. Variações estacionais que ocorrem após ter-se um certo volume de produção. Os custos de armazenamento e preservação e a escassez de capital financeiro resultam em oscilações periódicas dos preços e do abastecimento. 


\subsubsection{Fluxogramas da comercialização do complexo soja}

A figura 10 ilustra os possíveis canais de comercialização do complexo soja, entre estados e portos, até chegar ao seu destino final. Este mapa possibilita a realização os testes de causalidade com maior segurança. Dessa forma, somente serão relacionadas as regiões que possuem comércio entre si.

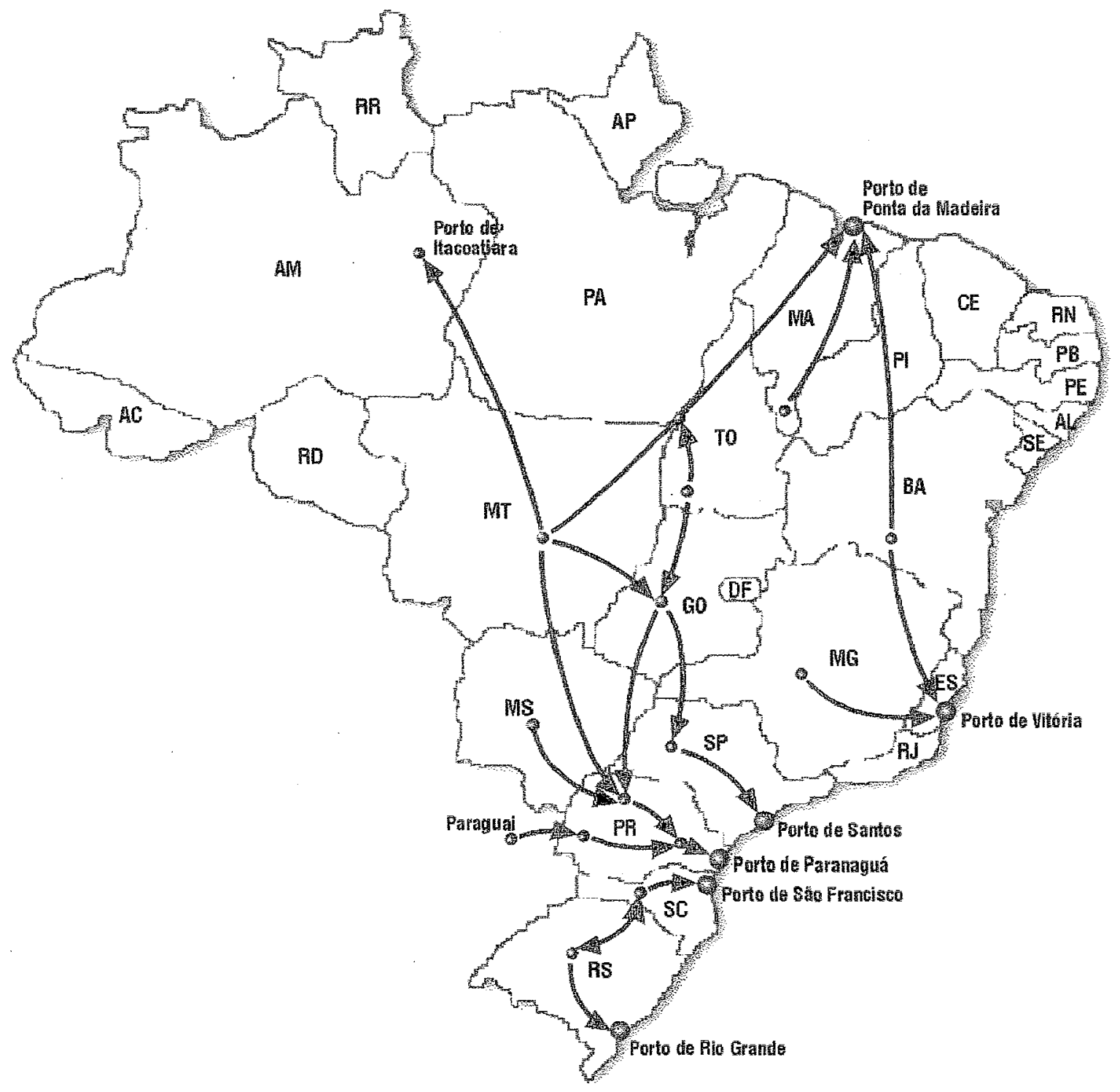

Fonte: elaboração do autor, com base em dados do GEIPOT e agentes do mercado.

Figura 10 - Mapa dos canais de comercialização do complexo soja 
A figura 11 ilustra o balanço de oferta e demanda de soja e farelo nos principais estados brasileiros em produção e consumo, sendo apresentado no mapa abaixo o saldo do respectivo balanço.

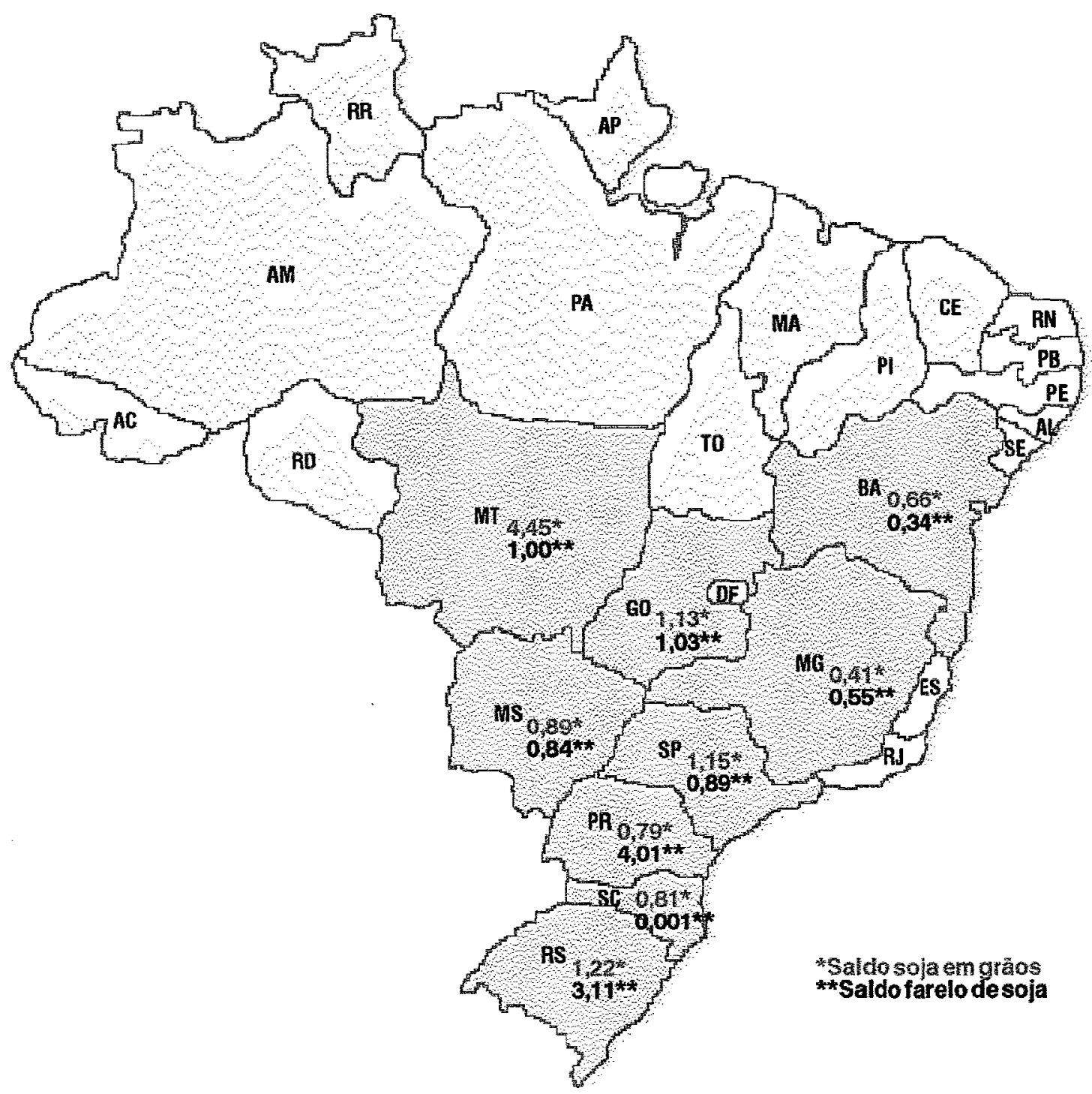

Fonte: elaboração do autor, com base em dados do GEIPOT/DEPRO.

Figura 11 - Saldo do balanço de oferta e demanda dos estados, valores de 1996. 
A figura 12 é importante para visualizar as ligações entre os diversos elos do complexo soja e o número de transações que ocorrem com o produto, desde o setor de insumos (antes da porteira), passando pelo produtor rural nos seus diferentes sistemas de produção (dentro da porteira) e chegando até o consumo intermediário e/ou final (pósporteira). Estas interações entre os diversos elos do complexo soja são coordenadas pelo mercado exportador e pela agroindústria, que é bastante organizada e tem reduzido número de intermediários.

É de fundamental importância entender as forças de mercado que dão origem a formas diferentes de formação e transmissão de preços de produtos agropecuários. Para isto, precisa-se conhecer as cadeias produtivas, suas inter-relações contratuais, a estrutura dos mercados, a oferta e a demanda do produto e seus substitutos. Estes conhecimentos compreendem o que se denominam fundamentos do mercado.

A figura 13 parte da produção nacional de soja em milhões de toneladas, rendimento em derivados e respectivos percentuais de exportações, importações e consumo doméstico. 


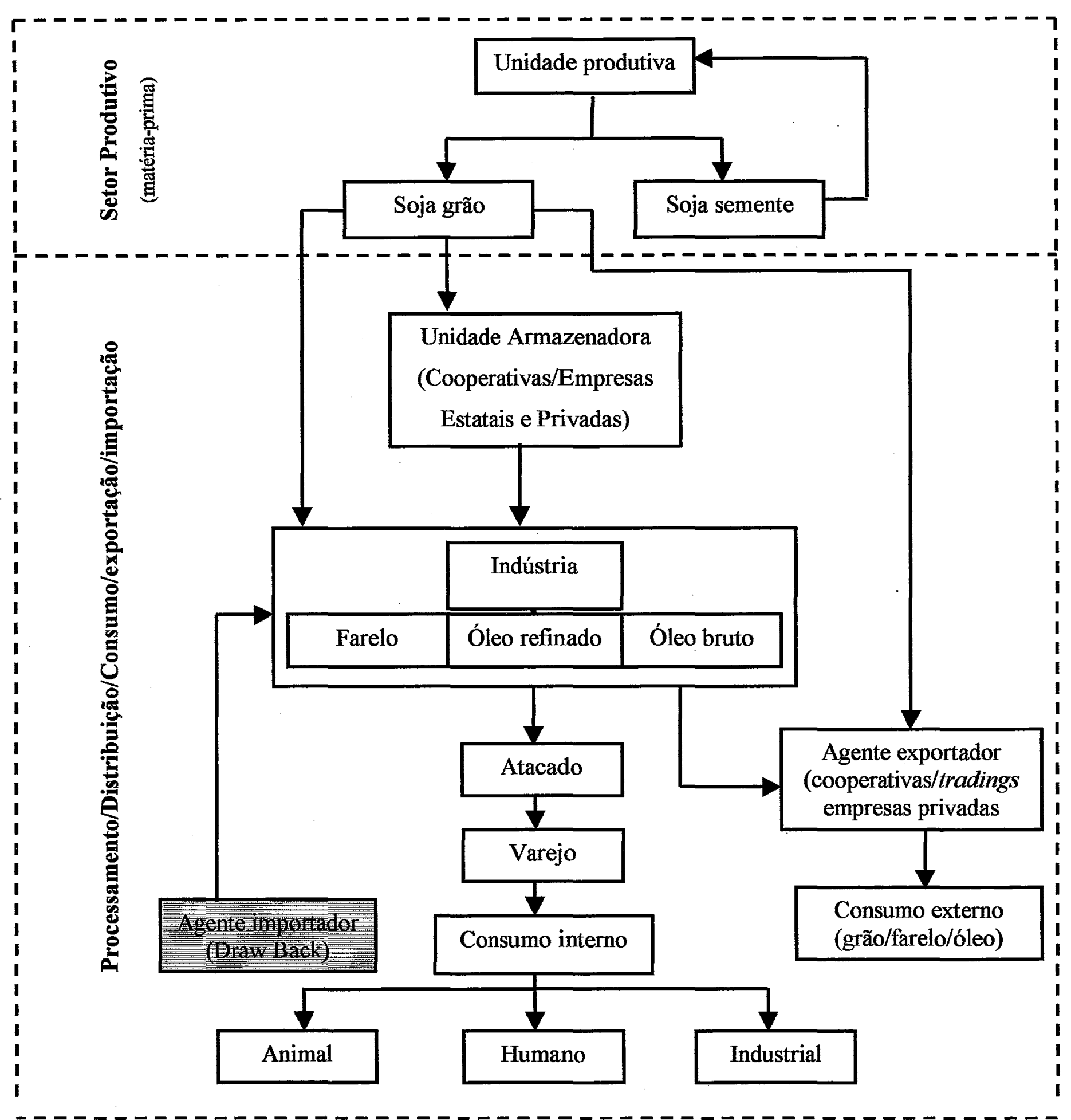

Fonte: EMATER-PR e EMBRAPA/CNPSO, 1995 - adaptação do autor.

Figura 12 - Fluxograma do complexo soja 


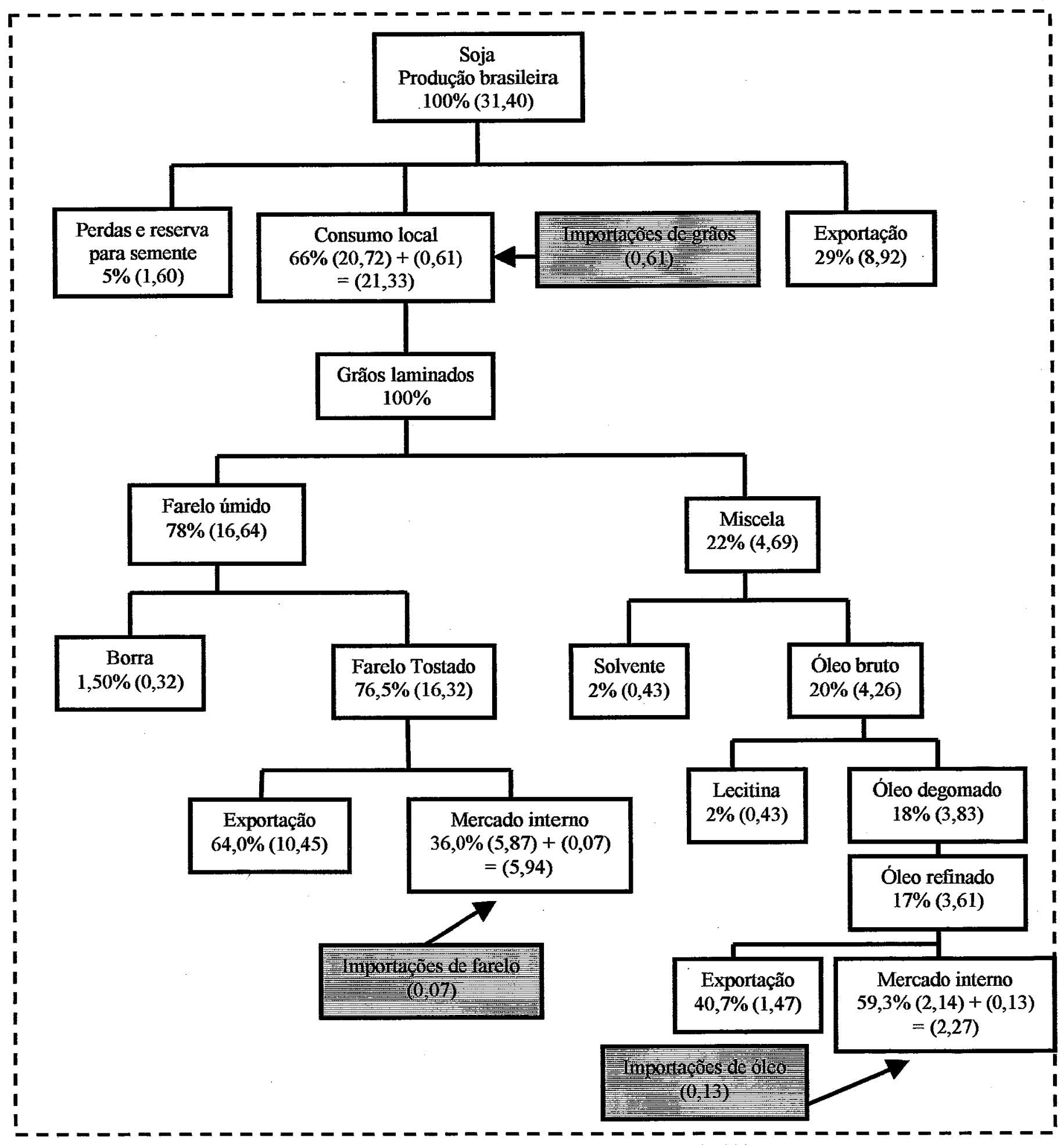

Fonte: SEAB/1998 para o Paraná - Adaptado para o Brasil pelo autor 2000. Dados da Abiove.

Figura 13 - Fluxograma do complexo soja para 1999 - valores entre parênteses em milhões de toneladas 


\subsubsection{Como são formados os preços do complexo soja no mercado interno}

Zanlorenzi (1992) citando Bertrand et alli (1987) informa que até 1973 a fixação dos preços da soja em grão, do farelo e do óleo dependia das condições da oferta e da industrialização americanas. A partir de meados da década de 1970 o aparecimento de novos produtores de soja, o consequente deslocamento estratégico das grandes companhias esmagadoras e as políticas intervencionistas dos paises tornaram a situação mais complexa. Desde então devem ser considerados para a formação do preço internacional da soja em grão Estados Unidos, Brasil e Argentina. Esse preço está sujeito a outras influências, mas permanece comandado pelo nível da produção americana e, secundariamente, pela reação dos produtores brasileiros e argentinos.

Os autores informam também que a partir do preço do grão, dos custos de transporte e das variações cambiais, os preços dos derivados farelo e óleo de soja resultam da estratégia das grandes indústrias esmagadoras (lado da oferta); das indústrias de rações, de alimentos para consumo humano e da indústria química (lado da demanda), e das políticas adotadas pelos Estados Unidos, pelo Brasil e pela Comunidade Econômica Européia. Grandes empresas controlam o comércio do grão, a industrialização e o comércio dos derivados no mercado mundial, como a Cargill (EUA), a Archer Daniels Midland Company - ADM - (EUA), a Coinbra - Louis Dreyfus (França) e a Bunge \& Born (Argentina e Brasil).

Margarido \& Sousa (1998) afirmam que mesmo o Brasil sendo o segundo produtor e exportador mundial, é tomador de preços, ou seja, as cotações dos preços no mercado interno são baseadas nas cotações da Bolsa de Chicago.

A figura 14 ilustra os canais de comercialização por onde a soja proveniente do produtor rural passa até chegar ao seu destino final, através de diferentes formas de negociação. Com este fluxograma é possivel estabelecer os mercados que primeiro são impactados com variações dos preços internacionais ou aumento da demanda por carnes e óleo. 


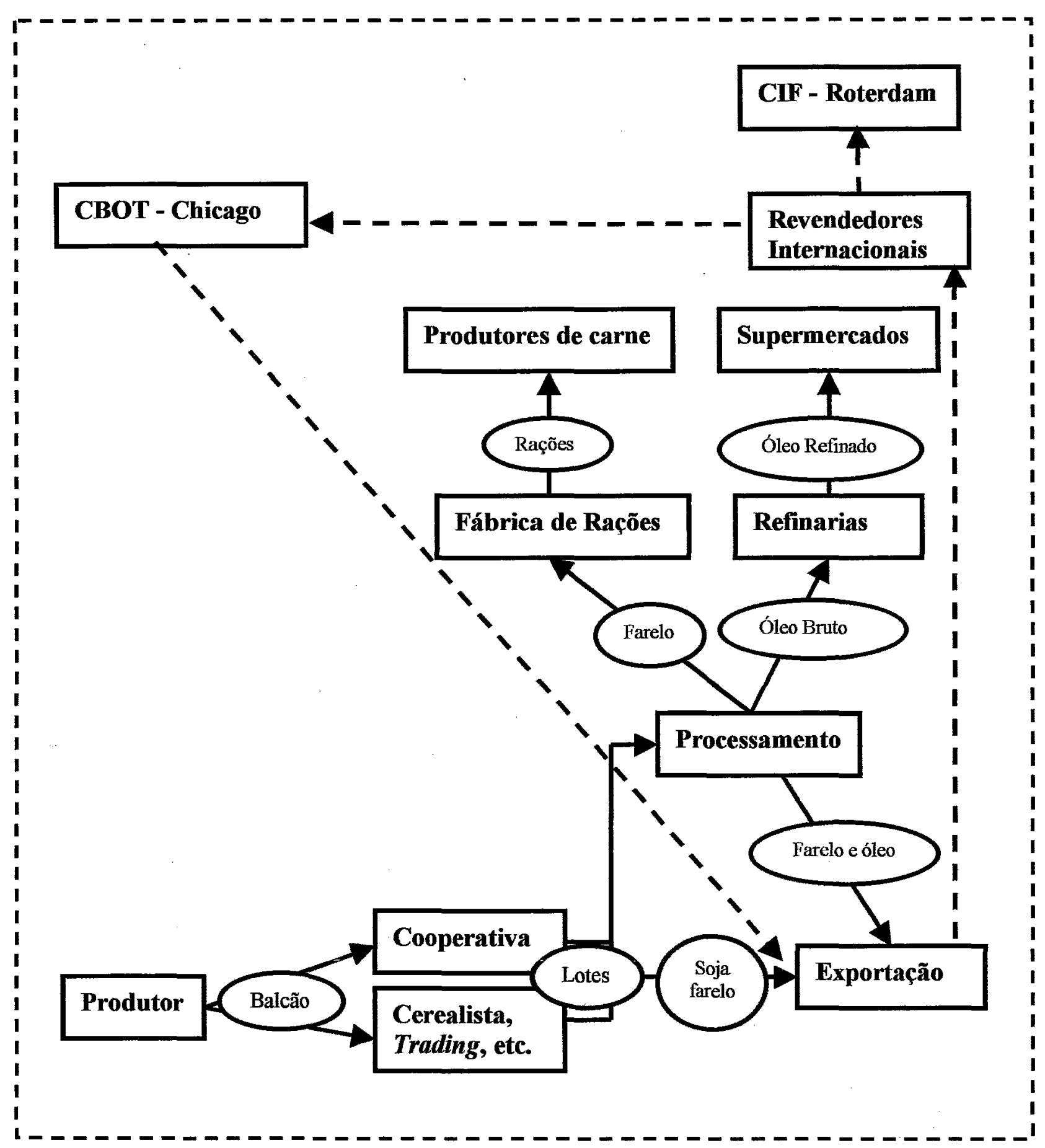

Fonte: Dados primários da Ocepar - elaboração do autor.

Nota: O sentido das setas indica o percurso que a soja percorre até chegar ao consumidor, linhas pontilhadas indicam influência dos preços

Figura 14 - Fluxograma dos canais de comercialização do complexo soja 
A formação dos preços no mercado interno acontece em dois níveis: i) preços recebidos pelos exportadores e ii) preços recebidos pelos produtores. No primeiro caso, os preços baseiam-se nas cotações da Bolsa de Chicago, às quais são somados prêmios específicos (mercado de lotes da figura 14). Esses prêmios são determinados de acordo com uma série de critérios, podendo ser positivos ou negativos. Os principais critérios são: i) condições de oferta e demanda no mercado interno; ii) pequenas diferenças de qualidade, principalmente ligadas ao teor de proteína do farelo; iii) eficiência do porto exportador e; iv) condições de pagamento, principalmente para o óleo, Aguiar (1990); Caffagni (1999) inclui também nesta lista outros fatores, como greves portuárias, chuva, disponibilidade de produto em armazéns portuários, etc.

Barros et al (1997) afirmam que, no caso particular do preço da soja no Brasil, estudos econométricos têm mostrado que a formação do seu preço dá-se de fora para dentro. Os preços se formariam em mercados internacionais e os produtores seriam bem informados e passariam a reivindicar internamente preços compatíveis com os praticados no mercado externo. Dessa forma a formação dos preços da soja em nível mundial começa com Roterdã, refletindo-se nas cotações da bolsa de futuros de Chicago $(C B O T)$, derivando dai a demanda pelo produto brasileiro, o qual recebe um ágio ou deságio (prêmio) e deduzem-se os custos de frete, chegando-se ao preço no porto de Paranaguá. 
Deste preço porto são deduzidos custos de impostos, fretes, etc., chegando-se ao preço na processadora, deste preço deduzindo-se os custos de frete, operacionais, etc., chega-se ao preço que, juntamente com a concorrência em cada região, formará o preço a ser pago ao produtor. É interessante notar que a formação de preços vai depender dos custos operacionais e da concorrência, isto é, o preço final vai depender muito da necessidade da processadora obter o produto, repor estoques, etc. Além disso, o preço final também pode refletir uma operação financeira rentável como, por exemplo, venda de performance ${ }^{2}$.

A BM\&F disponibiliza em seu site na Internet um quadro para o cálculo da paridade de exportação, baseado na cotação da bolsa de Chicago (CBOT) para o preço da soja no porto exportador. Esta paridade não é o preço praticado na região produtora, mas sim um indicativo, uma vez que o preço também está sujeito às variações do mercado interno. A influência do mercado interno varia de acordo com a época do ano.

$\mathrm{Na}$ safra, os preços da bolsa têm um peso maior e o cálculo da paridade representa melhor o preço nas diversas praças. Na entressafra, no entanto, os preços dependem quase que totalmente das variações de oferta e demanda da indústria esmagadora nacional. Estas variações, por seu lado, são influenciadas principalmente pelo mercado de farelo, pois este é o principal produto oriundo do esmagamento da soja.

\footnotetext{
2 'É um direito de venda que funciona como um ativo financeiro“c. Regulamentada via resolução 2.312 do Banco Central. Representa uma operação especulativa em que uma empresa cadastrada (habilitada) como exportadora tem acesso a Adiantamento de Contrato de Câmbio (ACC) que é recurso a juros de mercado internacional pelo prazo de 180 dias, tomando compromissos em valor monetário e não em mercadoria. Essa empresa aplica os recursos no mercado financeiro e próximo ao vencimento do compromisso procura outra empresa que é efetivamente exportadora para realizar a operação e normalmente divide os ganhos com o ACC que custa, variação cambial mais $6 \%$ ao ano, e internamente ganha $+/-20 \%$ mais TJP, sendo uma operação legal e da liquidez ao mercado exportador, normalmente, a empresa vendedora, também exportadora, vende a mercadoria acompanhada de contrato mercantil externo, ou seja, já indicando o importador, e muitas vezes já amparada em carta de crédito.
} 
Na tabela 05 a seguir mostra-se o cálculo de paridade do preço da soja no mercado interno.

Tabela 05 - Procedimento de cálculo para internalização do preço da soja em grão para Rondonópolis, novembro - 1997.

\begin{tabular}{l|l}
\hline \multicolumn{1}{c|}{ Descrição } & \multicolumn{1}{c}{ Valor } \\
\hline 1. Cotação CBOT, novembro/97 & 691,00 cents/Bushel \\
\hline 2. Prêmio & 50,00 cents/Bushel \\
\hline 3. Subtotal (1+2) & 741,00 cents/Bushel \\
\hline 4. Fator de conversão para tonelada & 0,3674541 \\
\hline 5. FOB porto (3x4) & US\$ 272,28/ton \\
\hline 6. Comissão do corretor de fisico & US\$ 0,50/ton \\
\hline 7. Receita bruta em US\$ (5-6) & US\$ 271,78/ton \\
\hline 7.1. Receita bruta em R\$ (7x1,0639) & $\mathrm{R} \$ 289,15 /$ ton \\
\hline 8. Corretagem de câmbio (0,1875\% de 7.1) & $\mathrm{R} \$ 0,55 /$ ton \\
\hline 9. Despesas portuárias. & $\mathrm{R} \$ 11,00 /$ ton \\
\hline 10. Quebra de transporte (0,25\% de 7.1) & $\mathrm{R} \$ 0,73$ \\
\hline 11. Tributos (ICMS, PIS, COFINS, etc) & 0,00 \\
\hline 12 Frete para o porto & $\mathrm{R} \$ 60,00 /$ ton \\
\hline 13. Paridade Rondonópolis & $\mathrm{R} \$ 216,87 /$ ton ou 13,01/saco \\
\hline 14. Margem do comprador (3\% de 13) & $\mathrm{R} \$ 0,39 /$ saco \\
\hline 15. Preço de abertura para compra & $\mathrm{R} \$ 12,62 /$ saco \\
\hline Fo &
\end{tabular}

Fonte: Barros et all adaptado da ABIOVE (1997).

* Não inclui receita financeira de venda de performance.

*Prêmio do porto e outras despesas podem variar.

Margarido \& Sousa (1998) demonstram que o comportamento dos preços internos são influenciados instantaneamente pelas variações nos preços do mercado externo (CBOT). No entanto, estas variações não são totalmente repassadas para os preços recebidos pelos produtores brasileiros. Eles observaram que é repassado ao 
produtor apenas $70,57 \%$ da variação internacional ao preço médio da soja brasileira e apenas $62,22 \%$ para o preço da soja paranaense. Esta pesquisa não identificou o efeito sazonal dos preços, mas apenas uma média anual dos preços.

Como causa do não repasse total das cotações de Chicago, os autores citam o consumo de uma parcela da produção no mercado interno e o "Custo Brasil" 3.

Neves (1993) relata que as variações nos preços recebidos pelos produtores resultam da combinação de três fatores: i) deslocamento da curva de demanda de algum dos produtos derivados (farelo ou óleo de soja); ii) soma dos preços dos diversos serviços adicionados (insumos de comercialização) e; iii) variações na quantidade produzida face às variações climáticas, estrutura de custos, entre outros.

\subsection{0 setor de transportes, portos e armazenamento}

Caixeta (1996) afirma que o "Custo Brasil" vem sendo apontado como uma das principais causas de perda de competitividade da soja brasileira frente à dos Estados Unidos e Argentina. Dentro destas ineficiências, destaca-se o setor de transportes, que apresenta-se muito mal dimensionado e bastante precário para as necessidades nacionais. Portanto, pode-se afirmar que a infra-estrutura de transportes é um importante fator diferenciador dos preços da soja no mercado interno, prejudicando as regiões de fronteira que possuem estrutura mais precária.

Segundo ABIOVE (1997) o transporte do complexo soja brasileiro é realizado predominantemente por rodovias, enquanto nos Estados Unidos o transporte é realizado predominantemente por hidrovia, conforme as figuras (15 e 16) a seguir. Porém, os custos no transporte são bem maiores no rodoviário em comparação aos do transporte hidroviário e os custos do sistema ferroviário são intermediários entre o rodoviário e o hidroviário, conforme as figuras (17 e 18) a seguir. Dessa forma, reduz-se a competitividade da soja brasileira em relação a americana no segmento "pós-porteira".

\footnotetext{
${ }^{3}$ Bulhões (1998) citando a definição da Confederação Nacional da indústria, define o Custo Brasil como sendo um conjunto de ineficiências e distorções acumuladas nos últimos anos no sistema tributário, na legislação trabalhista, na precariedade da educação e saúde, na obsolescência da infra-estrutura de transportes, nos elevados custos portuários, na deterioração das comunicações, no estrangulamento do sistema energético, no elevado custo de financiamento e de transações.
} 


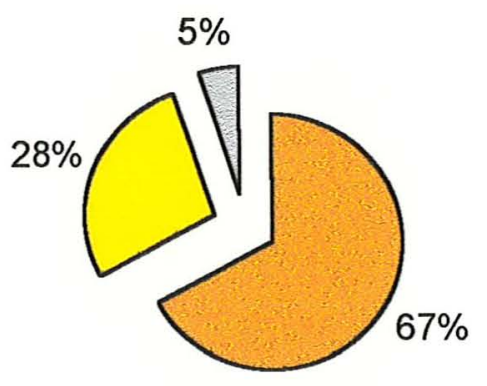

口RODOVIA 口FERROVIA $\square$ HIDROVIA

Fonte: ABIOVE - 1997

Figura 15 - Meios de transporte do complexo soja no Brasil

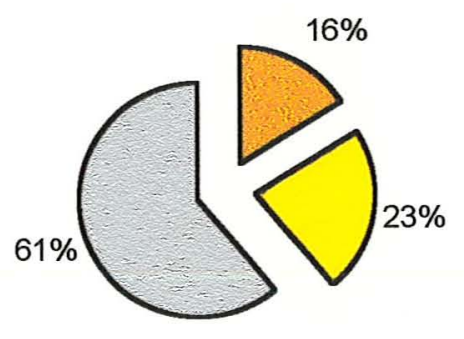

$\square$ RODOVIA 口FERROVIA GHIDROVIA

Fonte: ABIOVE - 1997

Figura 16 - Meios de transporte do complexo soja nos Estados Unidos 


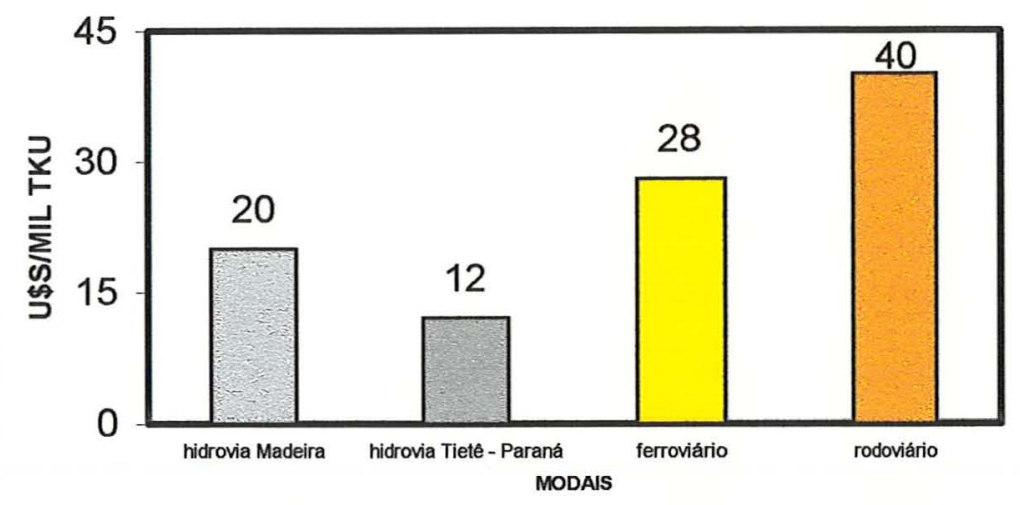

Fonte: Agroanalysis - FGV/ 98

Figura 17 - Custo de transporte da soja no Brasil - 1998

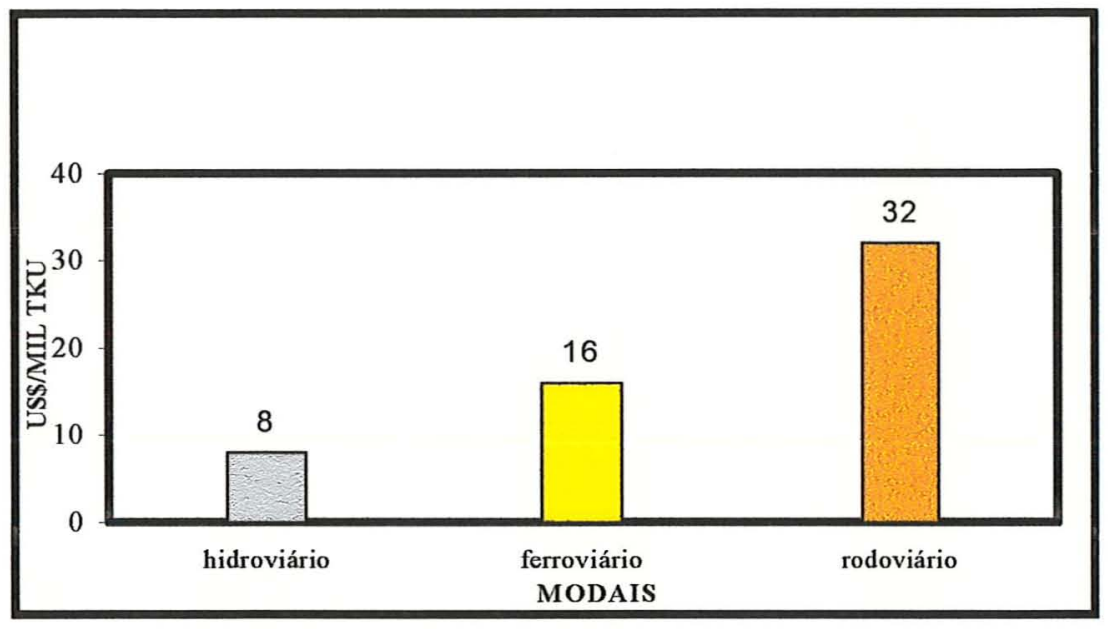

Fonte: Agroanalisys - FGV/98

Figura 18 - Custo de transporte da soja nos (EUA) - 1998

$\mathrm{Na}$ área de armazenagem, Lazzarini \& Nunes (1998) asseguram que o Brasil tem problema de ordem mais qualitativa relacionado à capacidade de armazenagem do que propriamente de ordem quantitativa. O Brasil apresenta uma capacidade de armazenagem estática somente de soja da ordem de 35 milhões de toneladas, sendo $47,2 \%$ pertencente a indústria, $41,4 \%$ às cooperativas e $11,3 \%$ a órgãos governamentais. Segundo dados da CONAB de 1997, considerando-se outros grãos, o Brasil apresenta 
6,4 mil armazéns com capacidade estática da ordem de 60 milhões de toneladas. Se estivessem em boas condições haveria capacidade de armazenar $75 \%$ de nossa produção anual de grãos que está por volta de 83 milhões de toneladas.

Bulhões (1998) citando Moreira (1997) afirma que o Brasil deixa de receber 5 bilhões de dólares ao ano devido aos altos custos da rede portuária, seja porque as tarifas cobradas são elevadas, seja porque o manuseio das cargas é lento e caro demais. Este mesmo autor citando Pavan (1998) diz que, no caso da soja, os custos portuários no Brasil respondem por $3 \%$ a $5 \%$ do valor de exportação (valor FOB), enquanto nos Estados Unidos e Argentina chegam no máximo de 1\% a 1,5\%. 


\section{REVISÃo DOS MODELOS TEÓRICOS DE FORMAÇÃO DE PREÇOS}

\subsection{Modelo de GARDNER (1975)}

O principal modelo teórico que relaciona os preços em diferentes níveis de mercado é o de Gardner (1975). Sua importância pode ser dimensionada observando-se que a maioria dos trabalhos teóricos de transmissão de preços entre níveis de mercado após 1975 se basearam nele.

As pressuposições são de que a economia funciona em concorrência perfeita com equilíbrio instantâneo nos três níveis de mercado (do produto final, da matéria-prima agrícola e do agregado de insumos de comercialização). Este modelo é de natureza estático-comparativa, mostrando o comportamento de um mercado onde a matéria-prima agrícola é combinada com os insumos de comercialização (um agregado de serviços de processamento e transporte entre outros, com preços relativos dos componentes constantes) para a produção do produto final a ser vendido no varejo.

\subsection{Modelo de HEIEN (1980)}

Segundo Aguiar (1994), a principal diferença entre os modelos de Gardner e de Heien é a suposição, deste, de desequilíbrio de curto prazo no mercado varejista. Heien (1980) afirma que o equilíbrio simultâneo nos três níveis de mercado do modelo de Gardner só é realista quando se têm situações envolvendo períodos de tempo, em que alterações no estoque são pequenas ou inexistentes em relação à demanda total. Entretanto, para períodos de tempo considerados curtos, ocorrem desequilíbrios nestes mercados. O modelo de Heien tenta ocupar uma lacuna deixada pelo modelo de 
Gardner, no que diz respeito à dinâmica do processo de transmissão e formação de preços. Incluindo uma análise que demonstra a trajetória dinâmica percorrida entre um equilíbrio e outro dos mercados de produtor, atacado e varejo.

\subsection{Modelo de BARROS (1990)}

Este modelo é bastante semelhante ao de Heien, porém com maior ênfase ao papel do mercado atacadista na formação dos preços. Heien inicia seu modelo considerando os três níveis de mercado, mas acaba por analisar a dinâmica de ajustamento através da relação direta entre produtor e varejo. Barros, por sua vez, analisa as relações dinâmicas envolvendo os três niveis de mercado. Considera que o mercado atacadista, por trabalhar com maiores quantidades do produto, pode assumir o papel de líder nas variações de preços, já que o modelo leva em conta a questão de que o acesso à informação não é uniforme entre as partes envolvidas na comercialização de produtos agrícolas.

Neste modelo, tem-se que, no atacado, o ajustamento de preços ocorre instantaneamente, enquanto que, nos níveis de produtor e varejo, este ajustamento seria defasado em relação ao atacado, devido ao produtor comercializar pequena quantidade de produto e os varejistas não serem especializados. O preço ao produtor se dirigiria até o equilíbrio por meio de ajustes parciais. Por outro lado, os varejistas adotariam uma política de "markup" para a definição do preço de equilíbrio para o qual o mercado se dirigiria também por meio de ajustes parciais.

\subsection{Modelo de equilíbrio para o mercado de soja brasileiro}

Modelos econômicos são simplificações da realidade, procurando identificar e relacionar os fatores mais importantes para explicar os acontecimentos. Na sua especificação e análise utilizam-se dados passados para tentar antever o futuro, o que envolve um risco, uma vez que tais condições podem não mais prevalecer. A condição básica para tentar estabelecer modelos é conhecer o mercado, o que pode ser feito pela pesquisa e pela análise de relacionamento entre os preços do produto e das demais 
condições do mercado. Os "fundamentalistas" acreditam que o preço de uma commodity está em constante movimento em direção a um ponto de equilíbrio definitivo que pode estar numa posição totalmente diferente da observada num dado momento qualquer.

$\mathrm{O}$ modelo proposto a seguir tenta retratar o mercado de soja e derivados, visto que os modelos de formação e transmissão de preços expostos anteriormente não são específicos para este mercado. Baseia-se no modelo desenvolvido por Houck \& Mann (1972) para o mercado de soja e derivados nos Estados Unidos. O objetivo principal deste modelo teórico é estudar o complexo soja com suas características peculiares, a fim de tirar conclusões mais precisas a respeito do equilíbrio entre oferta e demanda no mercado de soja em grãos e derivados, e também, do processo de formação e transmissão dos preços.

\subsubsection{O mecanismo de preços}

Estabelecer os níveis de produção e preços são os objetivos mais importantes da análise do equilíbrio do complexo soja, ilustrada na figura 19. Este diagrama é especificamente concebido para focar atenção no processo de estabelecimento do preço para uma dada safra. Iniciando no topo do diagrama, observa-se que a produção de soja no Brasil é determinada pela área colhida e produtividade. Deduzindo as pequenas porções da produção utilizadas diretamente para a alimentação humana, sementes e perdas, o remanescente da produção mais carry-in (estoques das safras prévias), resulta na oferta comercial corrente.

A interação da oferta comercial e da demanda de mercado para soja em cada ano safra determina os preços da soja recebidos pelos produtores. Embora os preços mínimos também tenham impacto em alguns anos esta discussão não será realizada. Para o momento, simplesmente imagine-se que o preço de mercado é livremente determinado pelas forças de mercado e acima do preço mínimo. O preço corrente da soja mais outros fatores incluindo decisões governamentais relacionadas aos preços mínimos, tanto da soja quanto de outras commodities como (milho, algodão) afetam a decisão dos produtores nas decisões de plantio para o ano seguinte. A demanda total de mercado 
para a soja está ilustrada na porção central da figura, sendo composta pela demanda por soja para a exportação e demanda por soja para esmagamento. A demanda dos esmagadores por soja deriva-se da demanda pelos produtos do processamento de soja, (farelo e óleo), que podem ser vendidos dentro de vários mercados de uso final.

A margem de processamento e manuseio situa-se entre a receita média dos esmagadores provenientes dos produtos processados e dos preços recebidos pelos produtores de soja. Esta margem é o preço dos serviços oferecidos ao mercado pelas firmas para realização do manuseio e processamento. Ela depende não somente da tecnologia da indústria, mas das plantas individuais, localização, eficiência operacional e integração com outras operações de mercado.

A receita obtida pelos processadores de soja depende do preço ao atacado dos produtos processados e da taxa física à qual eles são extraídos da matéria-prima, largamente determinada pelas proporções fixas de farelo e óleo extraídas do grão de soja. De outro lado, os preços do óleo e farelo são determinados pela interação de suas demandas de mercados individuais com os montantes produzidos. Farelo e óleo de soja são essencialmente independentes um do outro em seus usos. As forças econômicas que atuam sobre a demanda por farelo são largamente não relacionadas com aquelas que agem sobre a demanda por óleo. Portanto, são os aspectos conjuntos de produção de farelo e óleo que asseguram que a oferta destas commodities sejam ligadas muito proximamente. Desse modo, os preços do farelo e óleo devem ajustar-se ao balanço das demandas para estas duas commodities com suas ofertas. Os preços da soja no nível do produtor são uma composição dos preços de farelo e óleo mais a influência de fatores afetando custos de manuseio e processamento. O Programa de Garantia de Preços Mínimos - (PGPM) provém um piso de preço para todo o sistema. 


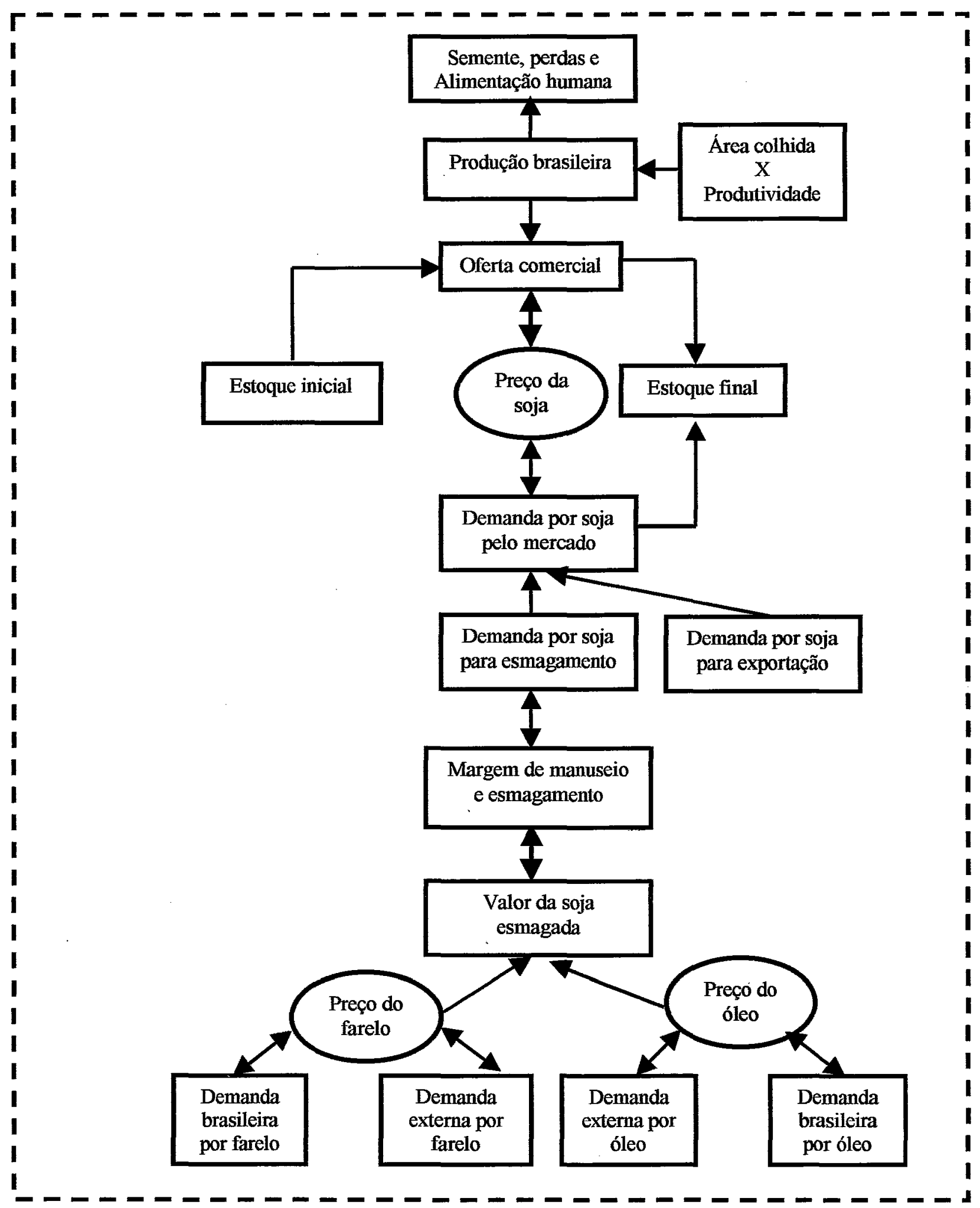

Figura 19 - Fluxograma do mercado de soja brasileiro.

Nota: As setas indicam direção de influência 


\subsubsection{A demanda em blocos - modelos e estimativas}

No modelo original de Houck \& Mann, há um ajuste simultâneo do mercado de soja e derivados com 13 equações, das quais, sete equações são comportamentais com os parâmetros estruturais estimados estatisticamente e as demais são relações físicas e técnicas do mercado. No entanto, este estudo abordará somente o equilibrio gráfico do mercado, que está ilustrado na figura 20 a seguir.

Este modelo pode ser representado em diagramas bidimensionais baseados na teoria econômica estática, sendo estes diagramas preço-quantidade versões generalizadas do mercado de farelo, óleo e soja para um dado momento no tempo, com todos os fatores extrapreço mantidos constantes, ou seja, na condição "ceteris paribus".

i) Aspectos conjuntos de farelo e óleo de soja - Processando uma tonelada de soja em grão produz-se farelo e óleo em proporções fixas ( $78 \%$ de farelo e $20 \%$ de óleo). Uma vez que o esmagamento de soja tenha sido determinado, a oferta de farelo e óleo já são conhecidas. Eles devem ser vendidos para seus usos finais ou mantidos como estoques. Desse modo, ofertantes de farelo e óleo são fortemente ligados um ao outro pela quantidade de soja esmagada domesticamente.

ii) Múltiplos mercados de vendas para soja, farelo e óleo - Vários mercados distintos competem pela disponibilidade de oferta de soja, farelo e óleo. A soja move-se adiante para esmagamento doméstico, exportação e estoques. A pequena quantidade utilizada como semente, alimentação humana e outros derivados pode ser ignorada. Similarmente farelo e óleo, uma vez produzidos, movem-se adiante para utilização doméstica, exportação e estoques.

iii) Interdependência de soja e derivados da soja com os grandes setores econômicos - Embora os mercados de óleo e farelo sejam largamente independentes um do outro, cada um destes dois produtos é parte de um complexo setor econômico nos quais a competição e substituição entre as commodities são importantes. Farelo de soja é um dos vários produtos de alto valor protéico para a alimentação das criações. Óleo de soja é um dos muitos óleos vegetais comestíveis no complexo de óleos e gorduras. Soja é uma oleaginosa específica em uma vasta gama de produtos competitivos. 
iv) Determinação simultânea de preços dos produtos e fluxos de mercado dentro de cada ano safra. No mercado da soja, a influência mútua e a interdependência do lado da demanda não pode ser ignorada, especialmente quando a análise é lançada em uma estrutura de safra. Os aspectos conjuntos dos múltiplos mercados e produtos do setor soja asseguram esta simultaneidade.

Embora farelo e óleo de soja sejam relatados juntamente do lado da oferta, suas respectivas flutuações de preços refletem fortemente as influências geradas pela demanda nos seus vários mercados de commodities.

A seguir são listadas as variáveis que fazem parte do modelo de equilíbrio no mercado da soja e derivados.

$\mathrm{PF}=$ Preço do farelo;

$\mathrm{PO}=$ Preço do óleo;

PS = Preço da soja;

$\mathrm{DFB}=$ Demanda por farelo no Brasil;

DFX $=$ Demanda por farelo para exportação;

$\mathrm{DFT}=$ Demanda total por farelo;

$\mathrm{DOB}=$ Demanda por óleo no Brasil;

DOX = Demanda por óleo para exportação;

DOT $=$ Demanda total por óleo;

$\mathrm{DSB}=$ Demanda por soja no Brasil;

DSX = Demanda por soja para exportação;

ODTS = Oferta e demanda total por soja;

$\mathrm{W}=$ Margem dos diversos intermediários do complexo soja.

$\mathrm{Na}$ figura 20 utilizam-se as variáveis preço do mercado de lotes para soja em grãos farelo e óleo no mercado interno, e no mercado externo as variáveis preço são da CBOT primeiro vencimento, como proxy do preço do mercado internacional.

O modelo proposto pode ser analisado e/ou interpretado da seguinte forma. Sabendo-se que a soja e derivados são intimamente relacionados através de proporções fixas de rendimento, um choque em qualquer mercado (soja, farelo e óleo) alterará o 
equilíbrio nos demais mercados. Para entender melhor os efeitos, toma-se o exemplo que ocorreu neste mercado em 1996, com a isenção total do ICMS sobre a exportação de produtos primários, quando houve um brusco aumento nas quantidades exportadas de grãos em detrimento das exportações de óleo e farelo. Esta medida de isenção do ICMS afetou o mercado de soja em grãos pelo aumento dos preços pagos ao produtor $e_{\text {, }}$ também, aumento das margens dos exportadores. O aumento deslocou a curva de demanda por soja para a direita, fazendo com que o novo equilíbrio no mercado de soja em grãos, afetasse o equilíbrio nos demais mercados, via aumento de preços, estabelecendo o equilíbrio a maiores preços de farelo e óleo, reduzindo dessa forma a quantidade demandada de farelo e óleo e não sendo atrativo processar a soja.

A relação do modelo proposto a seguir com os modelos econométricos e os resultados e discussões, abordados nos capítulos 04 e 05 está em que trabalha-se com as mesmas séries de preços dos três níveis de mercado do complexo soja para as diferentes regiões de comercialização.

As variáveis preços utilizadas para determinar o equilíbrio no complexo soja, identificadas na figura 20 são:

Psch - Preço da soja em Chicago, como proxy do preço no mercado internacional; Pspr - Preço da soja no Paraná, como proxy do preço da soja no Brasil;

Psrs - Preço da soja no Rio Grande do Sul, como proxy do preço da soja no Brasil; Pfch - Preço do farelo em Chicago, como proxy do preço no mercado internacional; Pfsp - Preço do farelo em São Paulo, como proxy do preço do farelo no Brasil; Pfpr - Preço do farelo no Paraná, como proxy do preço do farelo no Brasil; Poch - Preço do óleo em Chicago, como proxy do preço no mercado internacional; Pospat - Preço do óleo em São Paulo, como proxy do preço do óleo ao atacado no Brasil.

$\mathrm{Na}$ parte empírica deste trabalho vai-se testar basicamente a hipótese de que o mercado externo exerce influência relevante sobre os preços do mercado interno. $\mathrm{O}$ Brasil não possui poder no mercado externo, é fundamentalmente - por hipótese - um tomador de preços internacionais. 
É verdade que oscilações da produção doméstica de grãos e das demandas internas dos derivados podem, dentro de certos limites, alterar os preços na cadeia da soja. Entretanto aqueles limites são estreitos. Por exemplo, uma queda de produção de soja no Brasil provocará elevações de preços ao produtor até o limite do preço FOB do grão. Somente quando este último se altera, tenderá a haver alteração no primeiro.

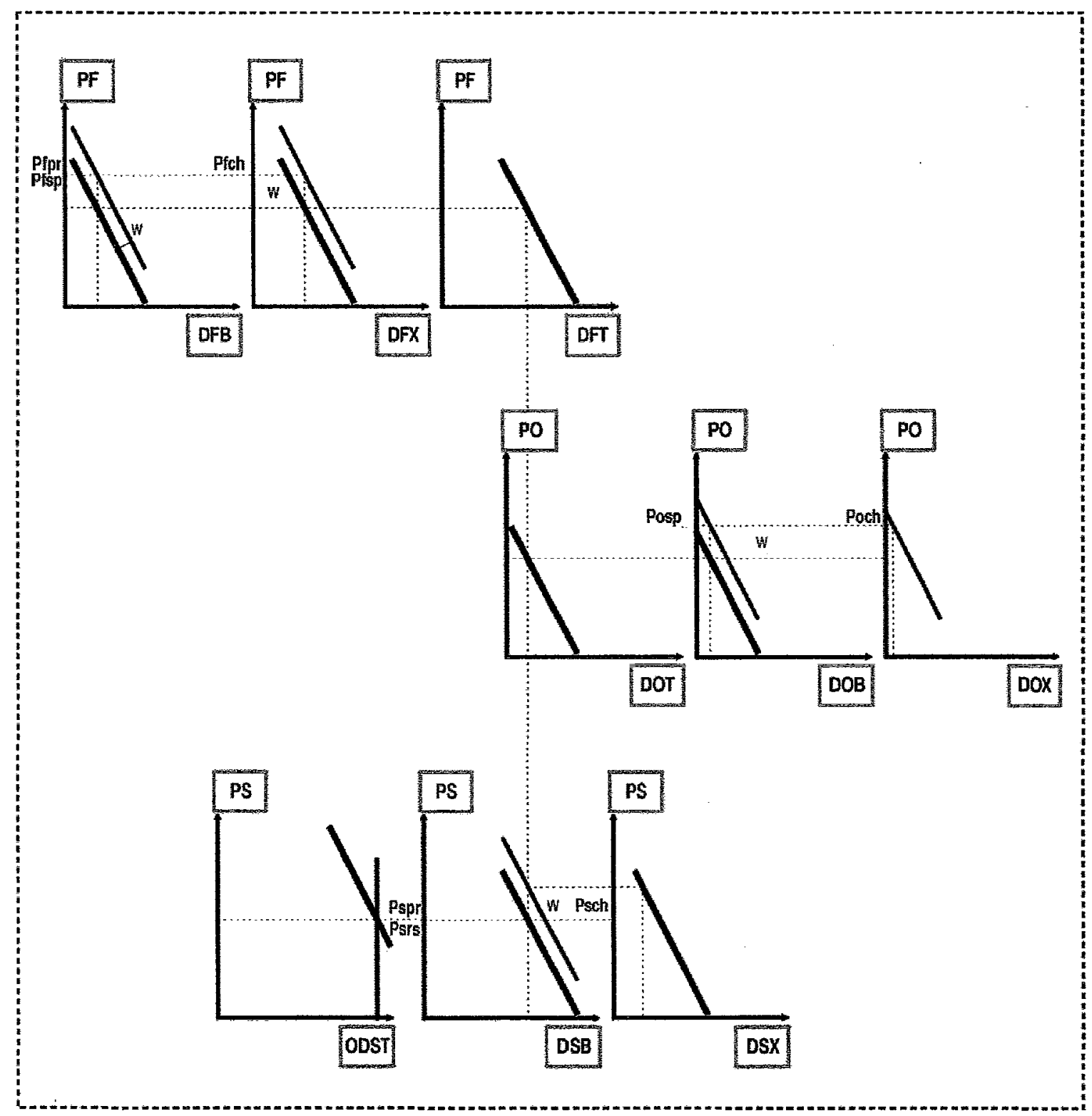

Fonte: Adaptado pelo autor a partir de Houck \& Mann (1972)

Figura 20 - Fluxograma do modelo simplificado da demanda de soja em grãos e derivados (farelo e óleo) para o Brasil. 


\section{MODELOS ECONOMÉTRICOS}

Tendo sido revisados os modelos teóricos de formação de preços, parte-se agora para a exposição dos modelos econométricos a serem utilizados para se atingir o objetivo estabelecido, que é o melhor entendimento dos mecanismos de formação e transmissão dos preços do complexo soja.

As análises serão feitas considerando-se o período de janeiro de 1980 a dezembro de 1989 e janeiro de 1990 a dezembro de 1999, para soja em grãos, farelo e óleo considerando as cotações de preços do mercado interno e externo, conforme já definido anteriormente. As séries de preços serão subdivididas em dois períodos com o intuito de captar os efeitos das mudanças ocorridas em virtude da abertura comercial e maior desregulamentação dos mercados nesta última década.

\subsection{Intensidade e período de transmissão de preço}

A análise da intensidade de transmissão de preços se dá através da estimação da elasticidade de transmissão de preços. A elasticidade de transmissão de preços refere-se à variação relativa no preço em um nível de mercado em relação à variação relativa no preço em outro nível, mantidos em equilíbrio esses dois níveis de mercado após o choque inicial num deles (Barros \& Burnquist 1987). Evidências empíricas mostram que pode haver diferença na transmissão dos preços de um nível de mercado para outro, para acréscimos e decréscimos. Por isso, necessita-se verificar a assimetria na transmissão dos preços. A análise do período de tempo necessário para que cada nível de mercado ajuste seus preços também é importante em termos de eficiência do mercado. O tempo 
no ajuste de preço em um nível de mercado pode estar associado à baixa fluidez de informações e consequentemente a ineficiência de mercado.

\subsubsection{Teste de causalidade}

Testes de causalidade foram estabelecidos por Granger (1969), que considerou que há existência de causalidade de uma variável $\mathrm{X}$ para uma variável $\mathrm{Y}$ se, e somente se, valores passados de $\mathrm{X}$ ajudam na previsão de $\mathrm{Y}$. A partir deste conceito de causalidade de Granger, Sims (1972) desenvolveu um procedimento para testar o sentido da causalidade entre variáveis econômicas. Bishop (1979) discute o conceito de causalidade proposto por Sims de forma mais aplicada. $\mathrm{O}$ aspecto de causalidade entre preços agrícolas tem sido relacionado à questão de estrutura de mercado e intervenção governamental.

Vários trabalhos foram realizados no Brasil para verificar o sentido de causalidade entre preços agrícolas a diversos níveis de mercado, como Burnquist (1986); Barros \& Martines F. ${ }^{\circ}$ (1987); Martines F. $(1988)$; Aguiar \& Barros (1989); entre outros. Todos estes trabalhos utilizaram a metodologia proposta por Sims. Dos resultados destes trabalhos pode se afirmar que existe uma tendência das variações de preços iniciarem ao nível de atacado, por este comercializar uma variedade menor e um volume maior de produtos, por ter acesso a informações de forma mais rápida sobre variações nos demais níveis e por possuir menor custo de alteração dos preços. Exceção ocorre em alguns produtos com maior elasticidade renda (carnes nobres e frutas), onde $o$ varejo pode originar as variações devido às oscilações do poder de compra dos consumidores. No presente trabalho será utilizada a metodologia proposta por Granger (1969).

A seguir, para uma exposição mais detalhada do método, estão as duas equações do teste de causalidade entre o preço da soja no Paraná e preço da soja em Chicago (CBOT):

$\operatorname{Psch}_{t}=\alpha_{0}+\sum_{i=1}^{12} \alpha_{1 i} P_{s p r_{t-i}}+\sum_{k=1}^{12} \alpha_{2 k} P_{s c h_{t-k}}+\sum_{j=1}^{11} \alpha_{3 j} D_{j}+\alpha_{4} T+\varepsilon_{1 t}$ 


$$
P_{s p r_{t}}=\beta_{0}+\sum_{i=1}^{12} \beta_{1 i} P s c h_{t-i}+\sum_{k=1}^{12} \beta_{2 k} P s p r_{t-k}+\sum_{j=1}^{11} \beta_{3 j} D_{j}+\beta_{4} T+\varepsilon_{2 t}
$$

Sendo:

$\mathbf{P}_{\text {sch }}$ - Logaritmo do preço da soja em Chicago (CBOT);

$P_{\text {spr }}$ - Logaritmo do preço da soja no Paraná;

$D_{\mathrm{j}}$ - Variáveis binárias para controle dos efeitos de sazonalidade;

T - Variável tendência

$\alpha_{0}, \alpha_{1}, \alpha_{2 i}, \alpha_{3 k}, \alpha_{4 j} \quad$ - Parâmetros estimados na equação (01);

$\beta_{0}, \beta_{1}, \beta_{2 i}, \beta_{3 k}, \beta_{4 j}$ - Parâmetros estimados na equação (02);

$\varepsilon_{1 t}, \varepsilon_{2 t}$ - Erros aleatórios.

Ao se estimar as equações (01) e (02) para realizar o teste de causalidade, alguns cuidados devem ser tomados. Um deles é a definição do número de defasagens que devem ser usadas (nas equações 01 e 02 ).

No presente estudo com o teste de causalidade de Granger, serão utilizados 12 valores passados da variável explicativa e 12 valores passados da variável dependente. As variáveis binárias são utilizadas para efeito do controle de sazonalidade (variação estacional), variação esta que ocorre em uma série temporal nos mesmos meses do ano, mais ou menos com a mesma intensidade e tem aplicação na explicação de movimentos de preços de produtos agrícolas, cuja safra e entressafra corresponde a períodos determinados do ano. Após isso as hipóteses de nulidade testadas serão as dispostas nas equações (01) e (02):

$$
\begin{aligned}
& \alpha_{11}=\alpha_{12}=\ldots=\alpha_{112}=0(\text { na equação } 01) \mathrm{e} \\
& \left.\beta_{11}=\beta_{12}=\ldots=\beta_{112}=0 \text { (na equação } 02\right) .
\end{aligned}
$$

Se as duas hipóteses forem rejeitadas ter-se-á relação bi-causal; se ambas não forem rejeitadas ter-se-á ausência de causalidade; se a primeira hipótese for rejeitada e a segunda não, a causalidade será de Pspr para Psch e, finalmente, caso a primeira hipótese não seja rejeitada e a segunda seja, a causalidade será de Psch para Pspr. 
Para testar essas hipóteses utiliza-se a estatística $F$, estimando seu valor pela fórmula que vem a seguir para as equações (01) e (02).

$$
\mathrm{F}=\frac{(\mathrm{SQRr}-\mathrm{SQRu}) / \mathrm{m}}{\mathrm{SQRu} /(\mathrm{n}-\mathrm{k})}
$$

Sendo, SQRr a soma dos quadrados dos resíduos da equação com restrição; SQRu a soma dos quadrados dos resíduos da equação sem restrição; $\mathrm{k}$ o número de parâmetros estimados na equação sem restrição; m o número de termos defasados e $\mathrm{n}$ o número de observações. Sendo que todos os preços estão na forma de logaritmos neperianos e $D_{j}$ e $T$ são as variáveis definidas anteriormente.

\subsubsection{Teste do padrão sazonal de formação dos preços}

Os testes para verificar o padrão sazonal de formação de preços da soja são realizados antes de se estimar as equações de transmissão de preços, pois dependendo dos resultados destes testes ajusta-se as equações de transmissão de preços.

Os agentes do mercado da soja acreditam que os preços da soja possuem padrão sazonal, sendo no período de março a setembro o preço formado de "fora para dentro", ou seja, da CBOT para o Brasil e posteriormente os preços são formados somente internamente. Sendo assim, será testado essa relação de formação de preços da soja, com a equação 03 a seguir.

As equações a serem estimadas, podem ser representadas pela relação dos preços da soja na CBOT para o preço da soja no Paraná.

$\operatorname{Pspr}_{t}=\alpha_{1}+\alpha_{2} D_{(\text {mar-set) }}+\beta_{1} P_{\text {sch }_{t}}+\beta_{2}$ Pspr $_{t, t-1 \ldots 12}+\beta_{3} \operatorname{Psch}_{t} D_{(\text {mar-set })}+\epsilon_{t}$

Sendo:

Pspr - Logaritmo do preço da soja no Paraná;

Psch - Logaritmo do preço da soja em Chicago;

D - Variável Dummy, março a setembro $=1$, demais meses $=0$.

$\operatorname{Psch}_{t} D_{\text {(mar-set) }}$ - Interação entre preço da soja em Chicago com Dummy

$\alpha_{1}, \alpha_{2}, \beta_{1}, \beta_{2}, \beta_{3}$ - Parâmetros estimados na equação (03);

$\epsilon_{\mathrm{t}}$ - Erro aleatório, 


\subsubsection{Elasticidades de transmissão de preços em modelos de causalidade uni-direcional}

Após a realização do teste de causalidade, e do padrão sazonal na formação dos preços, estimam-se as equações de transmissão de preços obedecendo ao sentido de causalidade verificado. No caso de sentido de causalidade do preço da soja na (CBOT) para o preço da soja no Paraná, a equação básica seria:

$$
\operatorname{Pspr}_{t}=\sigma_{0}+\sigma_{1} P_{s c h}+\sum_{i=1}^{12} \sigma_{2 i} P_{s c h}{ }_{t-i}+\sum_{j=1}^{11} \sigma_{3 j} D_{j}+\sigma_{4} T+\varepsilon_{t}
$$

Partindo-se dessa equação, testa-se o número de defasagens significativas para se definir a equação de transmissão de preços. $O$ procedimento consiste em avaliar a significância do teste $\mathrm{F}$ de exclusão de variáveis a um nível de $5 \%$, à medida que se excluem as defasagens (1 a 12), ( 2 a 12),....(11 e 12), sucessivamente. Após a definição da forma final, os valores de $\sigma_{1}$ e $\sigma_{2 i}$ serão as elasticidades mensais de transmissão de preços.

Quanto a autocorrelação entre os resíduos para o teste de Granger, estes não apresentam problemas, pois com a utilização de valores defasados da variável dependente, elimina-se o problema de autocorrelação que usualmente ocorre quando se utiliza o teste de Sims. Uma maneira de se filtrar as variáveis quando existe autocorrelação entre os resíduos, apresentada por Bishop (1979), é o método interativo de Cochrane-Orcutt.

Esse método tem sido bastante usado, inclusive no Brasil, por Burnquist (1986), Barros \& Martines F..$^{\circ}$ (1987), Martines F. ${ }^{\circ}$ (1988), Barros (1988), Aguiar \& Barros (1989), entre outros. Burnquist (1986) afirma que a fundamentação teórica desta filtragem está em que procedimentos econométricos a serem utilizados envolvem a realização sistemática de testes $F$ envolvendo variâncias, cujos vieses associados a problemas de correlação serial entre os erros devem ser evitados. 


\subsubsection{Elasticidades de transmissão de preços em modelos de causalidade}

\section{bi-direcional}

No caso de relação bi-causal, deve-se estimar um modelo de equações simultâneas como o descrito abaixo (a descrição corresponde à relação entre preço da soja no Paraná e preço da soja em Chicago). O número de defasagens foi definido ad hoc, consistindo de 12 valores passados mensais.

Forma estrutural:

$$
\begin{aligned}
& \mathrm{P}_{\mathrm{t}}^{\mathrm{ch}}=\sigma_{0}+\sigma_{1} \mathrm{P}_{\mathrm{t}}^{\mathrm{pr}}+\sum_{i=1}^{12} \sigma_{\mathrm{i}+1} \mathrm{P}_{\mathrm{t}-\mathrm{i}}^{\mathrm{pr}}+\mu_{1, \mathrm{t}} \\
& \mathrm{P}_{\mathrm{t}}^{\mathrm{pr}}=\phi_{0}+\phi_{1} \mathrm{P}_{t}^{\mathrm{ch}}+\sum_{i=1}^{12} \phi_{i+1} \mathrm{P}^{\mathrm{ch}}{ }_{\mathrm{t}-\mathrm{i}}+\mu_{2, \mathrm{t}}
\end{aligned}
$$

Sendo:

$\mathrm{P}^{\mathrm{ch}}$ logaritmo do preço da soja grão em Chicago;

$\mathrm{P}^{\mathrm{pr}}$ logaritmo do preço da soja no Paraná;

$\sigma_{1}$ a $\sigma_{13}$ e $\phi_{1}$ a $\phi_{13}$ são elasticidades de transmissão de preços parciais.

As equações do modelo em questão são super identificadas, exigindo a utilização do método dos mínimos quadrados em dois estágios para estimação. $O$ referido método consiste em:

$1^{\circ}$ Estágio: estimação de regressões das variáveis pré-determinadas (exógenas + endógenas defasadas). Para a equação (05), o primeiro estágio consistiria em:

$$
\hat{P}_{t}^{p c h}=\pi_{0}+\sum_{i=1}^{12} \gamma_{\mathrm{i}} \mathrm{P}^{\mathrm{ch}}{ }_{\mathrm{t}-\mathrm{i}}+\sum_{k=1}^{12} \rho_{\mathrm{k}} \mathrm{P}_{\mathrm{t}-\mathrm{k}}^{\mathrm{pr}}+\mu_{3, \mathrm{t}}
$$

$2^{\circ}$ Estágio: Consiste em estimar a equação (05), no caso da transmissão entre preço no Paraná para o preço em Chicago, utilizando o preço no Paraná estimado no primeiro estágio $\left(\hat{P}_{t}^{p r}\right)$. Para estimar a equação (06), o procedimento é o mesmo, estimando-se no primeiro estágio o preço da soja em Chicago $\left(\hat{P}_{t}^{c h}\right)$ que será relacionado com o preço no Paraná no segundo estágio. 


\subsection{Assimetria na transmissão de preços}

Neste caso, se reconhece a existência de duas diferentes elasticidades de transmissão de preços, uma para acréscimos e outra para decréscimos de preços. Os testes empregados para verificar a assimetria em sua forma mais simples partem de modelos com variáveis binárias que diferenciam os acréscimos dos decréscimos de preços. Os modelos que vem sendo mais utilizados são os desenvolvidos por Wollfram (1971) e Houck (1977). As primeiras aplicações desse teste de transmissão de preços foram realizados por Ward (1982) para o mercado de hortaliças, e Kinnuncan e Forker (1987) para o mercado de laticínios ambos estudos realizados nos Estados Unidos. No Brasil, o teste foi aplicado por Aguiar (1990), Aguiar \& Barros (1991) ao mercado de soja e derivados, Aguiar \& Coelho (1998) e Santana \& Aguiar (1998). Estes estudos constataram relações assimétricas entre os preços. Ward constatou transmissão mais intensa dos decréscimos de preços, enquanto que os demais trabalhos constataram transmissão mais intensa dos acréscimos de preços. Algumas justificativas para a existência de assimetria são inerentes as características dos produtos, concentração do mercado, transitoriedade das variações de preços, intervenção governamental, nível de exigência e organização dos consumidores, Aguiar (1993).

\subsubsection{Teste de Assimetria}

O teste de assimetria e a estimativa da elasticidade de transmissão de acréscimos e de decréscimos de preços foram realizadas através do procedimento desenvolvido por Wolfram (1971) e aperfeiçoado por Houck (1977). Este teste tem como função identificar se os acréscimos ou decréscimos de preços são transmitidos com a mesma intensidade. Houck (1977) considera um modelo com a variável dependente, Pv, sendo função de apenas uma variável independente, $\mathrm{Pp}$.

Dada a relação:

$$
\Delta \mathrm{Pv}_{\mathrm{i}}=\alpha_{0}+\alpha_{1} \Delta \mathrm{Pp}_{\mathrm{i}}+\alpha_{2} \Delta \mathrm{Pp}^{\prime \prime}{ }_{\mathrm{i}}+\varepsilon_{\mathrm{t}} \text { para } \mathrm{i}=1,2, \ldots, \mathrm{t},
$$


Sendo que

$$
\begin{aligned}
& \Delta P_{V_{i}}=P v_{i}-P v_{i-1} \\
& \Delta P p_{i}=P p_{i}-P p_{i-1} \quad \text { se } P p_{i}>P p_{i-1} \quad \text { e, } \\
& \Delta P p_{i}=0 \text { se } P p_{i}<P p_{i-1} \\
& \Delta P p^{\prime}{ }_{i}=P p_{i}-P p_{i-1} \quad \text { se } P p_{i}<P p_{i-1} \quad \text { e, } \\
& \Delta P p^{\prime}{ }_{i}=0 \text { se } P p_{i}>P p_{i-1}
\end{aligned}
$$

Sendo

$\mathrm{Pv}_{0}$ é o valor inicial de $\mathrm{Pv}$

$\mathrm{Pp}_{0} \quad$ é o valor inicial de $\mathrm{Pp}$

$\mathrm{O}$ valor de $\mathrm{Pv}$ num ponto qualquer $\mathrm{t}$ será:

$\mathbf{P v}_{\mathrm{t}}=\mathbf{P v}_{\mathrm{v}_{0}}+\sum_{i=1}^{t} \Delta \mathrm{pv}_{\mathrm{i}} \quad$ para $\mathrm{i}=1,2, \ldots \ldots \ldots, \mathrm{t}, \ldots \ldots ., \mathrm{T}$,

Sendo $\mathbf{T}$ o número total de observações além do valor inicial. A diferença entre os valores corrente e inicial de Pv é a soma, de período a período, das mudanças que tem ocorrido. Assim,

$$
\mathrm{Pv}_{\mathrm{t}}-\mathrm{P} \mathrm{v}_{\mathrm{o}}=\sum_{i=1}^{t} \Delta p \mathrm{v}_{\mathrm{i}}
$$

Substituindo a equação (08) em (09), e simplificando-a, tem-se:

$$
P v_{t}-P v_{o}=\alpha_{0} t+\alpha_{1}\left(\sum \Delta P p_{i}^{\prime}\right)+\alpha_{2}\left(\sum \Delta P p^{\prime}{ }_{i}\right)
$$

Fazendo $\mathrm{Y}_{\mathrm{t}}^{*}, \mathrm{~A}_{\mathrm{t}}^{*}$ e $\mathrm{D}_{\mathrm{t}}^{*}$ iguais a $\mathrm{Pv}_{\mathrm{t}}-\mathrm{Pv}_{0}, \sum \Delta \mathrm{Pp}_{\mathrm{i}}$ e $\sum \Delta \mathrm{Pp}_{\mathrm{i}}{ }_{\mathrm{i}}$ respectivamente, e incluindo o termo estocástico $u_{t}$, chega-se a equação a ser estimada:

$$
\mathrm{Y}_{\mathrm{t}}^{*}=\alpha_{0} \mathrm{t}+\alpha_{1} \mathrm{~A}_{\mathrm{t}}^{*}+\alpha_{2} \mathrm{D}_{\mathrm{t}}^{*}+\mathrm{u}_{\mathrm{t}}
$$

Sendo $\mathrm{A}_{\mathrm{t}}^{*}$ a soma de todos os acréscimos, período a período, desde o valor inicial até o período $\mathrm{t}, \mathrm{e} \mathrm{D}_{\mathrm{t}}^{*}$ o similar para decréscimos. Pode-se observar, ainda, que a variável $\mathrm{A}_{\mathrm{t}}$ é sempre positiva, enquanto que a variável $\mathrm{D}_{\mathfrak{t}}^{*}$ é sempre negativa. Se $\alpha_{0}$ não é zero, será considerado como um coeficiente de tendência na equação (12).

O teste de assimetria é feito testando-se a hipótese de que $\alpha_{1}$ é estatisticamente igual a $\alpha_{2}$. Caso se rejeite esta hipótese haverá assimetria. As elasticidades de 
transmissão de preços serão os próprios coeficientes $\alpha_{1}$ e $\alpha_{2}$, no caso dos preços estarem na forma de logaritmos naturais, e a estes se denominara de elasticidade segmentada, ou seja, uma elasticidade para acréscimo e outra para decréscimo de preços.

\subsection{Fonte dos dados}

Os dados a serem utilizados são preços ao produtor para a soja grão nos principais estados produtores, Paraná, Mato Grosso, Rio Grande do Sul, Goiás e Mato Grosso do Sul, que representam $85 \%$ da produção nacional.

Para farelo serão utilizados os preços praticados em São Paulo e Paraná, principais estados consumidor e produtor do país, respectivamente.

Para óleo ao atacado e varejo serão utilizados os preços praticados em São Paulo maior centro de refino e consumo de óleo do país.

Para as cotações de preços da soja, farelo e óleo no mercado internacional serão utilizados as da CBOT - Chicago. Os preços são das décadas de 80 e 90, (todas as séries de preços estão no anexo 01). A seguir lista-se as fontes de dados: Instituto Brasileiro de Geografia e Estatística - (IBGE), United States Departament of Agriculture - (USDA), Associação Brasileira das Indústrias de Óleos Vegetais - (ABIOVE), Companhia Brasileira de Abastecimento - (CONAB), Safras \& Mercado, Secretaria de Estado da Agricultura e do Abastecimento do Estado do Paraná - (SEAB/PR) e Centro de Pesquisa Avançada em Economia Aplicada (CEPEA). 


\section{RESULTADOS E DISCUSSÕES}

Os resultados apresentados a seguir são referentes aos testes econométricos propostos no capítulo 04 .

Os preços estão expressos em reais deflacionados pelo IGP/Di da Fundação Getúlio Vargas (base outubro de 1999). As séries de preços referem-se ao período de janeiro de 1982 a dezembro de 1999.

Dessa forma foram realizados os testes para o período todo, para a década de 80 e para a década de 90 separadamente e comparados entre si, e ao estudo de formação e transmissão de preços do complexo soja, realizado por Aguiar na década de 80, para o Estado de São Paulo.

Foram realizados testes entre as séries de preços do mercado externo (CBOT), ou seja, soja com farelo, soja com óleo e farelo com óleo para os três períodos distintos citados acima, e verificou-se que não há um nível líder na variação dos preços no mercado internacional.

Dessa forma foram relacionados os preços da soja e derivados no mercado externo com as mesmas formas no mercado interno, ou seja, soja-soja, farelo-farelo e óleo-óleo.

\subsection{Análise dos testes de causalidade (Granger)}

Os resultados dos testes de causalidade estão apresentados nas tabelas 06, 07 e 08. Nestas tabelas especificam-se a variável dependente e a variável independente excluída, bem como a significância do teste $\mathrm{F}$ (de exclusão de variáveis), e os graus de liberdade do teste. 
As variáveis básicas são as seguintes:

$P^{s p r}{ }_{t}$ - Logaritmo neperiano do preço da soja no Paraná;

$P^{s r s}{ }_{t}$ - Logaritmo neperiano do preço da soja no Rio Grande do Sul;

$P^{s m t}{ }_{t}$ - Logaritmo neperiano do preço da soja no Mato Grosso;

$P^{s m s}{ }_{t}$ - Logaritmo neperiano do preço da soja no Mato Grosso do Sul;

$P^{s g o}{ }_{t}$ - Logaritmo neperiano do preço da soja em Goiás;

$P^{\text {sch }}{ }_{t}$ - Logaritmo neperiano do preço da soja em Chicago;

$P^{f p r}{ }_{t}$ - Logaritmo neperiano do preço do farelo no Paraná;

$P^{f s p}{ }_{t}$ - Logaritmo neperiano do preço do farelo em São Paulo;

$P^{f c h}{ }_{t}$ - Logaritmo neperiano do preço do farelo em Chicago;

$P^{o s p a t}{ }_{t}$ - Logaritmo neperiano do preço do óleo ao atacado em São Paulo;

$P^{o s p v j}{ }_{t}$ - Logaritmo neperiano do preço do óleo ao varejo em São Paulo;

$P^{o c h}{ }_{t}$ - Logaritmo neperiano do preço do óleo ao atacado em Chicago;

$A P=$ Acréscimos de preços (estando esses na forma de logaritmos neperianos);

$D P=$ Decréscimos de preços (estando esses na forma de logaritmos neperianos);

Tabela 06 - Teste de causalidade entre preços da soja e derivados em diferentes regiões de comercialização no mercado interno e externo, 1982 - 1999

\begin{tabular}{|c|c|c|}
\hline Variável dependente & $\begin{array}{c}\text { Variável independente } \\
\text { Excluída }\end{array}$ & $F^{(1)}$ \\
\hline $\mathbf{P}^{\mathrm{spr}}$ & $\mathbf{P}^{\text {sch }}$ & $1,75^{* *}(12,167)$ \\
\hline $\mathrm{P}^{\text {sch }}$ & $\mathrm{P}^{\mathrm{spr}}$ & $1,31 \quad(12,167)$ \\
\hline $\mathbf{P}^{\mathrm{srs}}$ & $\mathbf{P}^{\text {sch }}$ & $5,50^{*}(12,167)$ \\
\hline $\mathbf{P}^{\text {sct }}$ & $\mathrm{P}^{\mathrm{srs}}$ & $1,59(12,167)$ \\
\hline $\mathbf{P}^{\mathrm{sms}}$ & $\mathrm{P}^{\mathrm{spr}}$ & $7,28^{*}(12,167)$ \\
\hline $\mathbf{P}^{\mathrm{spr}}$ & $\mathrm{P}^{\mathrm{sms}}$ & $0,32(12,167)$ \\
\hline $\mathrm{P}^{\mathrm{sgo}}$ & $\mathbf{P}^{\mathrm{spr}}$ & $5,24^{*}(12,167)$ \\
\hline $\mathbf{P}^{\mathrm{spr}}$ & $\mathrm{P}^{\mathrm{sgo}}$ & $0,67(12,167)$ \\
\hline $\mathbf{P}^{\mathrm{smit}}$ & $\overline{\mathbf{P}^{\mathrm{spr}}}$ & $8,46 *(12,167)$ \\
\hline
\end{tabular}




\begin{tabular}{|c|c|c|}
\hline $\mathbf{P}^{\mathrm{spr}}$ & $\mathrm{P}^{\mathrm{smt}}$ & $0,92(12,167)$ \\
\hline $\mathrm{P}^{\mathrm{sgo}}$ & $\mathrm{p}^{\mathrm{smt}}$ & $2,65^{*}(12,167)$ \\
\hline $\mathbf{P}^{\mathrm{smnt}}$ & $\mathrm{P}^{\mathrm{sgo}}$ & $0,76(12,167)$ \\
\hline $\mathrm{P}^{\mathrm{smit}}$ & $\mathbf{P}^{\mathrm{sms}}$ & $2,94 *(12,167)$ \\
\hline $\mathbf{P}^{\mathrm{sms}}$ & $\mathrm{P}^{\mathrm{smt}}$ & $4,14^{*}(12,167)$ \\
\hline $\mathrm{P}^{\mathrm{sms}}$ & $\mathbf{P}^{\text {sgo }}$ & $3,47^{*}(12,167)$ \\
\hline $\mathrm{P}^{\text {sgo }}$ & $\mathrm{P}^{\mathrm{sms}}$ & $4,00 *(12,167)$ \\
\hline $\mathbf{p}^{\mathrm{tsp}}$ & $\mathrm{p}^{\text {fic }}$ & $3,44^{*}(12,167)$ \\
\hline $\mathrm{P}^{\mathrm{fc} \text { क }}$ & $\mathrm{P}^{\mathrm{fsp}}$ & $1,20(12,167)$ \\
\hline $\mathbf{P}^{\mathrm{fpr}}$ & $\mathrm{P}^{\mathrm{fch}}$ & $2,90^{*}(12,167)$ \\
\hline $\mathbf{P}^{\mathrm{fch}}$ & $\mathbf{P}^{\mathrm{tpr}}$ & $0,99(12,167)$ \\
\hline $\mathrm{P}^{\mathrm{fsp}}$ & $\mathrm{P}^{\mathrm{rpr}}$ & $1,28(12,167)$ \\
\hline $\mathrm{p}^{\mathrm{fpr}}$ & $\mathrm{P}^{\mathrm{fsp}}$ & $1,19(12,167)$ \\
\hline $\mathbf{P}^{\text {ospat }}$ & $\mathrm{P}^{\mathrm{och}}$ & $3,72 *(12,167)$ \\
\hline $\mathrm{P}^{\text {och }}$ & $\mathrm{P}^{\text {ospat }}$ & $1,39(12,167)$ \\
\hline $\mathrm{P}^{\text {ospvj }}$ & $\mathrm{P}^{\text {ospat }}$ & $3,57 *(12,167)$ \\
\hline $\mathrm{P}^{\text {ospat }}$ & $\mathrm{P}^{\text {ospvj }}$ & $1,21(12,167)$ \\
\hline $\mathrm{P}^{\mathrm{fch}}$ & $\mathrm{p}^{\text {sch }}$ & $0,98 \quad(12,167)$ \\
\hline $\mathbf{P}^{\mathrm{sch}}$ & $\mathbf{P}^{\mathrm{fch}}$ & $1,02(12,167)$ \\
\hline $\mathbf{P}^{\mathrm{fo}}$ & $\mathbf{P}^{\text {och }}$ & $1,24(12,167)$ \\
\hline $\mathrm{P}^{\text {och }}$ & $\mathrm{P}^{\mathrm{fch}}$ & $0,99(12,167)$ \\
\hline $\mathbf{P}^{\mathrm{sch}}$ & $\mathrm{P}^{\text {och }}$ & $0,68 \quad(12,167)$ \\
\hline $\mathbf{P}^{\text {och }}$ & $\mathbf{P}^{\text {sch }}$ & $1,08(12,167)$ \\
\hline
\end{tabular}

(1) Entre parênteses estão os graus de liberdade do teste

* Nível de significância : $1 \%$

** Nível de significância: $\mathbf{5 \%}$

Os dados da tabela 06, para o período todo, demostram que entre os preços da soja no Mato Grosso e Mato Grosso do Sul, Goiás e Mato Grosso do Sul, há relação bicausal. Os outros resultados foram: (i) causalidade do preço da soja em Chicago para o 
Paraná; (ii) causalidade do preço da soja em Chicago para o Rio Grande do Sul; (iii) do Paraná para Mato Grosso; (iv) do Paraná para Mato Grosso do Sul; (v) do Paraná para Goiás; (vi) do Mato Grosso para Goiás .

No mercado de farelo há uma relação de causalidade do preço do farelo em Chicago para os preços de São Paulo e Paraná.

No mercado de óleo há uma relação de causalidade do preço de Chicago para São Paulo no atacado e do preço do óleo ao atacado para o preço do varejo em São Paulo.

Nos esquemas a seguir são apresentados resumos das relações encontradas para o período todo para os mercados de soja, farelo e óleo. 


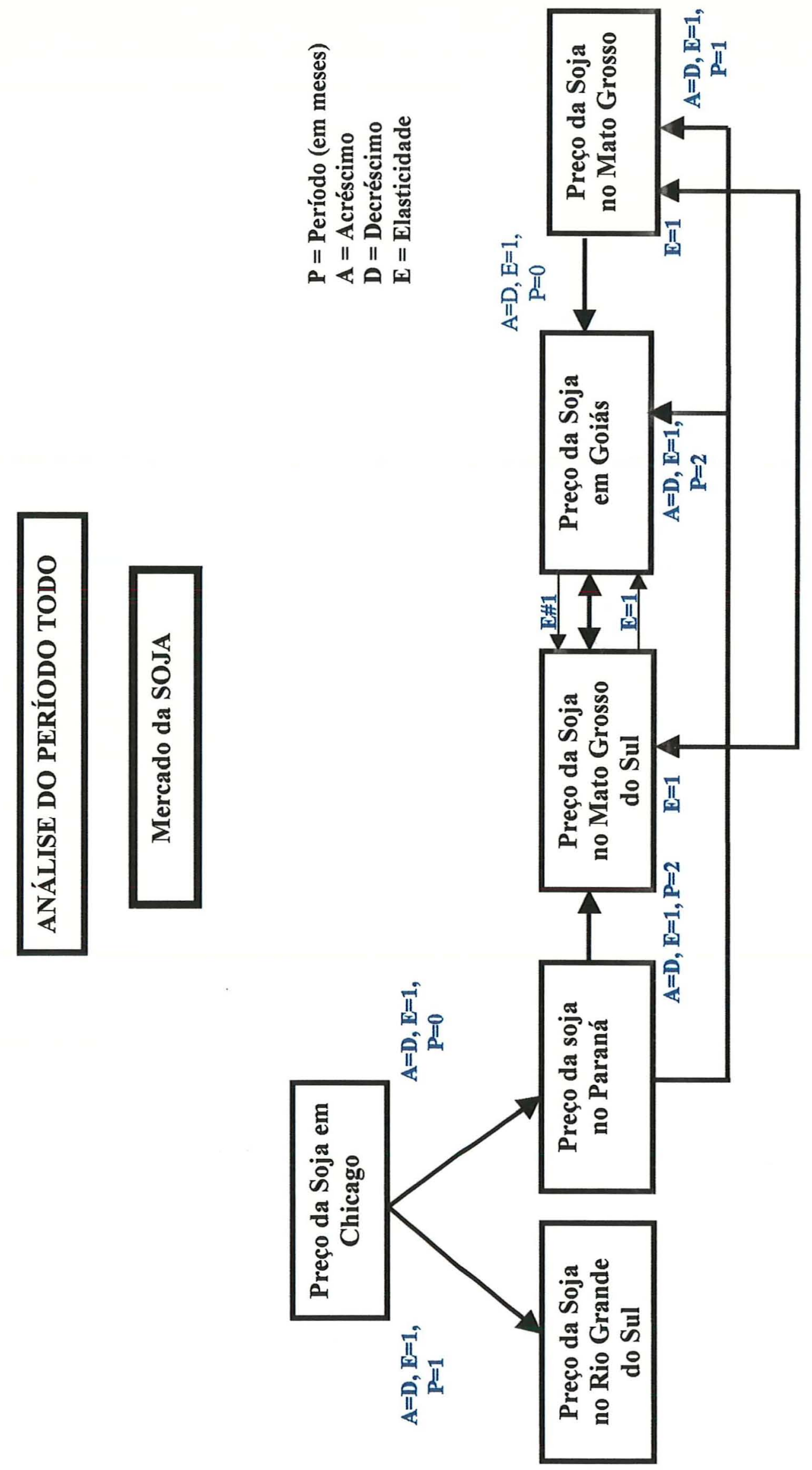




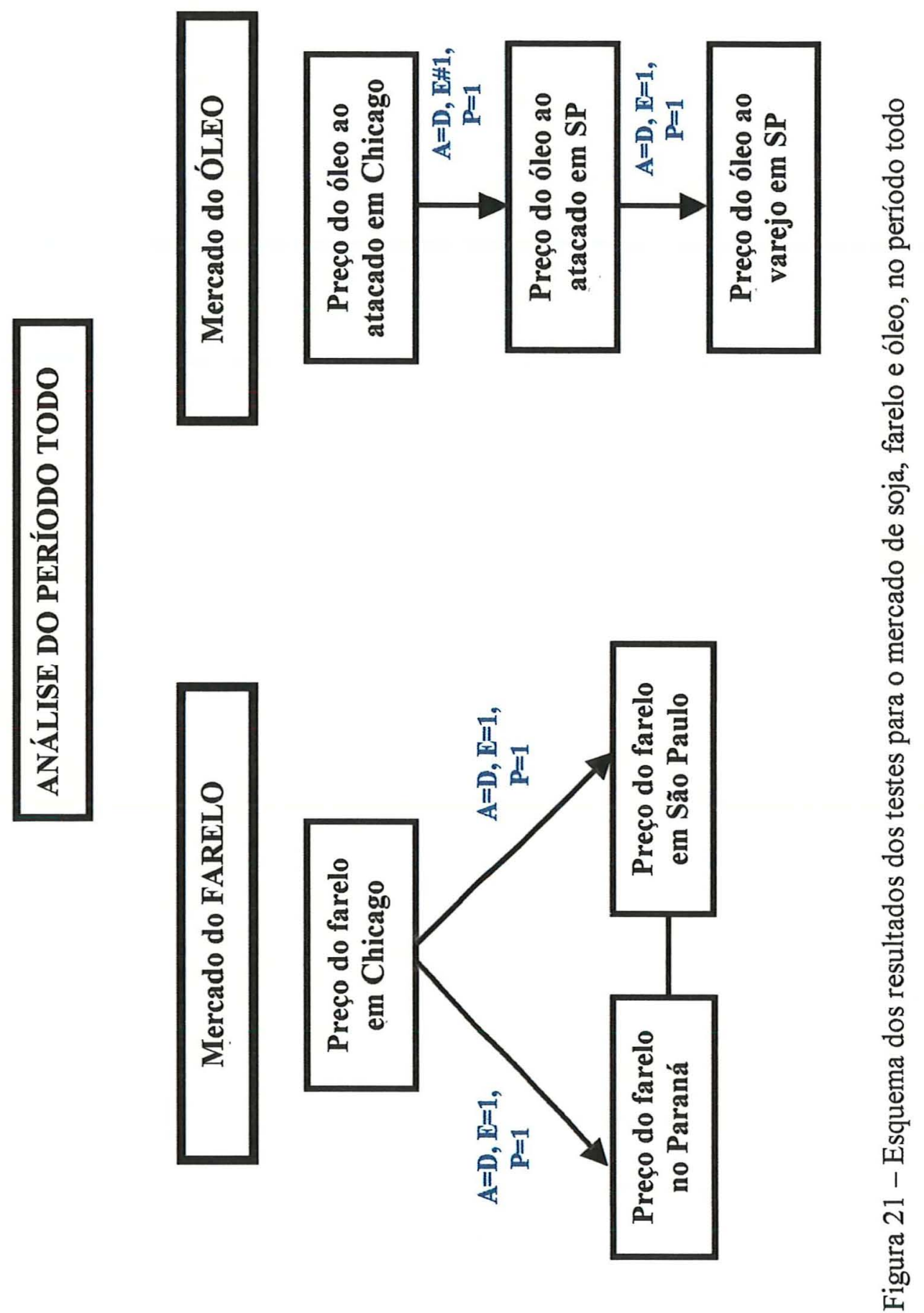


Tabela 07 - Teste de causalidade entre preços da soja e derivados em diferentes regiões de comercialização no mercado interno e externo, na década de 80

\begin{tabular}{|c|c|c|}
\hline Variável dependente & $\begin{array}{c}\text { Variável independente } \\
\text { excluída }\end{array}$ & $F^{(1)}$ \\
\hline$\overline{\mathbf{P}^{\mathrm{sms}}}$ & $\mathbf{P}^{\text {spr }}$ & $3,09 *(12,47)$ \\
\hline $\mathrm{P}^{\mathrm{spr}}$ & $\mathrm{P}^{\mathrm{sms}}$ & $0,40(12,47)$ \\
\hline $\mathrm{P}^{\mathrm{smt}}$ & $\mathbf{P}^{\mathrm{spr}}$ & $3,76 *(12,47)$ \\
\hline $\mathbf{P}^{\mathrm{spr}}$ & $\mathbf{P}^{\mathrm{smit}}$ & $0,86(12,47)$ \\
\hline$\overline{P^{\text {smis }}}$ & $\mathrm{P}^{\mathrm{sgo}}$ & $3,10 *(12,47)$ \\
\hline $\mathrm{P}^{\mathrm{sgo}}$ & $\overline{\mathrm{P}^{\mathrm{sms}}}$ & $1,51(12,47)$ \\
\hline $\mathrm{P}^{\mathrm{fsp}}$ & $P^{\mathrm{fch}}$ & $1,95 *(12,47)$ \\
\hline $\mathrm{P}^{\mathrm{fch}}$ & $\mathbf{P}^{\mathrm{Tsp}}$ & $0,89(12,47)$ \\
\hline $\mathrm{P}^{\mathrm{jpr}}$ & $\mathbf{P}^{\mathrm{fch}}$ & $1,76(12,47)$ \\
\hline $\mathrm{P}^{\mathrm{fch}}$ & $\mathrm{P}^{\mathrm{fip}}$ & $0,73(12,47)$ \\
\hline $\mathrm{P}^{\mathrm{ospat}}$ & $\mathbf{P}^{\text {ospvj }}$ & $3,28 *(12,47)$ \\
\hline $\mathbf{P}^{\text {ospvj }}$ & $\mathbf{P}^{\text {ospat }}$ & $2,06^{* *}(12,47)$ \\
\hline $\mathrm{P}^{\mathrm{fch}}$ & $\mathbf{P}^{\text {sch }}$ & $1,63(12,47)$ \\
\hline $\mathbf{P}^{\text {sch }}$ & $\mathbf{P}^{\mathrm{rch}}$ & $0,77(12,47)$ \\
\hline $\mathrm{P}^{\mathrm{fch}}$ & $\mathrm{P}^{\mathrm{och}}$ & $1,27(12,47)$ \\
\hline$\overline{P^{\text {och }}}$ & $\mathbf{P}^{\mathrm{Ich}}$ & $0,53(12,47)$ \\
\hline $\mathrm{P}^{\mathrm{sch}}$ & $\mathbf{P}^{\text {och }}$ & $0,66(12,47)$ \\
\hline $\mathbf{P}^{\text {och }}$ & $\mathbf{P}^{\text {sch }}$ & $0,46(12,47)$ \\
\hline $\mathrm{P}^{\mathrm{tsp}}$ & $\mathbf{P}^{\mathrm{Ipr}}$ & $1,08(12,47)$ \\
\hline$P^{\mathrm{fpr}}$ & $\mathrm{P}^{\mathrm{fsp}}$ & $0,85(12,47)$ \\
\hline $\mathbf{P}^{\mathrm{smmt}}$ & $\mathbf{p}^{\mathrm{sms}}$ & $0,74(12,47)$ \\
\hline $\mathrm{P}^{\mathrm{sms}}$ & $\mathrm{P}^{\mathrm{smmt}}$ & $1,48(12,47)$ \\
\hline $\mathrm{P}^{\mathrm{spr}}$ & $\overline{P^{\text {sgo }}}$ & $0,54(12,47)$ \\
\hline $\mathrm{P}^{\text {sgo }}$ & $\mathbf{P}^{\mathrm{spr}}$ & $1,07(12,47)$ \\
\hline $\mathbf{P}^{\mathrm{smt}}$ & $\mathbf{P}^{\mathrm{sgo}}$ & $1,68(12,47)$ \\
\hline
\end{tabular}




\begin{tabular}{c|c|c}
\hline $\mathbf{P}^{\text {sgo }}$ & $\mathbf{P}^{\text {smi }}$ & $0,74(12,47)$ \\
\hline $\mathbf{P}^{\text {sch }}$ & $\mathbf{P}^{\text {spr }}$ & $0,67(12,47)$ \\
\hline $\mathbf{P}^{\text {spr }}$ & $\mathbf{P}^{\text {sch }}$ & $0,75(12,47)$ \\
\hline $\mathbf{P}^{\text {sch }}$ & $\mathbf{P}^{\text {srs }}$ & $1,00(12,47)$ \\
\hline $\mathbf{P}^{\text {srs }}$ & $\mathbf{P}^{\text {sch }}$ & $1,04(12,47)$ \\
\hline $\mathbf{P}^{\text {och }}$ & $\mathbf{P}^{\text {ospat }}$ & $0,88(12,47)$ \\
\hline $\mathbf{P}^{\text {ospat }}$ & $\mathbf{P}^{\text {och }}$ & $1,64(12,47)$ \\
\hline
\end{tabular}

(1) Entre parênteses estão os graus de liberdade do teste

* Nível de significância : $1 \%$

** Nível de significância: $5 \%$

Os dados da tabela 07 , para a década de 80 , demonstram que há relação de causalidade do preço da soja no Paraná para os preços da soja no Mato Grosso e Mato Grosso do Sul, e de Goiás para Mato Grosso do Sul.

No mercado de farelo há uma relação de causalidade do preço do farelo em Chicago para os preços de São Paulo e Paraná.

No mercado de óleo há relação bi-causal entre os preços ao atacado e varejo em São Paulo.

Nos esquemas a seguir são apresentados um resumo das relações encontradas para os mercados de soja, farelo e óleo para a década de 80 . 


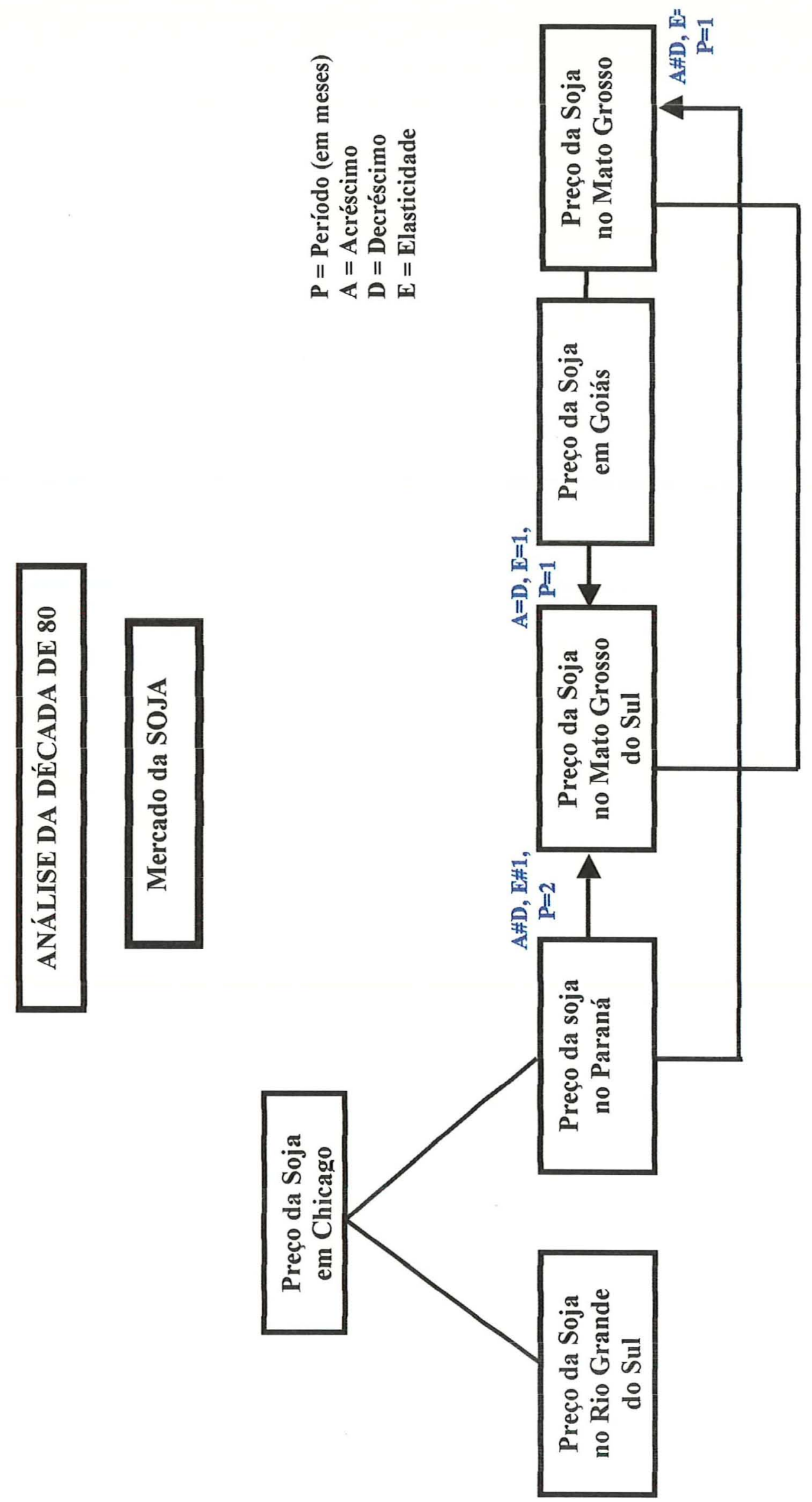




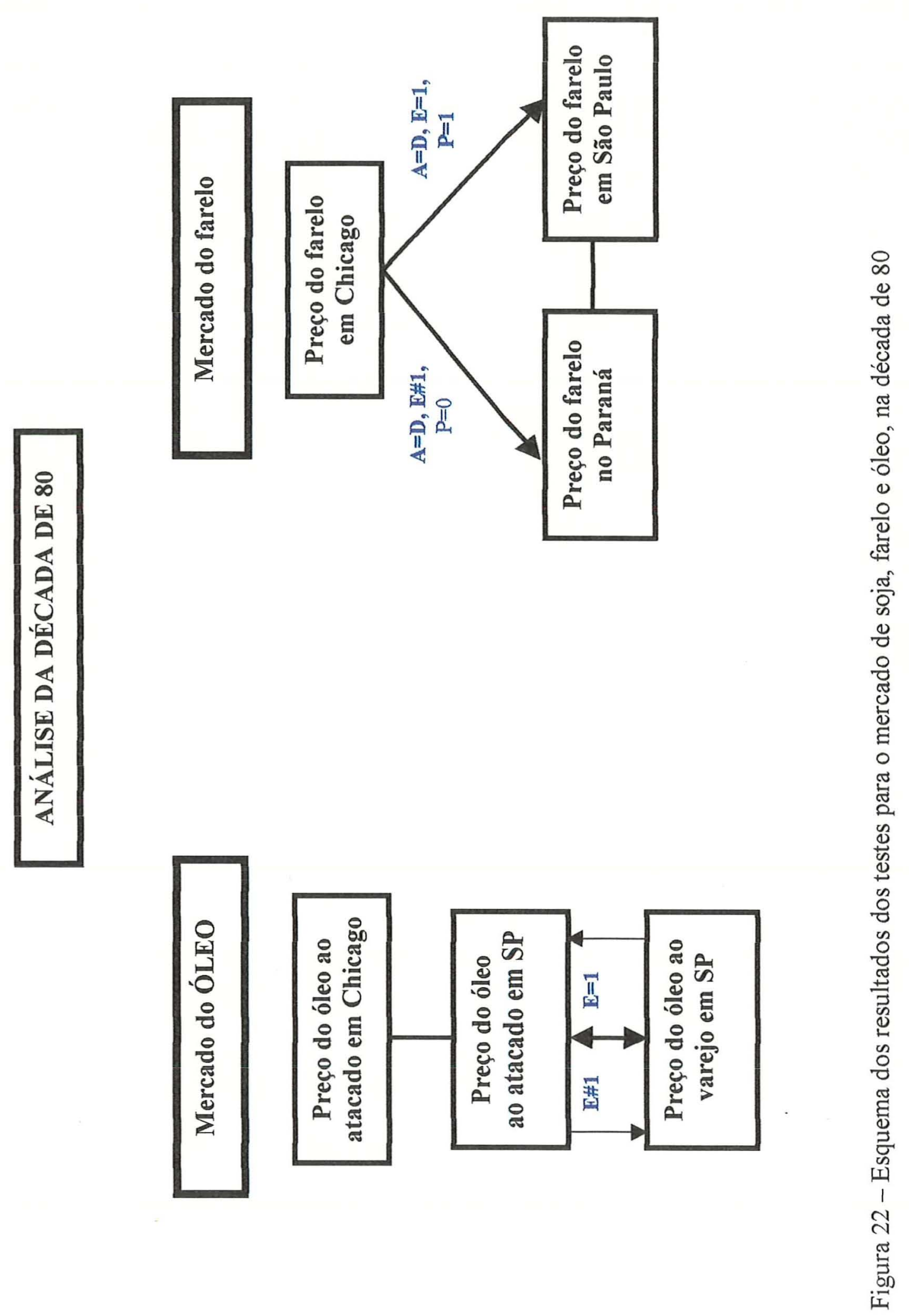


Tabela 08 - Teste de causalidade entre preços da soja e derivados em diferentes regiões de comercialização no mercado interno e externo, na década de 90

\begin{tabular}{|c|c|c|}
\hline Variável dependente & $\begin{array}{c}\text { Variável independente } \\
\text { excluída }\end{array}$ & $F^{(1)}$ \\
\hline $\mathbf{P}^{\mathrm{spr}}$ & $\mathrm{P}^{\text {sch }}$ & $2,95 *(12,71)$ \\
\hline $\mathbf{P}^{\text {sch }}$ & $\mathbf{p}^{\mathrm{spr}}$ & $1,17(12,71)$ \\
\hline $\mathrm{P}^{\mathrm{srs}}$ & $\mathbf{P}^{\mathrm{sch}}$ & $3,01 *(12,71)$ \\
\hline $\mathbf{P}^{\text {sch }}$ & $\mathbf{P}^{\mathrm{srs}}$ & $1,18(12,71)$ \\
\hline $\mathbf{P}^{\text {sms }}$ & $\overline{\mathrm{P}^{\mathrm{spr}}}$ & $2,49^{*}(12,71)$ \\
\hline $\mathrm{P}^{\mathrm{spr}}$ & $\mathrm{P}^{\mathrm{sms}}$ & $0,47(12,71)$ \\
\hline $\mathbf{P}^{\mathrm{smt}}$ & $\mathrm{P}^{\mathrm{spr}}$ & $5,54^{*}(12,71)$ \\
\hline $\mathbf{P}^{\mathrm{spr}}$ & $\mathrm{P}^{\mathrm{smt}}$ & $1,04 *(12,71)$ \\
\hline $\mathbf{P}^{\mathrm{sgo}}$ & $\mathrm{P}^{\mathrm{spr}}$ & $3,66 *(12,71)$ \\
\hline $\mathrm{P}^{\mathrm{spr}}$ & $\mathrm{P}^{\mathrm{sgo}}$ & $0,66(12,71)$ \\
\hline $\mathbf{P}^{\mathrm{sgo}}$ & $\mathbf{P}^{\mathrm{sms}}$ & $2,95^{* *}(12,71)$ \\
\hline$\overline{\mathrm{P}^{\mathrm{sms}}}$ & $\mathbf{P}^{\mathrm{sgo}}$ & $1,08(12,71)$ \\
\hline $\mathbf{P}^{\mathrm{sms}}$ & $\mathrm{P}^{\mathrm{smmt}}$ & $2,49^{*}(12,71)$ \\
\hline $\mathrm{P}^{\mathrm{smt}}$ & $\mathbf{P}^{\mathrm{sms}}$ & $2,31^{*}(12,71)$ \\
\hline $\mathbf{P}^{\mathrm{smt}}$ & $\mathrm{P}^{\mathrm{sgo}}$ & $0,32(12,71)$ \\
\hline $\mathbf{P}^{\mathrm{sgo}}$ & $\mathbf{P}^{\mathrm{smt}}$ & $1,31(12,71)$ \\
\hline $\mathbf{P}^{\mathrm{tsp}}$ & $\mathrm{P}^{\mathrm{fch}}$ & $2,64^{*}(12,71)$ \\
\hline $\mathbf{P}^{\mathrm{fch}}$ & $\mathrm{P}^{\mathrm{fsp}}$ & $1,33(12,71)$ \\
\hline $\mathrm{P}^{\mathrm{fpr}}$ & $\mathrm{P}^{\mathrm{Ih}}$ & $2,53^{*}(12,71)$ \\
\hline $\mathbf{P}^{\mathrm{fch}}$ & $\mathrm{P}^{\mathrm{fpr}}$ & $0,88(12,71)$ \\
\hline $\mathbf{P}^{\mathrm{fpr}}$ & $\mathbf{P}^{\mathrm{tsp}}$ & $3,15^{*}(12,71)$ \\
\hline $\mathbf{P}^{\mathrm{tsp}}$ & $\mathrm{P}^{\mathrm{fpr}}$ & $1,79(12,71)$ \\
\hline $\mathrm{P}^{\text {ospat }}$ & $\mathrm{P}^{\text {och }}$ & $1,91 * *(12,71)$ \\
\hline $\mathbf{P}^{\text {och }}$ & $\mathbf{P}^{\text {ospat }}$ & $1,58(12,71)$ \\
\hline $\mathbf{P}^{\text {ospat }}$ & $\mathbf{P}^{\text {ospvj }}$ & $1,28(12,71)$ \\
\hline
\end{tabular}




\begin{tabular}{c|c|c}
\hline $\mathbf{P}^{\text {ospvj }}$ & $\mathrm{P}^{\text {ospat }}$ & $0,91(12,71)$ \\
\hline $\mathbf{P}^{\mathrm{fch}}$ & $\mathrm{P}^{\text {sch }}$ & $0,94(12,71)$ \\
\hline $\mathbf{P}^{\text {sch }}$ & $\mathrm{P}^{\mathrm{fch}}$ & $0,97(12,71)$ \\
\hline $\mathbf{P}^{\mathrm{fch}}$ & $\mathrm{P}^{\text {och }}$ & $0,98(12,71)$ \\
\hline $\mathbf{P}^{\text {och }}$ & $\mathrm{P}^{\mathrm{fch}}$ & $1,30(12,71)$ \\
\hline $\mathbf{P}^{\text {sch }}$ & $\mathrm{P}^{\text {och }}$ & $1,21(12,71)$ \\
\hline $\mathbf{P}^{\text {och }}$ & $\mathrm{P}^{\text {sch }}$ & $1,52(12,71)$ \\
\hline
\end{tabular}

(1) Entre parênteses estão os graus de liberdade do teste

* Nível de significância : 1\%

** Nível de significância: $5 \%$

Os dados da tabela 08, para a década de 90, demostram que entre os preços da soja no Mato Grosso e Mato Grosso do Sul há relação bi-causal. Os outros resultados foram: (i) causalidade do preço da soja em Chicago para o Paraná; (ii) causalidade do preço da soja em Chicago para o Rio Grande do Sul; (iii) do Paraná para Mato Grosso; (iv) do Paraná para Mato Grosso do Sul; (v) do Paraná para Goiás; (vi) e do Mato Grosso do Sul para Goiás.

No mercado de farelo há uma relação de causalidade do preço do farelo em Chicago para os preços de São Paulo e Paraná e dos preços do farelo em São Paulo para os do Paraná.

No mercado de óleo há uma relação de causalidade do preço de Chicago para São Paulo ao atacado.

Estes resultados eram esperados, sendo os preços formados na CBOT e internalizados via Rio Grande do Sul e Paraná e, após, repassados para as diferentes regiões de comercialização no interior do país. Internamente, a relação causal dos preços dá-se das praças mais próximas ao porto para as mais afastadas, notando-se, também, a importância da capacidade instalada de processamento em cada estado.

Nos esquemas a seguir são apresentados um resumo das relações encontradas para os mercados de soja, farelo e óleo para a década de 90 . 

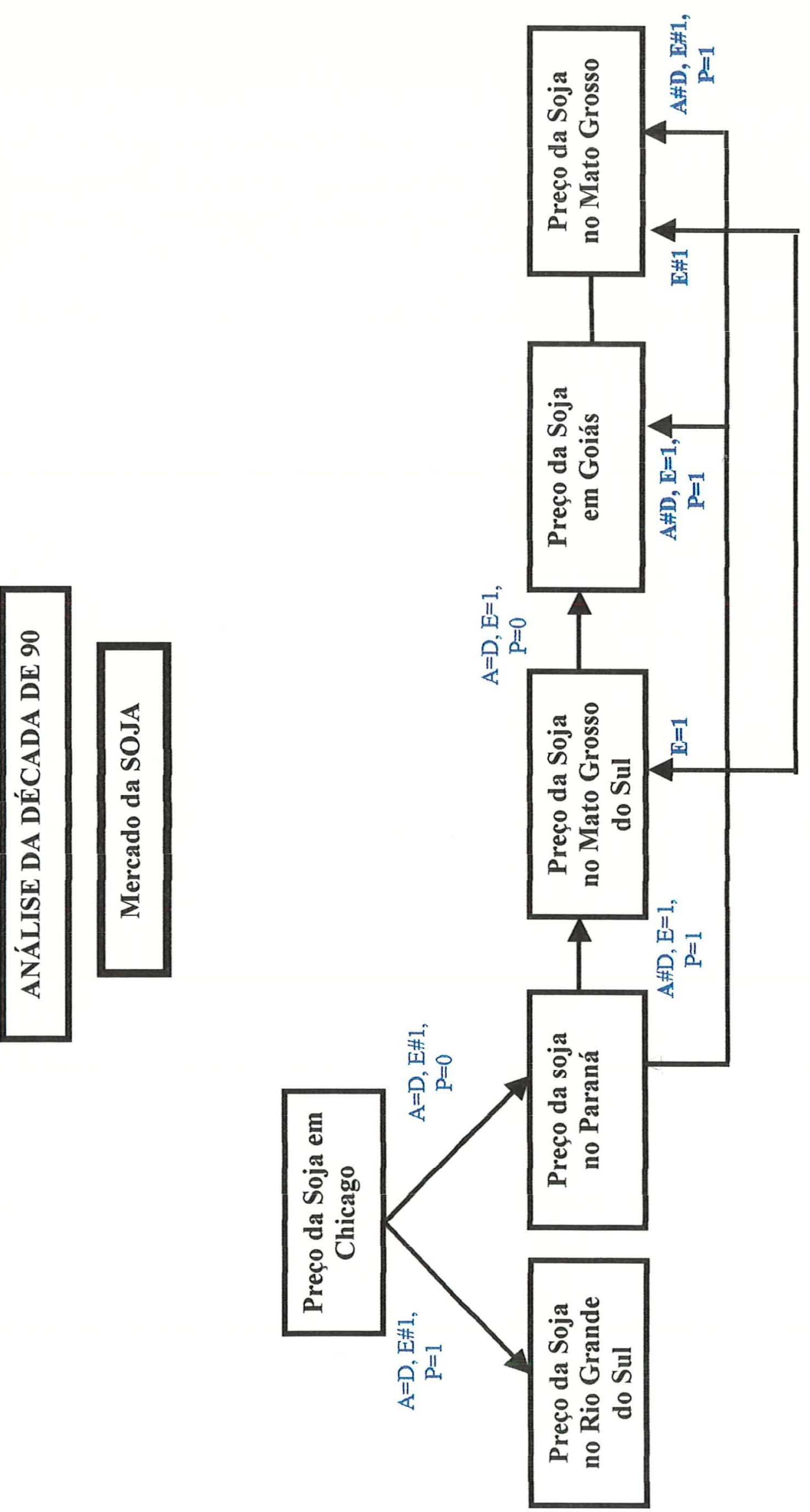


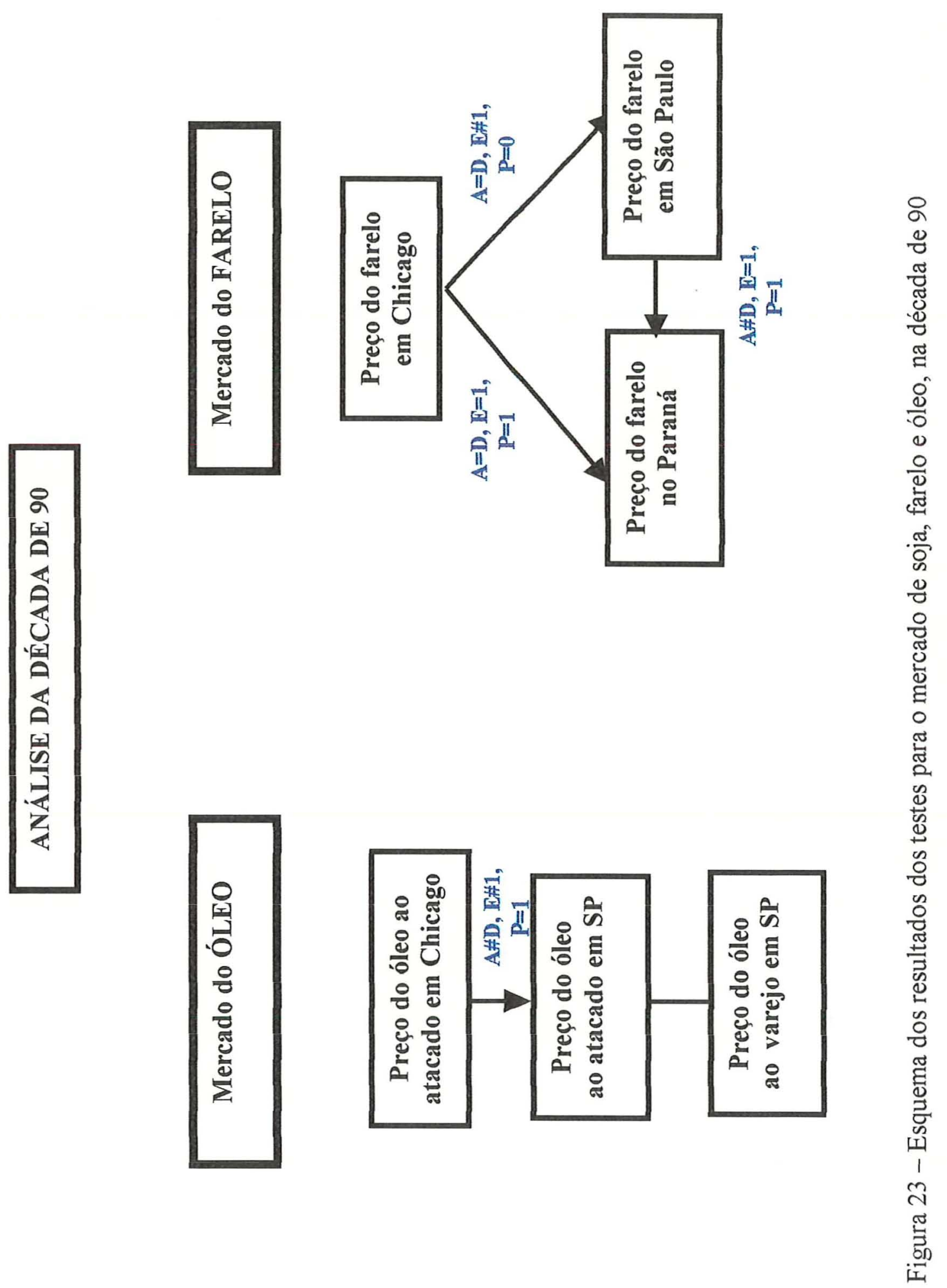




\subsection{Teste do padrão sazonal de formação dos preços}

Os resultados dos testes do padrão sazonal de formação de preços realizados, não foram significativos em nenhuma das equações estimadas, que foram as relações dos preços da soja na CBOT com os preços da soja no Paraná e Rio Grande do Sul para as décadas de 1980,1990 e período todo.

Os resultados encontrados foram surpreendentes, pois não comprovam as hipóteses dos agentes do mercado.

Tabela 09 - Equações de transmissão de preços da soja na década de 80 considerando o padrão sazonal de formação dos preços

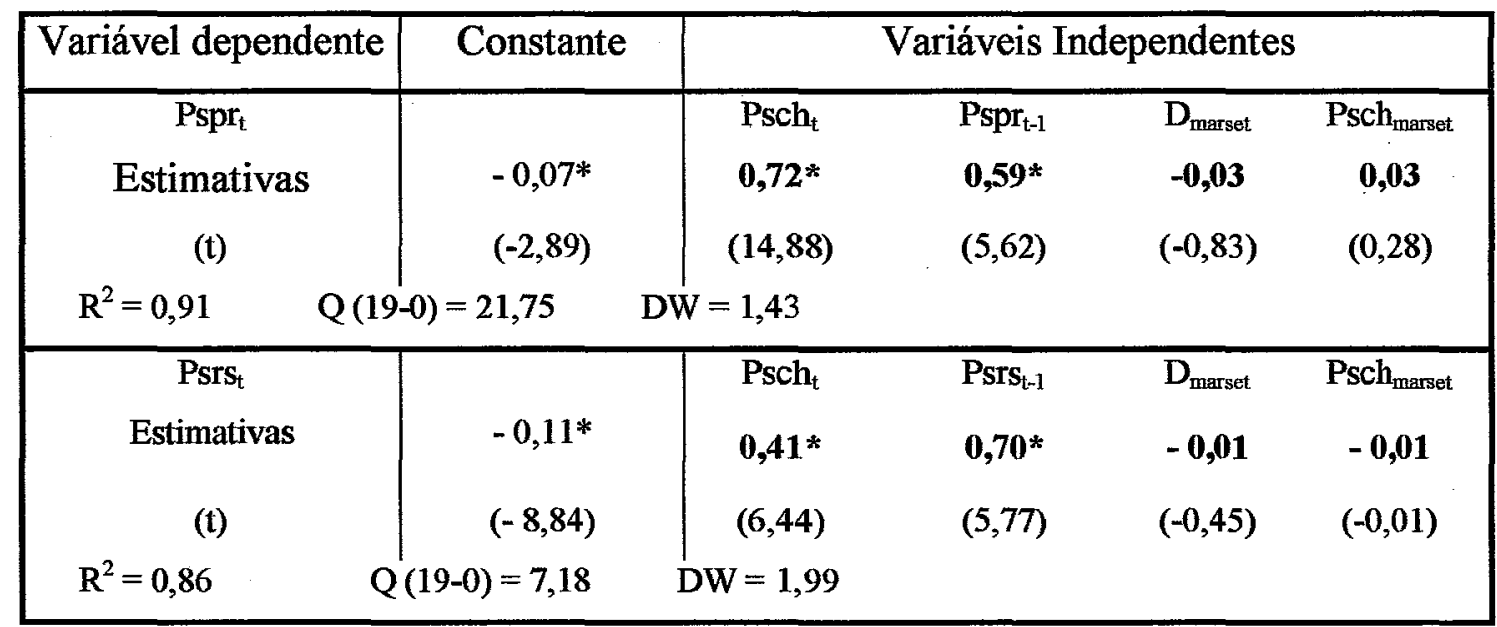

* Nível de significância do teste t e Q: 1\% 
Tabela 10 - Equações de transmissão de preços da soja na década de 90 considerando o padrão sazonal de formação dos preços

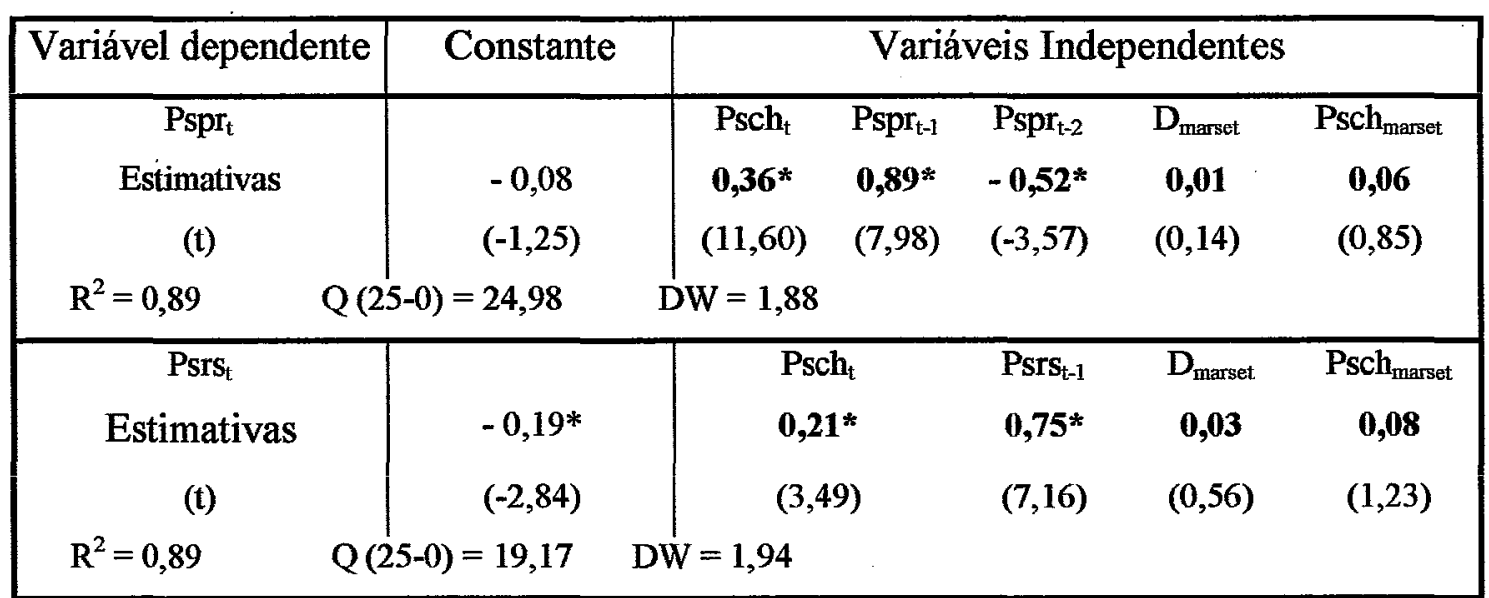

* Nível de significância do teste $t$ e Q: $1 \%$

Tabela 11 - Equações de transmissão de preços da soja no período todo considerando o padrão sazonal de formação dos preços

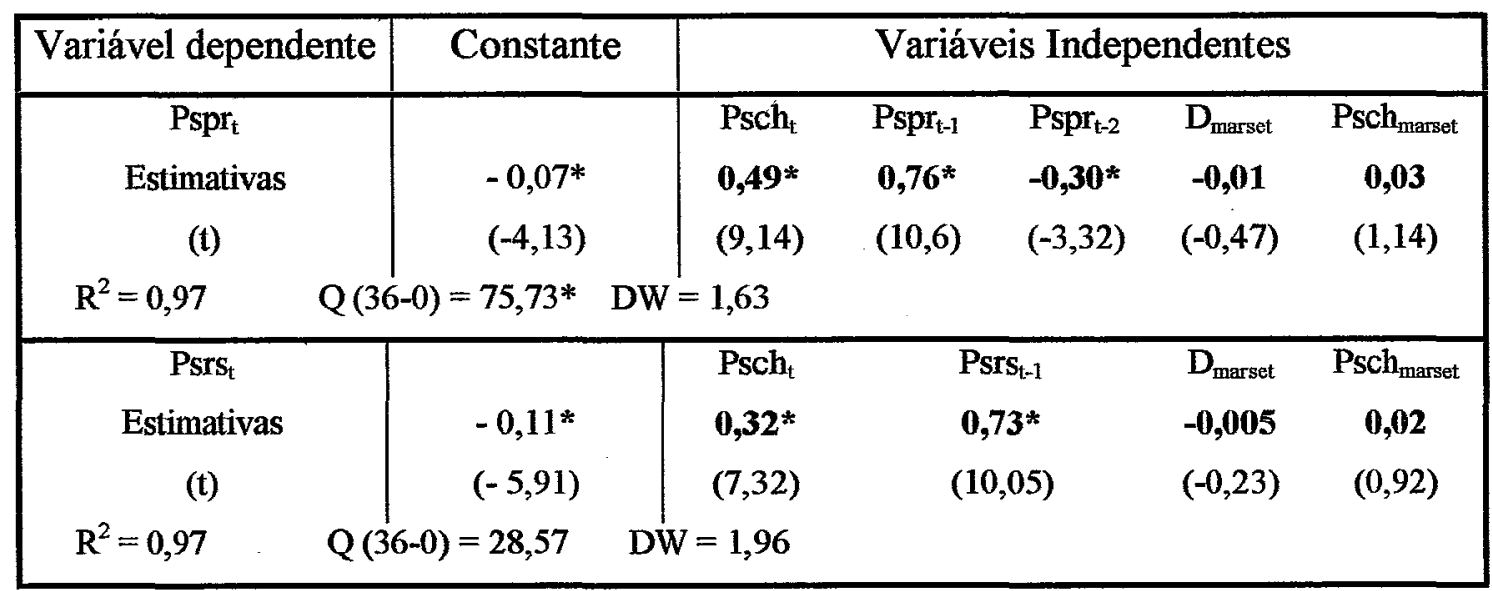

* Nível de significância do teste t e Q: 1\% 


\subsection{Elasticidades de transmissão de preços}

Os resultados dos testes $\mathrm{F}$ (de exclusão de variáveis) para verificar o número de defasagens significativas nas equações de transmissão de preços mostraram que em mais de $80 \%$ dos casos os ajustamentos foram com no máximo uma defasagem. Somente em três casos os ajustamentos ocorreram em dois meses e, em um caso, o ajustamento ocorreu em três meses. Esse curto espaço de tempo necessário para que, dada uma variação no preço em determinado nível de mercado, ocorra o ajustamento no outro, é indicativo de eficiência de mercado e de que as informações são transmitidas rapidamente. Além disso, foi verificado se o somatório das elasticidades nas equações de transmissão de preços é igual à unidade.

Tabela 12 - Duração das defasagens significativas (em meses) para as equações de transmissão de preços, conforme resultados das análises de causalidade, período todo

\begin{tabular}{|c|c|c|}
\hline Variável dependente & Variável independente & Defasagens \\
\hline $\mathrm{P}^{\mathrm{spr}}$ & $\mathbf{P}^{\text {sch }}$ & 0 \\
\hline $\mathbf{P}^{\mathrm{srs}}$ & $\mathrm{P}^{\mathrm{sch}}$ & 1 \\
\hline $\mathbf{P}^{\mathrm{sms}}$ & $\mathrm{p}^{\mathrm{spr}}$ & 2 \\
\hline $\mathbf{P}^{\text {sgo }}$ & $\mathrm{P}^{\mathrm{spr}}$ & 2 \\
\hline $\mathrm{P}^{\mathrm{smt}}$ & $\mathrm{P}^{\text {spr }}$ & 1 \\
\hline $\mathrm{P}^{\mathrm{sgo}}$ & $\mathbf{P}^{\mathrm{smt}}$ & 0 \\
\hline $\mathbf{P}^{\mathrm{fsp}}$ & $P^{\text {fch }}$ & 1 \\
\hline $\mathrm{P}^{\mathrm{fpr}}$ & $\mathrm{P}^{\mathrm{fch}}$ & 1 \\
\hline $\mathrm{P}^{\text {ospat }}$ & $\mathrm{P}^{\mathrm{och}}$ & 1 \\
\hline $\mathrm{P}^{\text {ospvi }}$ & $\mathrm{P}^{\text {ospat }}$ & 1 \\
\hline
\end{tabular}


Tabela 13 - Duração das defasagens significativas (em meses) para as equações de transmissão de preços, conforme resultados das análises de causalidade, década de 80

\begin{tabular}{c|c|c}
\hline Variável dependente & Variável independente & Defasagens \\
\hline $\mathrm{P}^{\mathrm{sms}}$ & $\mathrm{P}^{\mathrm{spr}}$ & 2 \\
\hline $\mathrm{P}^{\mathrm{smt}}$ & $\mathrm{P}^{\mathrm{spr}}$ & 1 \\
\hline $\mathrm{P}^{\mathrm{sms}}$ & $\mathrm{P}^{\mathrm{sgo}}$ & 1 \\
\hline $\mathrm{P}^{\mathrm{Ssp}}$ & $\mathrm{P}^{\mathrm{fch}}$ & 1 \\
\hline $\mathrm{P}^{\mathrm{fpr}}$ & $\mathrm{P}^{\mathrm{fch}}$ & 0 \\
\hline
\end{tabular}

Tabela 14 - Duração das defasagens significativas (em meses) para as equações de transmissão de preços, conforme resultados das análises de causalidade, década de 90

\begin{tabular}{c|c|c}
\hline Variável dependente & Variável independente & Defasagens \\
\hline $\mathrm{P}^{\mathrm{spr}}$ & $\mathrm{P}^{\mathrm{sch}}$ & 0 \\
\hline $\mathrm{P}^{\mathrm{srs}}$ & $\mathrm{P}^{\mathrm{sch}}$ & 3 \\
\hline $\mathrm{P}^{\mathrm{sms}}$ & $\mathrm{P}^{\mathrm{spr}}$ & 1 \\
\hline $\mathrm{P}^{\mathrm{sgo}}$ & $\mathrm{P}^{\mathrm{spr}}$ & 1 \\
\hline $\mathrm{P}^{\mathrm{smt}}$ & $\mathrm{P}^{\mathrm{spr}}$ & 0 \\
\hline $\mathrm{P}^{\mathrm{sgo}}$ & $\mathrm{P}^{\mathrm{sms}}$ & 0 \\
\hline $\mathrm{P}^{\mathrm{fsp}}$ & $\mathrm{P}^{\mathrm{fch}}$ & 1 \\
\hline $\mathrm{P}^{\mathrm{fpr}}$ & $\mathrm{P}^{\mathrm{fch}}$ & 1 \\
\hline $\mathrm{P}^{\mathrm{fpr}}$ & $\mathrm{P}^{\mathrm{fsp}}$ & 1 \\
\hline $\mathrm{P}^{\mathrm{ospat}}$ & $\mathrm{P}^{\mathrm{och}}$ & \\
\hline
\end{tabular}

A partir da definição da relação causal e do número de defasagens significativas, selecionaram-se as equações de transmissão de preços que estão apresentadas nas tabelas 15,16 e 17 . 
Tabela 15 - Equações de transmissão de preços da soja e derivados no período todo

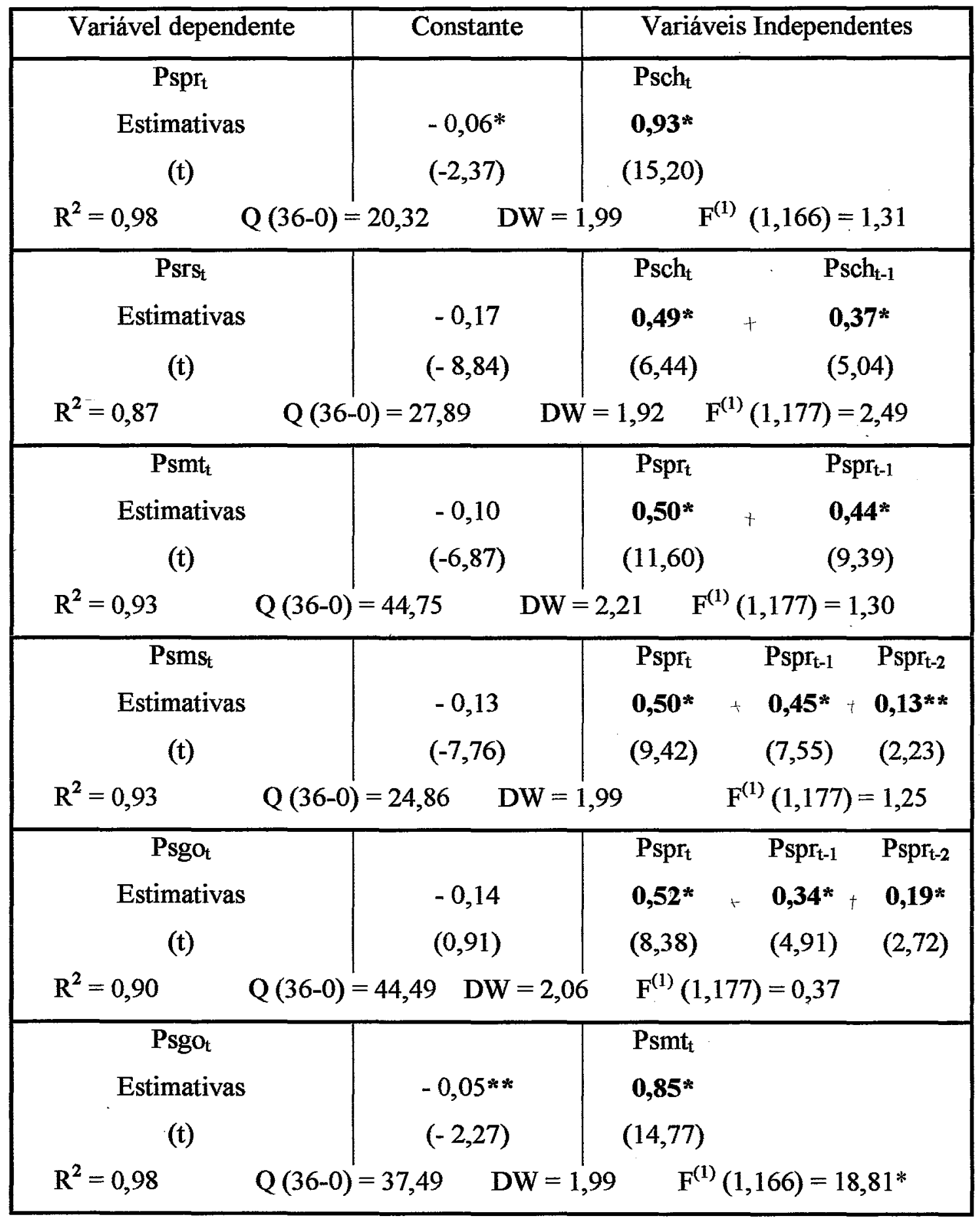




\begin{tabular}{|c|c|c|c|}
\hline $\begin{array}{c}\text { Psmst }_{\mathrm{t}} \\
\text { Estimativas } \\
(\mathrm{t})\end{array}$ & $\begin{array}{c}-0,08 \\
(-8,11)\end{array}$ & $\begin{array}{c}\text { Psmt }_{\mathrm{t}} \\
\mathbf{0 , 9 8 *} \\
(100,0)\end{array}$ & 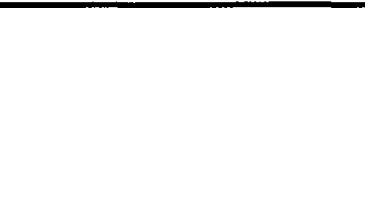 \\
\hline $\mathbf{R}^{2}=0,98$ & $Q(36-0)=143,82^{*}$ & $\mathrm{DW}=1,30$ & $\mathrm{~F}^{(1)}(1,202)=3,17$ \\
\hline $\begin{array}{c}\text { Psmt }_{t} \\
\text { Estimativas } \\
(\mathrm{t})\end{array}$ & $\begin{array}{l}-0,06^{*} \\
(5,84)\end{array}$ & $\begin{array}{c}\text { Psms }_{t} \\
\text { 0,99* } \\
(100,00)\end{array}$ & \\
\hline $\mathbf{R}^{2}=0,98$ & $Q(36-0)=131,96^{*}$ & $\mathrm{DW}=1,29$ & $\mathrm{~F}^{(1)}(1,202)=0,05$ \\
\hline $\begin{array}{c}\text { Psgo }_{\mathrm{t}} \\
\text { Estimativas } \\
\text { (t) }\end{array}$ & $\begin{array}{c}0,00 \\
(0,04)\end{array}$ & $\begin{array}{c}\text { Psmst } \\
\mathbf{1 , 0 1}^{*} \\
(91,54)\end{array}$ & \\
\hline $\mathbf{R}^{2}=0,98$ & $Q(36-0)=28,16$ & $\mathrm{DW}=1,71$ & $\mathrm{~F}^{(1)}(1,202)=1,78$ \\
\hline $\begin{array}{c}\text { Psms }_{t} \\
\text { Estimativas } \\
(\mathrm{t})\end{array}$ & $\begin{array}{l}-0,02^{* *} \\
(-2,06)\end{array}$ & $\begin{array}{c}\text { Psgo }_{t} \\
\text { 0,96* } \\
(91,54)\end{array}$ & \\
\hline $\mathbf{R}^{2}=0,98$ & $Q(36-0)=31,64$ & $\mathrm{DW}=1,71$ & $\mathrm{~F}^{(1)}(1,202)=12,91^{*}$ \\
\hline $\begin{array}{c}\text { Pfpr }_{\mathrm{t}} \\
\text { Estimativas } \\
\text { (t) }\end{array}$ & $\begin{array}{l}0,05^{*} \\
(2,47)\end{array}$ & \begin{tabular}{|l} 
Pfch $_{\mathrm{t}}$ \\
$\mathbf{0 , 6 6 ^ { * }}$ \\
$(9,35)$
\end{tabular} & $\begin{array}{c}\text { Pfch }_{\mathrm{t}-1} \\
+\quad \mathbf{0 , 3 6}^{*} \\
(4,99)\end{array}$ \\
\hline $\mathbf{R}^{2}=0,74$ & $Q(36-0)=45,66$ & $\mathrm{DW}=1,89$ & $F^{(1)}(1,177)=0,02$ \\
\hline $\begin{array}{c}\text { Pfsp }_{\mathrm{t}} \\
\text { Estimativas } \\
(\mathrm{t})\end{array}$ & $\begin{array}{l}0,07^{*} \\
(3,45)\end{array}$ & \begin{tabular}{|c|} 
Pfch $_{\mathrm{t}}$ \\
$\mathbf{0 , 6 4 ^ { * }}$ \\
$(8,56)$
\end{tabular} & $\begin{array}{c}\text { Pfch }_{\mathrm{t}-1} \\
+\quad \mathbf{0 , 3 8 *} \\
(4,99)\end{array}$ \\
\hline $\mathbf{R}^{2}=0,80$ & $Q(36-0)=41,78$ & DW $=1,89$ & $F^{(1)}(1,177)=0,83$ \\
\hline $\begin{array}{c}\text { Pospat }_{\mathrm{t}} \\
\text { Estimativas } \\
\text { (t) }\end{array}$ & $\begin{array}{c}0,14^{*} \\
(5,97)\end{array}$ & $\begin{array}{c}\text { Poch }_{4} \\
\text { 0,44* } \\
(10,23)\end{array}$ & $\begin{array}{c}\text { Poch }_{\mathrm{t}-1} \\
+\quad \mathbf{0 , 2 7 ^ { * }} \\
(5,90)\end{array}$ \\
\hline $\mathrm{R}^{2}=0,74$ & $Q(36-0)=44,37$ & $\mathrm{DW}=2,05$ & $\mathrm{~F}^{(1)}(1,177)=30,33^{*}$ \\
\hline
\end{tabular}




\begin{tabular}{c|c|cc}
$\begin{array}{c}\text { Pospvj } \\
\text { Estimativas } \\
\text { (t) }\end{array}$ & $-0,001$ & Pospat $_{\mathrm{t}}$ & Pospat $_{\mathrm{t}-1}$ \\
$\mathrm{R}^{2}=0,98$ & $(-0,26)$ & $\mathbf{0 , 6 7 *}$ & $\mathbf{0 , 2 3}^{*}$ \\
$(12,78)$ & $(-2,37)$ \\
& $\mathrm{Q}(36-0)=46,66$ & $\mathrm{DW}=1,94$ & $\mathrm{~F}^{(1)}(1,166)=54,91^{*}$
\end{tabular}

(1) Teste referente à hipótese da soma das elasticidades ser igual a um

* Nível de significância do teste t, Q e F : 1\%

** Nível de significância do teste t, Q e F: $5 \%$

Tabela 16 - Equações de transmissão de preços da soja e derivados na década de 80

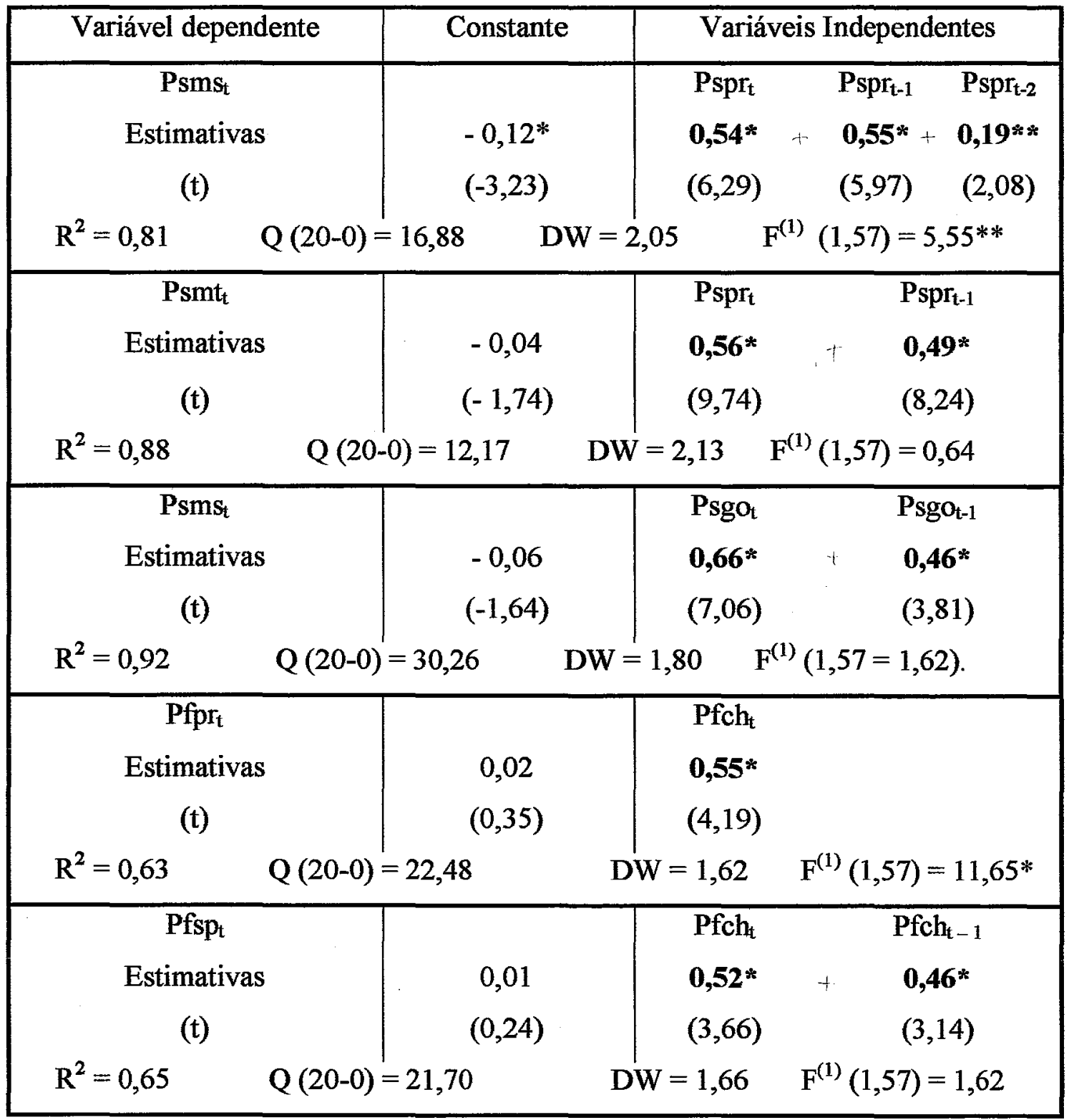




\begin{tabular}{|c|c|c|c|}
\hline $\begin{array}{c}\text { Pospat }_{t} \\
\text { Estimativas } \\
\text { (t) }\end{array}$ & $\begin{array}{r}-0,03 \\
(-1,27)\end{array}$ & $\begin{array}{c}\text { Pospvjt } \\
1,02^{*} \\
(41,95)\end{array}$ & ' \\
\hline $\mathbf{R}^{2}=0,95$ & $\mathrm{Q}(21-0)=65,92^{*}$ & $\mathrm{DW}=0,81$ & $F^{(1)}(1,82)=0,76$ \\
\hline Pospvj & & Pospat $_{t}$ & \\
\hline Estimativas & $0,07 *$ & $0,94^{*}$ & \\
\hline & & & \\
\hline $\mathbf{R}^{2}=0,95$ & $Q(21-0)=63,69^{*}$ & $\mathrm{DW}=0,80$ & $\mathrm{~F}^{(1)}(1,82)=8,32^{*}$ \\
\hline
\end{tabular}

(1) Teste referente a soma das elasticidades ser igual a um * Nível de significância do teste t, Q e F : 1\%

** Nível de significância do teste t, Q e F: 5\%

Tabela 17 - Equações de transmissão de preços da soja e derivados na década de 90

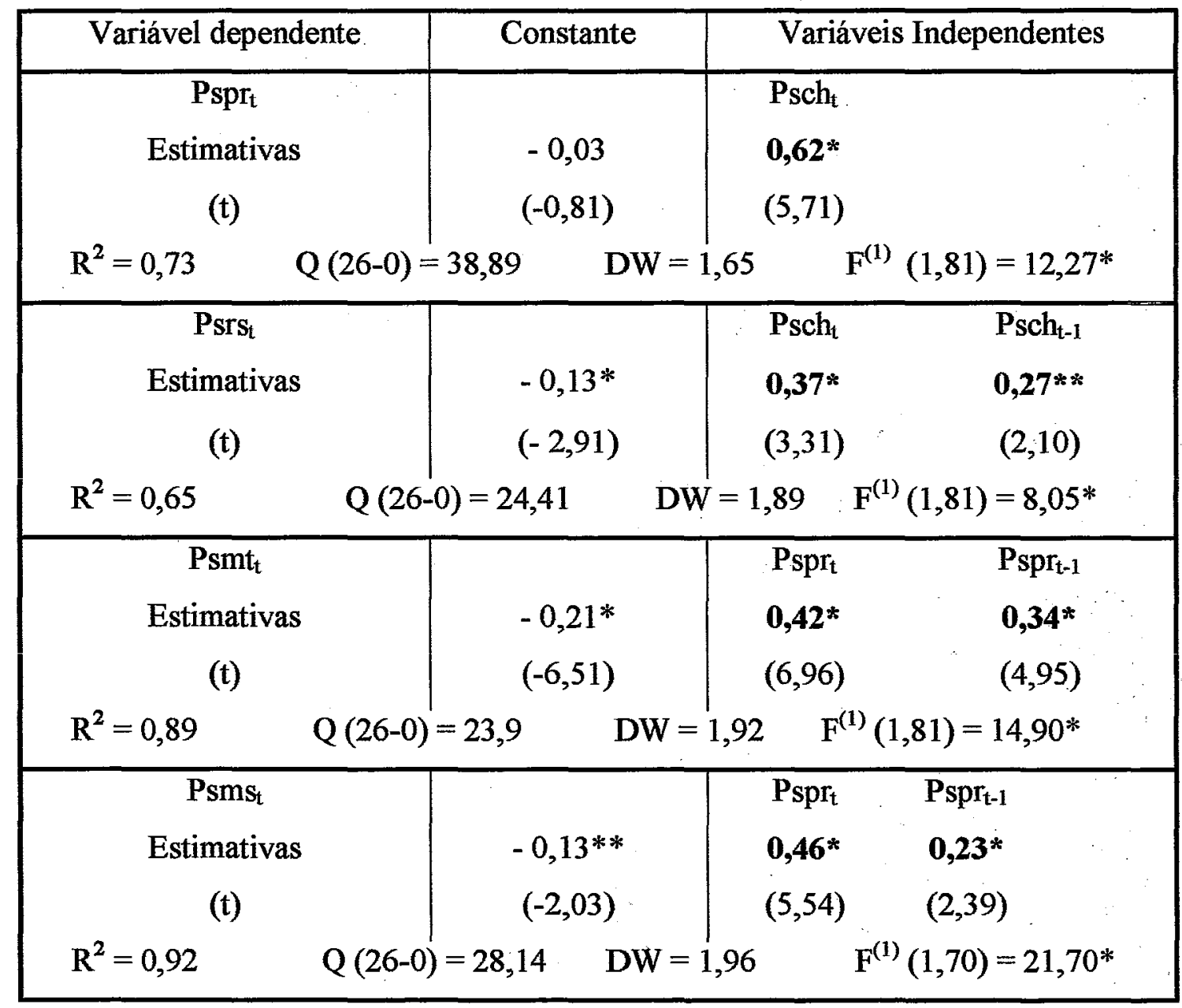




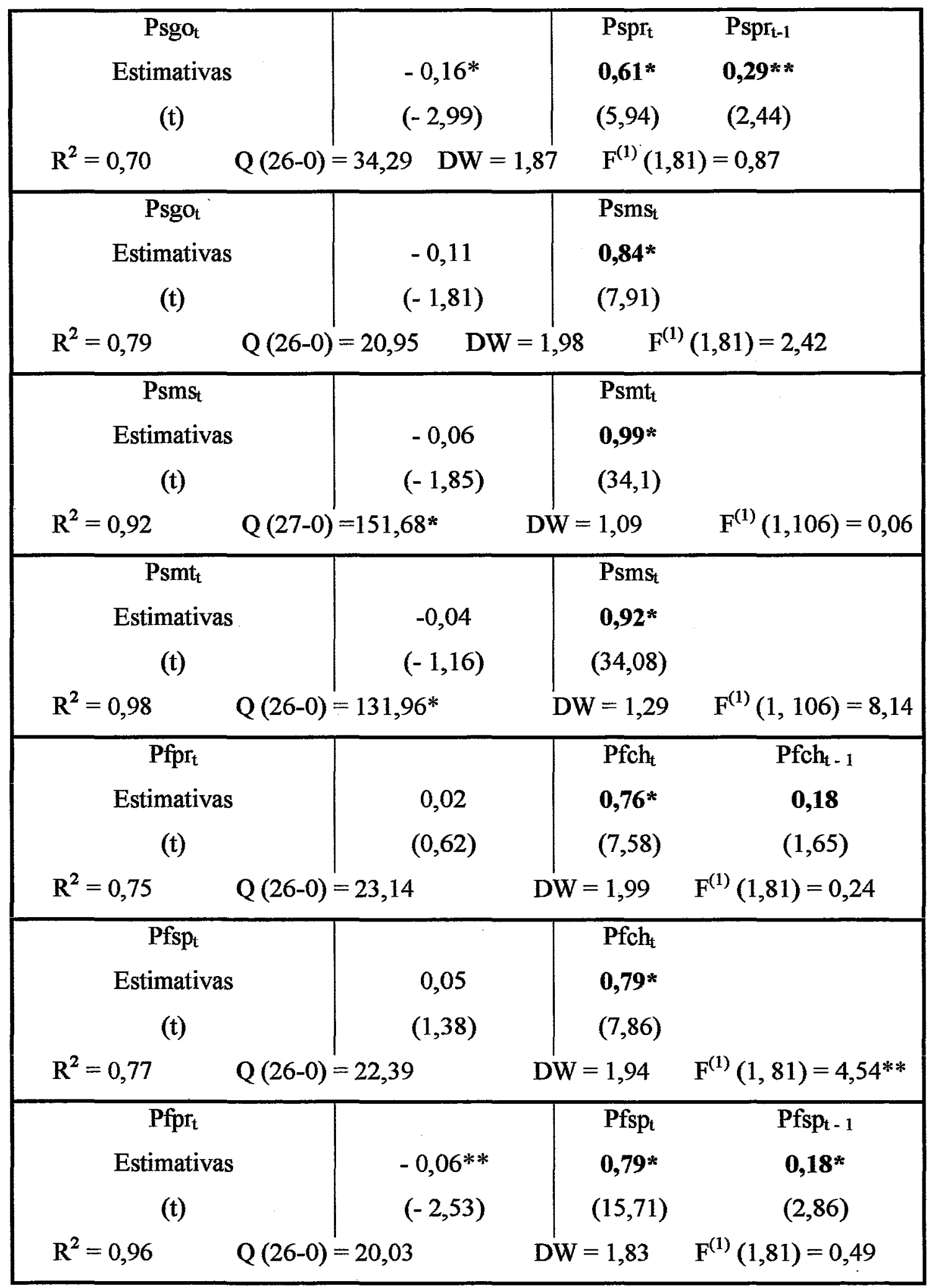




\begin{tabular}{|c|r|rc|}
\hline $\begin{array}{c}\text { Pospat } \\
\text { Estimativas }\end{array}$ & $0,20^{*}$ & Poch $_{\mathrm{t}}$ & Poch $_{\mathrm{t}-1}$ \\
$(\mathrm{t})$ & $(10,36)$ & $\mathbf{0 , 2 9 *}$ & $\mathbf{0 , 2 0 ^ { * }}$ \\
$\left.\mathrm{R}^{2}=0,68 \quad \mathrm{Q}, 76\right)$ & $(3,39)$ \\
\hline
\end{tabular}

(1) Teste referente a soma das elasticidades ser igual a um

* Nível de significância do teste t, Q e F : $1 \%$

** Nível de significância do teste $t, \mathrm{Q}$ e F: $5 \%$

Os coeficientes de determinação $\left(\mathbf{R}^{2}\right)$ mostraram-se satisfatórios em todas as equações, indicando que alterações nas variáveis dependentes são satisfatoriamente explicadas pelas variáveis independentes.

No caso do teste do somatório da elasticidade de transmissão de preços ser igual à unidade, temos que:

i) Considerando todo o período, ou seja, a década de 80 e 90 , foram estimadas quatorze equações e destas somente em quatro equações a soma da elasticidade não foi igual à unidade, conforme (tabela 15);

ii) Considerando a década de 80 , foram estimadas sete equações e destas três a soma da elasticidade não foi igual à unidade, conforme (tabela 16);

iii) Considerando a década de 90 , foram estimadas doze equações e destas seis a soma da elasticidade não foi igual à unidade, conforme (tabela 17).

Os resultados podem ser interpretados da seguinte forma. Tomando como exemplo a transmissão de preços de Chicago para o Paraná na tabela 15 , nota-se que, dado um acréscimo de $1 \%$ no preço da soja em Chicago, o preço da soja no Paraná aumentará instantaneamente, ou seja, no mesmo mês, em $0,93 \%$. 


\subsection{Assimetria na transmissão de preços}

Os resultados dos testes mostram que para o período todo não houve assimetria na transmissão dos preços, conforme pode ser observado na (tabela 18) a seguir.

Tabela 18 - Teste de assimetria na transmissão de preços da soja, no período todo

\begin{tabular}{|c|c|c|}
\hline Variável dependente & Variável independente & $F^{(1)}$ \\
\hline$\overline{\mathrm{P}^{\mathrm{spr}}}$ & $\mathbf{P}^{\text {sch }}$ & $0,03(1,212)$ \\
\hline $\mathrm{P}^{\mathrm{srs}}$ & $\mathbf{P}^{\mathrm{sch}}$ & $2,77(1,212)$ \\
\hline $\mathrm{P}^{\mathrm{smmt}}$ & $\mathrm{P}^{\mathrm{spr}}$ & $3,55(1,212)$ \\
\hline $\mathrm{P}^{\mathrm{sms}}$ & $\mathrm{P}^{\mathrm{spr}}$ & $2,56(1,212)$ \\
\hline $\mathrm{P}^{\text {sgo }}$ & $\mathbf{P}^{\mathrm{spr}}$ & $0,23(1,212)$ \\
\hline $\mathrm{P}^{\mathrm{sgo}}$ & $\mathrm{P}^{\mathrm{smmt}}$ & $1,22(1,212)$ \\
\hline $\mathrm{P}^{\mathrm{fpr} r}$ & $\mathrm{P}^{\mathrm{fch}}$ & $0,17(1,212)$ \\
\hline $\mathbf{P}^{\mathrm{tsp}}$ & $\mathbf{P}^{\mathrm{fch}}$ & $0,01(1,212)$ \\
\hline $\bar{P}^{\text {ospat }}$ & $\mathrm{P}^{\text {och }}$ & $0,53(1,212)$ \\
\hline $\mathrm{P}^{\text {ospvj }}$ & $\mathrm{P}^{\text {ospat }}$ & $0,23(1,212)$ \\
\hline
\end{tabular}

(1) Entre parênteses estão os graus de liberdade do teste

Na década de 80, há assimetria do preço da soja no Paraná para o preço da soja no Mato Grosso e no Mato Grosso do Sul, conforme pode ser observado na (tabela 19), a seguir.

Tabela 19 - Teste de assimetria na transmissão de preços da soja, na década de 80

\begin{tabular}{c|c|c}
\hline Variável dependente & Variável independente & $\mathrm{F}^{(1)}$ \\
\hline $\mathrm{P}^{\mathrm{smt}}$ & $\mathrm{P}^{\mathrm{spr}}$ & $7,28^{*}(1,92)$ \\
\hline $\mathrm{P}^{\mathrm{sms}}$ & $\mathrm{P}^{\mathrm{spr}}$ & $6,43^{*}(1,92)$ \\
\hline $\mathrm{P}^{\mathrm{sms}}$ & $\mathrm{P}^{\mathrm{sgo}}$ & $0,11(1,92)$ \\
\hline $\mathbf{P}^{\mathrm{fpr}}$ & $\mathrm{P}^{\mathrm{fch}}$ & $0,02(1,92)$ \\
\hline $\mathbf{P}^{\mathrm{fsp}}$ & $\mathrm{P}^{\mathrm{fch}}$ & $0,09(1,92)$ \\
\hline
\end{tabular}

(1) Entre parênteses estão os graus de liberdade do teste

* Nivel de significância (teste F): $1 \%$ 
Na década de 90, há assimetria entre o preço da soja no Paraná para o preço da soja no Mato Grosso, no Mato Grosso do Sul e em Goiás, do preço do farelo em São Paulo para o preço do farelo no Paraná, e preço do óleo em Chicago para preço do óleo em São Paulo no Atacado, conforme pode ser observado na (tabela 20), a seguir.

Tabela 20 - Teste de assimetria na transmissão de preços da soja, na década de 90

\begin{tabular}{c|c|c}
\hline Variável dependente & Variável independente & $\mathrm{F}^{(1)}$ \\
\hline $\mathrm{P}^{\mathrm{spr}}$ & $\mathrm{P}^{\mathrm{sch}}$ & $0,08(1,116)$ \\
\hline $\mathrm{P}^{\mathrm{srs}}$ & $\mathrm{P}^{\mathrm{sch}}$ & $2,88(1,116)$ \\
\hline $\mathrm{P}^{\mathrm{smt}}$ & $\mathrm{P}^{\mathrm{spr}}$ & $7,09^{*}(1,116)$ \\
\hline $\mathrm{P}^{\mathrm{sms}}$ & $\mathrm{P}^{\mathrm{spr}}$ & $5,71^{*}(1,116)$ \\
\hline $\mathrm{P}^{\mathrm{sgo}}$ & $\mathrm{P}^{\mathrm{spr}}$ & $9,54^{*}(1,116)$ \\
\hline $\mathrm{P}^{\mathrm{sgo}}$ & $\mathrm{P}^{\mathrm{sms}}$ & $0,26(1,116)$ \\
\hline $\mathrm{P}^{\mathrm{fpr}}$ & $\mathrm{P}^{\mathrm{fsp}}$ & $11,43^{*}(1,116)$ \\
\hline $\mathrm{P}^{\mathrm{fpr}}$ & $\mathrm{P}^{\mathrm{fch}}$ & $0,32(1,116)$ \\
\hline $\mathrm{P}^{\mathrm{fsp}}$ & $\mathrm{P}^{\mathrm{fch}}$ & $0,94(1,116)$ \\
\hline $\mathrm{P}^{\mathrm{ospat}}$ & $\mathrm{P}^{\mathrm{och}}$ & $5,06^{* *}(1,116)$ \\
\hline
\end{tabular}

(1) Entre parênteses estão os graus de liberdade do teste

*Nível de significância (teste F): $1 \%$

** Nível de significância (teste F): $5 \%$

Nos casos em que ocorreu assimetria foi estimada a elasticidade de transmissão de preços na forma segmentada, ou seja, uma elasticidade para acréscimo e outra para decréscimo de preços. Nas tabelas 21 e 22 estão as equações segmentadas de transmissão de preços das relações onde foi constatada assimetria, todas as relações com soja em grãos mostraram transmissão mais intensa de acréscimos que de decréscimos dos preços, sendo que, os acréscimos foram maiores que um, enquanto os decréscimos foram menores que um, em todos os casos. No caso do farelo e óleo a transmissão dos decréscimos de preços é mais intensa que dos acréscimos. 
A diferença das elasticidades segmentadas de acréscimos e decréscimos de preços, obtidas através do teste $\mathrm{F}$, demonstra que essa não difere de zero para todas as equações estimadas.

Para os decréscimos de preços, estes são transmitidos menos que proporcionalmente, elasticidade de transmissão menor que um, para o caso da soja em grãos, conforme pode ser observado na (tabela 21), a seguir.

Tabela 21 - Equações de transmissão de preços segmentadas para a década de 80

\begin{tabular}{|c|c|cl|}
\hline Variável dependente & Tendência & \multicolumn{2}{|c|}{ Variáveis Independentes } \\
\hline $\mathbf{P}_{\mathrm{t}}^{\mathrm{smt}}$ & & $\mathrm{AP}_{\mathrm{t}}^{\mathrm{spr}}$ & $\mathrm{DP}_{\mathrm{t}}^{\mathrm{spr}}$ \\
Estimativas & $-0,003^{*}$ & $\mathbf{1 , 0 5}^{*}$ & $\mathbf{0 , 7 5}^{*}$ \\
$(\mathrm{t})$ & $(-2,58)$ & $(17,54)$ & $(7,79)$ \\
$\mathrm{R}^{2}=0,82$ & $\mathrm{Q}(23-0)=12,40$ & $\mathrm{DW}=1,77$ & $\mathrm{~F}^{(1)}(1,92)=6,43^{*}$ \\
\hline $\mathrm{P}_{\mathrm{t}}^{\mathrm{sms}}$ & & $\mathrm{AP}_{\mathrm{t}}^{\mathrm{spr}}$ & $\mathrm{DP}_{\mathrm{t}}^{\mathrm{spr}}$ \\
Estimativas & $-0,003^{*}$ & $\mathbf{1 , 0 4}^{*}$ & $\mathbf{0 , 6 7}^{*}$ \\
$(\mathrm{t})$ & $(-2,65)$ & $(15,29)$ & $(6,20)$ \\
$\mathrm{R}^{2}=0,77$ & $\mathrm{Q}(23-0)=15,48$ & $\mathrm{DW}=1,74$ & $\mathrm{~F}^{(1)}(1,92)=7,29^{*}$ \\
\hline
\end{tabular}

(1) Teste $\mathrm{F}$ referente à hipótese de que a diferença entre a elasticidade total de transmissão de acréscimos de preços da elasticidade total de decréscimos de preços é zero.

* Nível de significância do teste t, Q e F: $1 \%$

** Nivel de significância do teste t, Q e F: $5 \%$

No caso do óleo verifica-se que os decréscimos de preços são transmitidos mais que proporcionalmente, e no farelo os preços são transmitidos menos que proporcionalmente.

As estimativas realizadas mostram a importância de se fazer à análise de assimetria entre os preços agrícolas. 
Tabela 22 - Equações de transmissão de preços segmentadas para a década de 90

\begin{tabular}{|c|c|c|c|c|}
\hline Variável depende & ente & Tendência & \multicolumn{2}{|c|}{ Variáveis Independentes } \\
\hline$P_{t}^{\text {smt }}$ & & & $\mathrm{AP}_{\mathrm{t}}^{\mathrm{spr}}$ & $\mathrm{DP}_{\mathrm{t}}^{\mathrm{spr}}$ \\
\hline Estimativas & & $-0,003 *$ & $1,03 *$ & $0,73^{*}$ \\
\hline$(\mathrm{t})$ & & $(-2,71)$ & $(19,21)$ & $(8,74)$ \\
\hline $\mathbf{R}^{2}=0,89$ & \multicolumn{2}{|c|}{$Q(29-0)=31,79$} & $\mathrm{DW}=1,96$ & $\mathrm{~F}^{(1)}(1,116)=7,09^{*}$ \\
\hline $\mathrm{P}_{\mathrm{t}}^{\mathrm{sms}}$ & & & $\mathbf{A P}_{t}^{\mathrm{spr}}$ & $\mathrm{DP}_{\mathrm{t}}^{\mathrm{spr}}$ \\
\hline Estimativas & & $-0,003 * *$ & $1,07 *$ & $\mathbf{0 , 7 8 *}$ \\
\hline (t) & & $(-2,37)$ & $(18,60)$ & $(8,72)$ \\
\hline $\mathbf{R}^{2}=0,88$ & \multicolumn{2}{|c|}{$Q(29-0)=18,94$} & $\mathrm{DW}=1,84$ & $\mathrm{~F}^{(1)}(1,116)=5,71^{*}$ \\
\hline $\mathrm{P}_{\mathrm{t}}^{\mathrm{sgo}}$ & & & $\mathbf{A P}_{\mathrm{t}}^{\mathrm{spr}}$ & $\mathrm{DP}_{\mathrm{t}}^{\mathrm{spr}}$ \\
\hline Estimativas & & $-0,004^{*}$ & $1,16^{*}$ & $0,67 *$ \\
\hline (t) & & $(-2,86)$ & $(15,43)$ & $(5,75)$ \\
\hline $\mathbf{R}^{2}=0,79$ & \multicolumn{2}{|c|}{$Q(29-0)=26,34$} & $\mathrm{DW}=1,86$ & $F^{(1)}(1,116)=9,54^{*}$ \\
\hline $\mathbf{P}_{t}^{\mathrm{fpr}}$ & & & $\mathbf{A P}_{t}^{\mathrm{spr}}{ }_{t}^{f \rho \rho}$ & $\mathrm{DP}_{t}^{\mathrm{spr} f 5 \mathrm{p}}$ \\
\hline Estimativas & & $-0,003^{*}$ & $0,63^{*}$ & $0,94^{*}$ \\
\hline$(t)$ & & $(3,34)$ & $(6,91)$ & $(18,74)$ \\
\hline $\mathbf{R}^{2}=0,83$ & \multicolumn{2}{|c|}{$Q(29-0)=26,87$} & $\mathrm{DW}=1,74$ & $\mathrm{~F}^{(1)}(1,116)=11,43^{*}$ \\
\hline$\overline{P_{t}^{\text {ospat }}}$ & & & $\overline{\mathrm{AP}_{\mathrm{t}}^{\text {och }}}$ & $\overline{\mathrm{DP}^{\text {och }}}$ \\
\hline Estimativas & & $-0,003^{*}$ & $1,01^{*}$ & $1,37^{*}$ \\
\hline$(\mathrm{t})$ & & $(2,42)$ & $(10,37)$ & $(11,07)$ \\
\hline $\mathrm{R}^{2}=0,72$ & $\mathrm{Q}(2$ & $-0)=41,90$ & $\mathrm{DW}=1,54$ & $F^{(1)}(1,116)=5,06^{*}$ \\
\hline
\end{tabular}

(1) Teste $\mathrm{F}$ referente à hipótese de que a diferença entre a elasticidade total de transmissão de acréscimos de preços da elasticidade total de decréscimos de preços é zero.

* Nível de significância do teste t, Q e F: $1 \%$

** Nível de significância do teste t, Q e F: 5\%

Nas tabelas 23 a 25 , estão as estimativas das elasticidades convencionais e segmentadas, onde se demonstra que normalmente as elasticidades convencionais situam-se entre as estimativas das elasticidades de acréscimos e decréscimos de preços, subestimando o efeito dos acréscimos e superestimando o efeito dos decréscimos de preços. 
Tabela 23 - Elasticidade de transmissão convencional e segmentada para acréscimo e decréscimo de preço da soja, para o período todo

\begin{tabular}{|c|c|c|c|c|}
\hline \multirow[t]{2}{*}{ Variável dependente } & \multirow{2}{*}{$\begin{array}{c}\text { Variável } \\
\text { independente }\end{array}$} & \multirow[t]{2}{*}{ Convencional } & \multicolumn{2}{|c|}{ Elasticidades } \\
\hline & & & Acréscimo & Decréscimo \\
\hline $\mathrm{P}^{\mathrm{spr}}$ & $\mathbf{P}^{\text {sch }}$ & $0,90^{3}$ & 0,76 & 0,73 \\
\hline $\mathrm{P}^{\mathrm{srs}}$ & $\mathrm{P}^{\mathrm{sch}}$ & 0.86 & 0,88 & 0,67 \\
\hline $\mathbf{P}^{\mathrm{smit}}$ & $\mathrm{P}^{\mathrm{spr}}$ & 0,94 & 0,86 & 0,99 \\
\hline$\overline{\mathrm{P}^{\mathrm{sms}}}$ & $\mathbf{P}^{\mathrm{spr}}$ & 1,08 & 0,92 & 1,03 \\
\hline $\mathrm{P}^{\mathrm{sgo}}$ & $\mathrm{P}^{\mathrm{spr}}$ & 1,05 & 0,97 & 0,93 \\
\hline $\mathbf{P}^{\mathrm{sgo}}$ & $\mathbf{P}^{\text {snt }}$ & 0,86 & 1,01 & 1,08 \\
\hline $\mathbf{P}^{\mathrm{sms}}$ & $\mathrm{P}^{\mathrm{smt}}$ & 0,98 & & \\
\hline $\mathrm{P}^{\mathrm{smt}}$ & $\mathrm{P}^{\mathrm{sms}}$ & 0,99 & & \\
\hline $\mathrm{P}^{\mathrm{sgo}}$ & $\mathrm{P}^{\mathrm{sms}}$ & 1,01 & & \\
\hline $\mathbf{P}^{\text {sms }}$ & $\mathrm{P}^{\mathrm{sgo}}$ & 0,96 & & \\
\hline $\mathrm{P}^{\mathrm{fsp}}$ & $\mathrm{P}^{\mathrm{fch}}$ & 1,02 & 0,53 & 0,51 \\
\hline $\mathrm{P}^{\mathrm{fpr}}$ & $\mathbf{P}^{\mathrm{fch}}$ & 1,02 & 0,70 & 0,61 \\
\hline $\mathrm{P}^{\text {ospat }}$ & $\mathrm{P}^{\mathrm{och}}$ & 0,71 & 0,66 & 0,64 \\
\hline $\mathrm{P}^{\text {ospvj }}$ & $\mathrm{P}^{\text {ospat }}$ & 0,91 & 0,79 & 0,81 \\
\hline
\end{tabular}


Tabela 24 - Elasticidade de transmissão total convencional e segmentada para acréscimo e decréscimo de preço da soja, para a década de 80

\begin{tabular}{c|c|c|c|c}
\hline Variável dependente & $\begin{array}{c}\text { Variável } \\
\text { independente }\end{array}$ & Convencional & \multicolumn{2}{|c}{ Elasticidades } \\
\cline { 4 - 5 } & $\mathbf{P}^{\mathrm{spr}}$ & $1,05^{*}$ & 1,05 & 0,75 \\
\hline $\mathbf{P}^{\mathrm{smit}}$ & $\mathbf{P}^{\mathrm{spr}}$ & $1,28^{*}$ & 1,04 & 0,67 \\
\hline $\mathbf{P}^{\mathrm{sms}}$ & $\mathbf{P}^{\mathrm{sgo}}$ & 1,12 & 0,76 & 0,71 \\
\hline $\mathbf{P}^{\mathrm{sms}}$ & $\mathbf{P}^{\mathrm{fch}}$ & 0,98 & 0,58 & 0,67 \\
\hline $\mathbf{P}^{\mathrm{fsp}}$ & $\mathbf{P}^{\mathrm{fch}}$ & 0,55 & 0,65 & 0,61 \\
\hline $\mathrm{P}^{\mathrm{fpr}}$ & $\mathbf{P}^{\text {ospvj }}$ & 1,02 & & \\
\hline $\mathbf{P}^{\text {ospat }}$ & $\mathbf{P}^{\text {ospat }}$ & 0,94 & & \\
\hline $\mathbf{P}^{\text {ospvj }}$ & & & &
\end{tabular}

Tabela 25 - Elasticidade de transmissão total convencional e segmentada para acréscimo e decréscimo de preço da soja, para a década de 90

\begin{tabular}{|c|c|c|c|c|}
\hline \multirow[t]{2}{*}{ Variável dependente } & \multirow{2}{*}{$\begin{array}{c}\text { Variável } \\
\text { independente }\end{array}$} & \multirow[t]{2}{*}{ Convencional } & \multicolumn{2}{|c|}{ Elasticidades } \\
\hline & & & Acréscimo & Decréscimo \\
\hline $\mathbf{P}^{\mathrm{spr}}$ & $\mathbf{P}^{\mathrm{sch}}$ & 0,62 & 0,95 & 0,91 \\
\hline $\mathrm{P}^{\mathrm{srs}}$ & $\mathbf{P}^{\mathrm{sch}}$ & 0,64 & 1,12 & 0,87 \\
\hline $\mathrm{P}^{\mathrm{smt}}$ & $\mathrm{P}^{\mathrm{spr}}$ & $0,76^{*}$ & 1,03 & 0,73 \\
\hline $\mathrm{P}^{\mathrm{sms}}$ & $\mathrm{P}^{\mathrm{spr}}$ & $0,71^{*}$ & 1,07 & 0,78 \\
\hline $\mathrm{P}^{\mathrm{sgo}}$ & $\mathrm{P}^{\mathrm{spr}}$ & $0,90^{*}$ & 1,16 & 0,67 \\
\hline $\mathrm{P}^{\text {sgo }}$ & $\mathrm{P}^{\mathrm{sms}}$ & 0,84 & 0,88 & 0,94 \\
\hline$\overline{\mathrm{P}^{\mathrm{sms}}}$ & $\overline{\mathrm{P}}^{\mathrm{smt}}$ & 0,99 & & \\
\hline $\mathrm{P}^{\mathrm{smmt}}$ & $\mathrm{P}^{\mathrm{sms}}$ & 0,92 & & \\
\hline $\mathrm{P}^{\mathrm{fsp}}$ & $\mathrm{P}^{\mathrm{fed}}$ & 0,79 & 0,63 & 0,89 \\
\hline $\mathbf{P}^{\mathrm{fpr}}$ & $\mathrm{P}^{\mathrm{fsp}}$ & $0,97^{*}$ & 0,62 & 0,94 \\
\hline $\mathrm{P}^{\mathrm{fpr}}$ & $\mathbf{P}^{\mathrm{fch}}$ & 0,94 & 0,69 & 0,84 \\
\hline $\mathbf{P}^{\text {ospat }}$ & $P^{\text {och }}$ & $0,49^{*}$ & 1,01 & 1,37 \\
\hline
\end{tabular}

* Constatada assimetria na transmissão dos preços, nas tabelas 24 e 25. 


\section{CONCLUSÕES}

Essa pesquisa analisou as relações entre os preços de soja em grão, farelo e óleo em diferentes níveis de mercado, ou seja, produtor, atacado e varejo e mercado externo. Também se analisou as diferentes regiões de produção e consumo no mercado interno.

No estudo do panorama do complexo soja ficou evidente a grande importância que este exerce em todo o agribusiness brasileiro. Tanto na produção de farelo e óleo para consumo interno, quanto na geração de divisas para o país, com a exportação de $70 \%$ da produção nas formas de soja em grãos, farelo e óleo. Nesta última década as exportações do complexo soja representaram $9 \%$ do total das receitas cambiais das exportações brasileiras.

Os modelos teóricos de formação de preços deram-nos suporte para a análise do processo de formação de preços nos diferentes níveis de mercado. Nesta pesquisa além da revisão dos modelos de formação de preços de Gardner, Heien e Barros, os quais são bastante estudados e aplicados em estudos empíricos, também foi proposto, graficamente, um novo modelo de equilíbrio específico para o complexo soja brasileiro.

Os modelos econométricos são os meios para se obter os resultados das relações causais entre as séries de preços no complexo soja (teste de causalidade); da transmissão dos preços entre os diferentes níveis de mercado e também entre as diferentes regiões estudadas, através da elasticidade de transmissão de preços e da assimetria na transmissão de preços, através do teste de assimetria de Houck..

Os resultados em termos gerais podem ser apresentados da seguinte forma:

i) Mudanças em algumas relações causais entre as séries de preços para os dois períodos estudados, ou seja, década de 80 e 90 ; 
ii) Na década de 1990 é mais intensa a transmissão das variações de preços ocorridas no mercado internacional (CBOT), para os preços da soja e derivados no mercado interno; iii) Verificou-se que o período de transmissão de preços no setor é bastante curto, com períodos de defasagem de, no máximo, um mês. Somente em poucos casos ocorreu período de transmissão de dois ou três meses. Isso é um indicativo de eficiência na transmissão dos preços entre os níveis de mercado e entre as regiões estudadas.

Em termos específicos, temos as seguintes conclusões: relação causal das séries de preços do mercado internacional para as séries de preços no mercado interno, principalmente para a década de 90 .

Observou-se ainda que as variações dos preços no nível do produtor tendem a ser antecedidas pelas variações que ocorrem no mercado internacional e no atacado (tanto do óleo como do farelo). Isso pode ser explicado pelo menor poder de mercado que o produtor rural tem em relação aos demais níveis, e a maior dificuldade de acesso às informações.

No caso das relações de assimetria, estas tendem a ser transmitidas mais que proporcionalmente no caso dos acréscimos de preços, que no caso dos decréscimos de preços em todos os casos estudados.

As análises realizadas trazem diversas implicações para política comercial e agrícola, como também para a política de estabilização de preços internos.

Os resultados encontrados por Aguiar no estudo do complexo soja na década de 80 indicaram que as variações dos preços externos foram transmitidas mais que proporcionalmente aos preços internos.

O presente estudo para a década de 80 não verificou relação de causalidade entre os preços da soja em grão do mercado externo para o mercado interno. No caso do farelo houve relação dos preços externos para os internos, no entanto, estas relações foram unicausais e transmissão menos que proporcional dos preços. No caso do óleo, não houve relação de causalidade dos preços externos para os preços internos, ocorrendo, no entanto, relação bi-causal dos preços do óleo ao atacado e varejo internamente. 
Algumas mudanças foram encontradas em relação aos resultados obtidos por Aguiar. Uma possível explicação para as diferenças encontradas, é a área de abrangência do estudo e o tipo de teste de causalidade utilizado.

$\mathrm{Na}$ década de 90 houve relação causal dos preços internacionais para os preços domésticos, representados pelos estados do Rio Grande do Sul e Paraná, para soja em grãos. No caso do farelo os preços continuaram sendo determinados no mercado internacional, no entanto, no Brasil considerou-se dois mercados (São Paulo e Paraná) e houve relação causal dos preços do farelo em São Paulo para os preços do farelo no Paraná, relação esta, que não ocorreu na década de 80. No caso do óleo as relações aconteceram dos preços externos para os internos e internamente não houve relação entre os preços ao atacado e ao varejo.

Os resultados permitem concluir que o mercado da soja brasileira intensificou sua interdependência com o mercado internacional como resultado do processo de abertura econômica a partir o início da década de 1990. Essa dependência passou a se dar em termos do grão e também de seus derivados.

É claro que a mudança elevou a importância da condução adequada da política comercial brasileira para o setor. A recente desvalorização cambial veio na direção de proporcionar maior rentabilidade ao setor como um todo, incrementando o grau de competitividade do mesmo.

Por outro lado, a recente desoneração do imposto ICMS sobre as exportações de grãos também teve substancial impacto no setor, com reflexos diferenciados entre os diversos elos da cadeia. A maior rentabilidade conferida aos grãos acaba por inibir parcialmente a atividade industrial, cujos custos (inclusive de matéria-prima) se elevaram. Como o Brasil é um tomador de preços dos derivados da soja, não há como repassar esses custos ao mercado externo. $\mathrm{O}$ resultado é a perda de competitividade e, assim, de parcela dos mercados de derivados. 
ANEXOS 


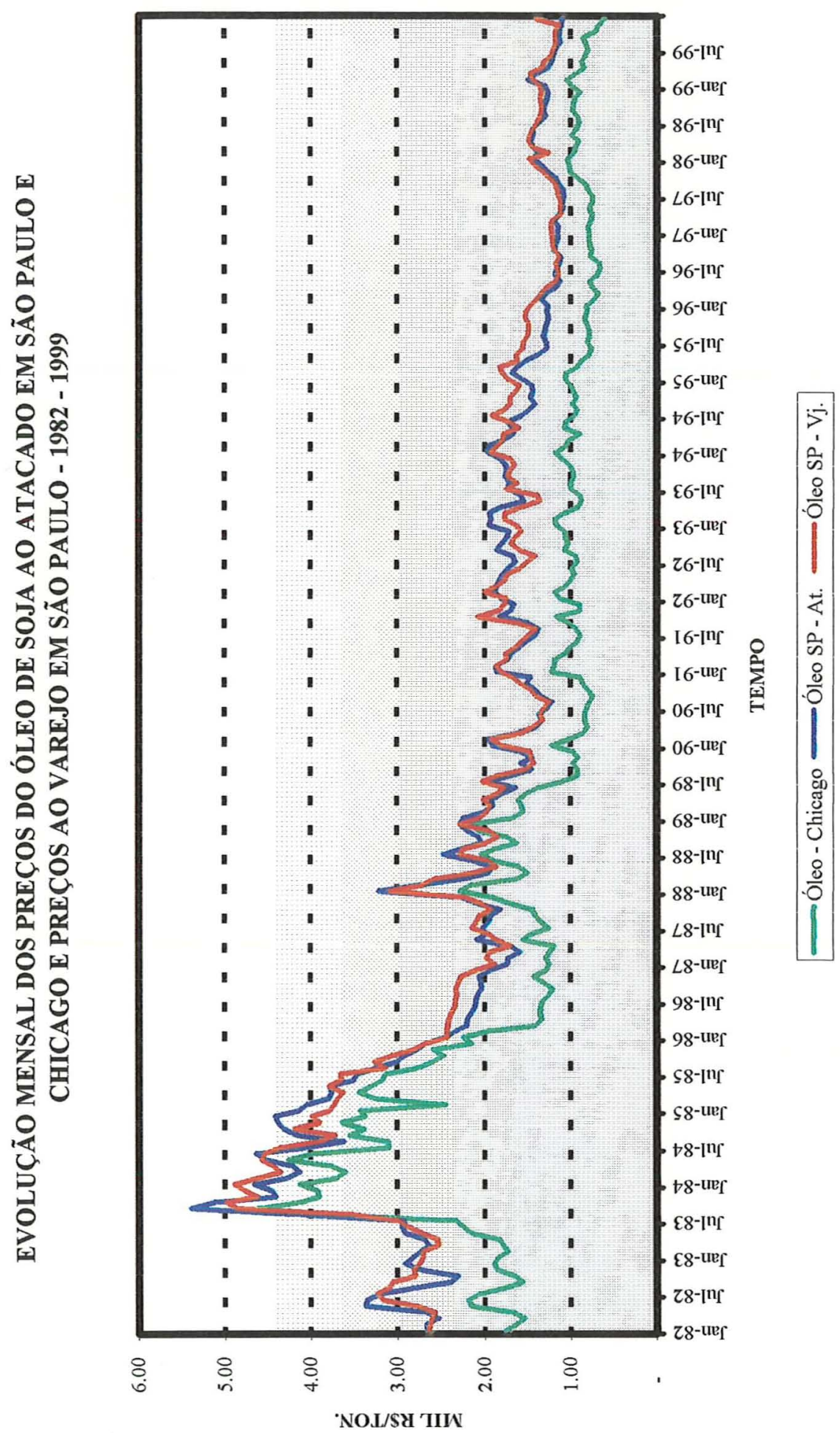




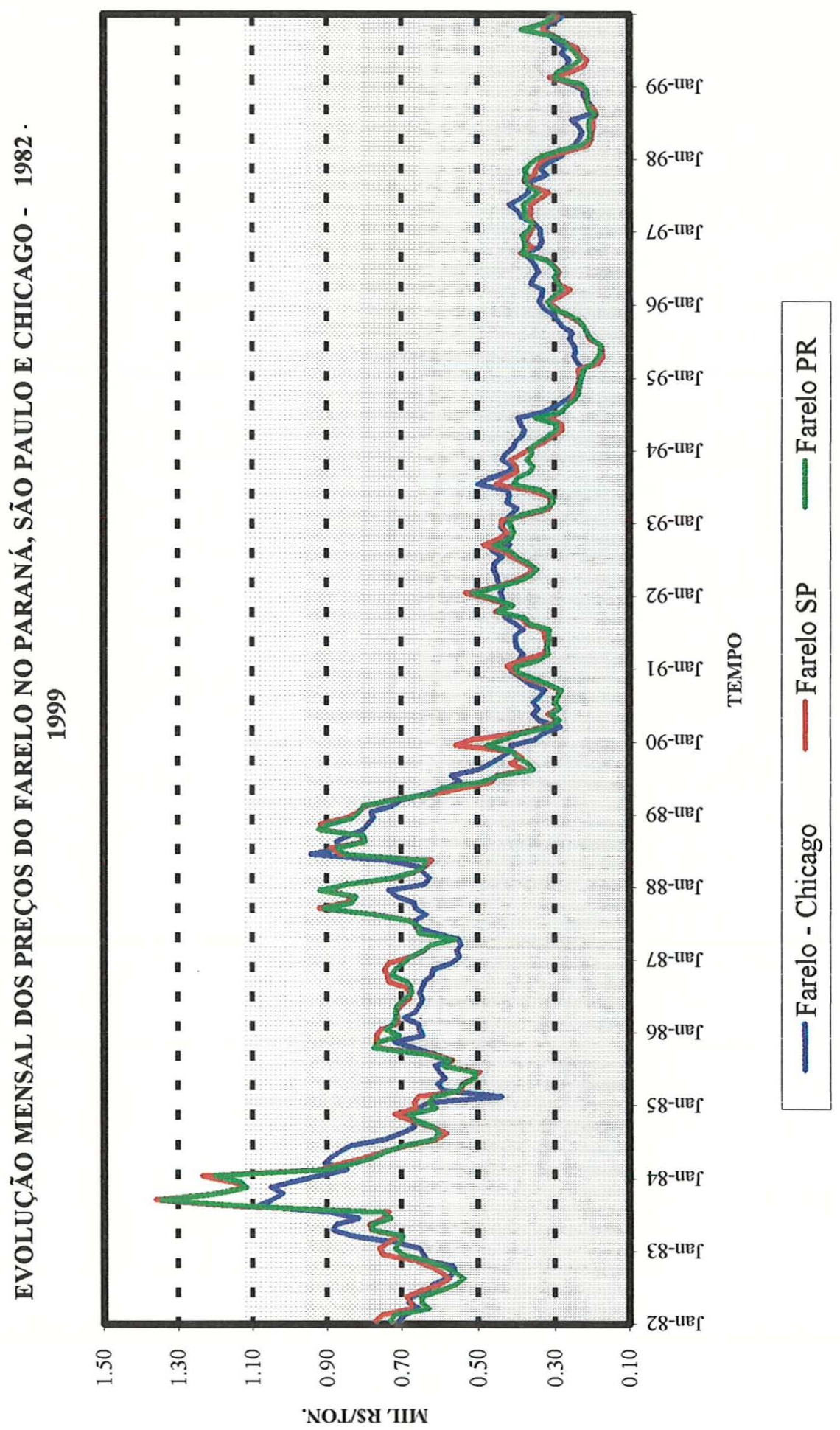




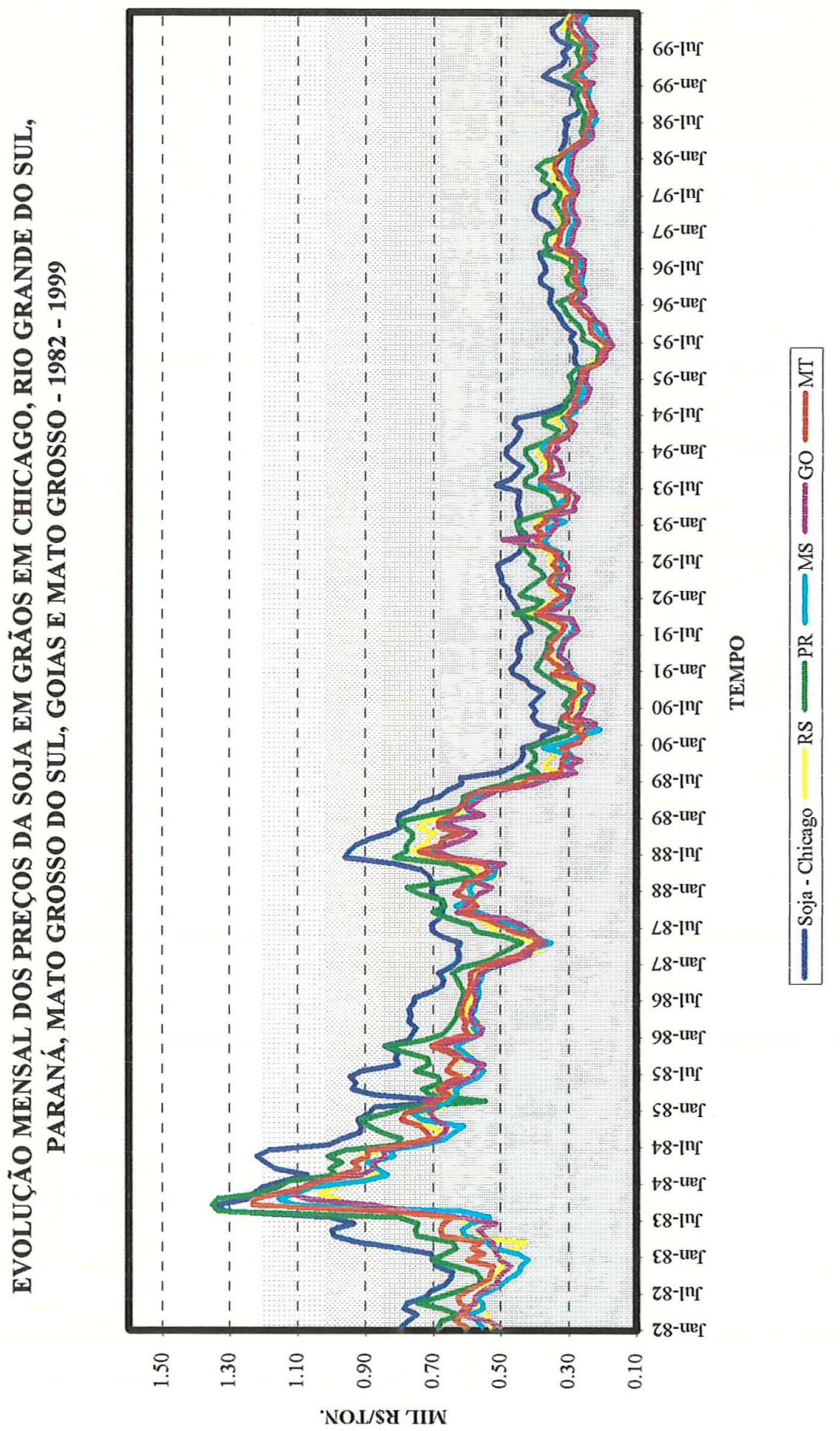




\section{REFERÊNCIAS BIBLIOGRÁFICAS}

ABIOVE. Banco de dados. São Paulo: 1998 e 1997.

Acompanhamento da Situação Agropecuária do Paraná, vários números, SEAB/DERAL, 2000 - Curitiba/PR.

AGUIAR, D.R.D.; G.S.A.C. BARROS. Transmissão de preços de laranja entre os mercados externo e interno. Revista de Economia e Sociologia Rural. Brasília, 27 (1): $61-70$, jan/mar. 1989.

AGUIAR, D.R.D. Formação de preços na indústria brasileira de soja - 1982/1989 Diss. (mestre) - ESALQ, Piracicaba, 1990 140p.

AGUIAR, D.R.D. A questão da transmissão de preços agrícolas. Revista de Economia e Sociologia Rural, Brasília 31(4): 291 - 308. Out - Dez. 1993.

BARROS. G.S.A.C. Economia da comercialização agrícola. Piracicaba, FEALQ, 1987. $306 \mathrm{p}$.

BARROS. G.S.A.C.; J. G. MARTINES F. . .Comercialização de produtos agrícolas e sua relação com a inflação brasileira. Brasília, Instituto de Planejamento Econômico e Social, 1987. (Relatório de pesquisa).

BARROS. G.S.A.C. Transmissão de preços pela central de abastecimento de São Paulo, Brasil. In: SEMINÁRIO DE PERSPECTIVAS DA AGRICULTURA, 4, Piracicaba, 1988. Anais. Piracicaba, FEALQ, 1988, P. 99 - 119.

BARROS. G.S.A.C. Formação de preços agrícolas e reflexos sobre o abastecimento. Revista de economia e sociologia rural. Baasilia, 27 (1): 1- 4, jan./mar. 1989. 
BARROS. G.S.A.C; P.V. MARQUES; M.R.P. BACCHI; L.C. CAFFAGNI. Elaboração de indicadores de preços de soja: um estudo preliminar. Piracicaba, CEPEA/ESALQ/USP, abril de 1997.

BISHOP, R.V. The Construcion and use of causality testes. Agricultural Economics Research, 31 (4): 1 - 6, october, 1979.

BITTENCOURT, M.V.L. Formação de preços e caracterização do mercado de frango em São Paulo Diss. (mestre) - ESALQ, Piracicaba, 1995 161p.

BULHÕES, R. Análise da competição entre os portos de Paranaguá e Santos para a movimentação de soja: aplicação de um modelo de equilíbrio espacial. Diss. (mestre) - ESALQ, Piracicaba, 1998 108p.

BURNQUIST, H.L. A questão da causalidade entre preços a diferentes níveis de mercados agrícolas. Diss. (mestre) - ESALQ, Piracicaba, 1986 83p.

CAFFAGNI, L.C. Curso de especialização em mercado de commodities agropecuárias 11/06/99. 15 p., 1999 (mimeo)

CAIXETA FILHO, J.V. Transporte e logística no sistema agroindustrial. Preços Agrícolas, set. - 1996.

CANZIANI, J.R.; R.L. MAFIOLETTI Clima favorece o plantio da soja nos Estados Unidos. Folha do Paraná -15/05/99.

COELHO, F.S. e AGUIAR, D.D.R. Análise do Mecanismo de Transmissão de Preços de Laranja entre os mercados externo e interno In: XXXVI CONGRESSO BRASILEIRO DE ECONOMIA E SOCIOLOGIA RURAL. Poços de Caldas, 1998. Anais. Poços de Caldas, 1998. 1102p. 
FEIGE, E.L.; D.K. PEARCE. The casual causal relationship between money and income: some caveats for time series analysis. The review of economics and estatistics. 61 (4), nov. , 1979.

GARDNER, B.L. The farm-retail price spread in a competitive food industry. American Journal of Agricultural Economics, 57 (3): 399 - 409, 1975.

GRANGER, C.W.J. Investigating causal relations by econometric models and cross spectral methods. Econometrica, 37 (3): 424 - 38, july, 1969.

GREENE, W. H. Econometric analysis. $2^{\text {a }}$. ed. Macmillan. 1993. 791 p.

HEIEN, D.M. Markup pricing in a dynamic model of The food industry. American Journal of Agricultural economics, 61 (1) : 10 -18, 1980.

HOMEM de MELO, F. Instabilidade da renda e estabilização de preços agrícolas. Pesquisa e Planejamento Econômico. Rio de Janeiro,13(3): 829-62,Dez. 1983.

HOUCK, J.P. An approach to specifying and estimating nonreversible functions. American Journal of Agricultural Economics, 59: 570 - 72, august, 1977.

HOUCK, J.P.; RYAN M.E.; SUBOTNIK A. Soybeans and Their Products - Markets, Models, and Policy - University of Minnesota Press Mineapolis, 1972.

LARSON D.W. Competitiveness in world soybean markets. V Seminário sobre problemas e perspectivas da agricultura. $19-21$ set 1989 USP/ESALQ FEALQ/CEPEA. 
LAZZARINI, S.G.; NUNES R. O Agribusiness Brasileiro - Competitividade do sistema agroindustrial da soja. PENSA/USP, FIPE/Agrícola (CD-ROM). 225p. 1998.

MADDALA, G.S. Introduction to Economitrics. MacMillan Publishing Company. New York. 1988. 472 p.

MARGARIDO, A.M.; E.L.L. SOUZA. Formação de preços da soja no Brasil. In: XXXVI CONGRESSO BRASILEIRO DE ECONOMIA E SOCIOLOGIA RURAL. Poços de Caldas, 1998. Anais. Poços de Caldas, 1998. p.773-84.

MARQUES, P.V.; D.R.D. AGUIAR. Comercialização de produtos agrícolas. Piracicaba, EDUSP 1993. 295 p.

MARTINES F. J. G. Margens de comercialização e causalidade de preços agrícolas. Piracicaba, 1988. Diss. (mestre) - ESALQ, Piracicaba, 146p.

NEVES, L.C.D. Margens de comercialização e elasticidades de transmissão de preços na indústria de esmagamento de soja Diss.(mestre)-ESALQ, Piracicaba,1993 90p.

PYNDYCK, R.S.; RUBINFELD, D.L. Econometric Spurious regressions in econometrics. Journal of Econometrics 2: 111-120. 1974

ROESSING, A.C. Exportações brasileiras de farelo de soja: um modelo de desequilíbrio. Viçosa: UFV, 1989. 224p.

SANTANA, J.A.; D.R.D. AGUIAR. Assimetria na transmissão de preços agrícolas no estado de São Paulo - 1987-1998. In: XXXVII CONGRESSO BRASILEIRO DE ECONOMIA E SOCIOLOGIA RURAL. Foz do Iguaçu, 1999. Anais. Foz do Iguaçu, 1999. 
SIMS, C.A. Money, income and causality. American Economic Review, 62(4): 540 552. Sept. 1972.

ZANLORENZI, M.R.P. Os custos sociais da política comercial brasileira para a soja Diss. (mestre) - ESALQ, Piracicaba, 1992 153p.

WARD, C. A. Asymmetriy in retail, wholesale and shipping point pricing for fresh vegetables. American Journal of Agricultural Economics, 64(2): $205-212$, 1982.

WILLIANS, G.W.; THOMPSON, R.L. A indústria da soja no Brasil: estrutura econômica e políticas de intervenção do governo no mercado. Brasília, CFP, 1988.(Coleção análise e pesquisa, 34).

WOLFRAM, R. Positivistic measures of aggregate supply elasticities: somenew appoaches -some critical notes. American Journal of Agricultural Economics, 53, n.2, 356-359. 1971. 